UNIVERSIDADE DE SÃO PAULO

\author{
LUCIANA VISMARI
}

\title{
PAPEL DO ANTIDEPRESSIVO AMITRIPTILINA SOBRE A RESPOSTA INFLAMATÓRIA AGUDA EM RATOS
}

São Paulo 2010 


\section{LUCIANA VISMARI}

\section{PAPEL DO ANTIDEPRESSIVO AMITRIPTILINA SOBRE A RESPOSTA INFLAMATÓRIA AGUDA EM RATOS}

Tese de Doutorado apresentada ao Programa de Pós-Graduação em Neurociências e Comportamento do Instituto de Psicologia da Universidade de São Paulo

Área de Concentração: Neurociências e Comportamento

Orientador: Prof. Dr. João Palermo-Neto 
AUTORIZO A REPRODUÇÃO E DIVULGAÇÃO TOTAL OU PARCIAL DESTE

TRABALHO, POR QUALQUER MEIO CONVENCIONAL OU ELETRÔNICO, PARA

FINS DE ESTUDO E PESQUISA, DESDE QUE CITADA A FONTE.

Catalogação na publicação

Biblioteca Dante Moreira Leite

Instituto de Psicologia da Universidade de São Paulo

Vismari, Luciana.

Papel do antidepressivo amitriptilina sobre a resposta inflamatória aguda em ratos / Luciana Vismari; orientador João Palermo-Neto. -São Paulo, 2010.

$143 \mathrm{f}$.

Tese (Doutorado - Programa de Pós-Graduação em Psicologia. Área de Concentração: Neurociências e Comportamento) - Instituto de Psicologia da Universidade de São Paulo.

1. Drogas antidepressivas 2. Inflamação 3 . Moléculas de adesão celular 4. Neuroimunomodulação 5. Citocinas 6. Microscopia 7. Óxido nítrico I. Título.

RM332 


\section{UNIVERSIDADE DE SÃO PAULO \\ Faculdade de Medicina Veterinária e Zootecnia \\ Comissão Bioética}

\section{CERTIFICADO}

Certificamos que o Projeto intitulado "Efeitos da amitriptilina sobre a resposta imune/inflamatória em ratos", protocolo $n^{\circ} 761 / 2005$, utilizando 560 (quinhentos e sessenta) ratos, sob a responsabilidade do Prof. Dr. João Palermo Neto, está de acordo com os princípios éticos de experimentação animal da Comissão de Bioética da Faculdade de Medicina Veterinária e Zootecnia da Universidade de São Paulo e foi aprovado "ad referendun".

(We certify that the Research "Effects of amitriptyline on immune/inflammatory response in rats", protocol number 761/2005, under the responsibility of Prof. Dr. João Palermo Neto, utilizing 560 (five hundred and sixty) rats, agree with Ethical Principles in Animal Research adopted by Bioethic Commission of the Faculty of Veterinary Medicine and Zootechny of University of São Paulo and was approved "ad referendun", meeting).

São Paulo, 25 de novembro de 2005

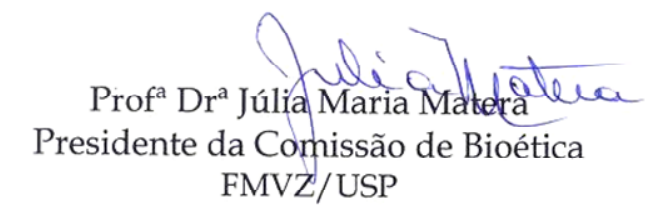

Av. Prof. Dr. Orlando Marques de Paiva, n 87 - 05508-270 - Cidade Universitária "Armando de Salles Oliveira". Fax: (11) 3032-2224 - fones: (11) 309107676/7671 - email: fmvz@edu.usp.br 
Nome:LUCIANA VISMARI

Título: PAPEL DO ANTIDEPRESSIVO AMITRIPTILINA SOBRE A RESPOSTA INFLAMATÓRIA AGUDA EM RATOS

Tese de Doutorado apresentada ao Programa de Pós-Graduação em Neurociências e Comportamento do Instituto de Psicologia da Universidade de São Paulo

Área de Concentração: Neurociências e Comportamento

Aprovada em:

Banca Examinadora

Prof. Dr.

Instituição Assinatura

Prof. Dr.

Instituição Assinatura

Prof. Dr.

Instituição Assinatura

Prof. Dr. Instituição Assinatura

Prof. Dr. Instituição Assinatura 
Este trabalho foi realizado no Laboratório de Farmacologia Aplicada e Toxicologia do Departamento de Patologia da Faculdade de Medicina Veterinária e Zootecnia da Universidade de São Paulo, com apoio financeiro da FAPESP - Modalidade Projeto Temático (04-14128-0) - e CNPq (472083/2007-4 e 301177/2007-4).

A amitriptilina foi gentilmente doada por Cristália Produtos Químicos Farmacêuticos Ltda. 


\title{
Dedícatórias
}

\begin{abstract}
À $\mathcal{D} \mathcal{E} U S$,
Princípio e fim de todas as coisas.

Sei que tudo em minha vida tem Seu amor e cuidado "Grandes são as obras do Senhor; nelas meditam todos os que as apreciam".
\end{abstract}

Salmos 111:2 


\title{
Dedicatórías
}

\begin{abstract}
Ao meu marido Fábio
"Por dar sentido a todos os ventos e calma a todos os mares".

Pelo amor, compreensão, paciência, respeito, incentivo, Por ser meu companheiro, amante, amigo e parceiro nesta jornada da vida.
\end{abstract}

$\mathcal{N}$ ão tenho palavras para agradecer seu incentivo e amor.

TE $\mathcal{A M O}$ !

\section{À minha fílha Letícía}

Por ter participado desta tese desde o ventre,

Apoiando em minha barriga os experimentos, acompanhando a redação em meu colo, acalentando minhas ansiedades com seu sorriso, seu abraço, suas primeiras palavras e passos. Você é e sempre será a melhor parte da vida. MEU AMOR!!

\section{Aos meus pais Liderce e Dorival}

Por terem sido fonte eterna de incentivo, inspiração, amor infinito, paciência. Por terem sempre colocado minha educação como prioridade, São os grandes responsáveis pelo meu vínculo irreversível com o aprender e ensinar. $\mathcal{N}$ os inúmeros dias onde estivemos ausentes, vocês foram, e são, os pais de nossa filha.

Sem vocês esta tese simplesmente não existiria.

Obrigada por serem o eterno berço onde sei que posso repousar. ESTA TESE É DE VOCÊS, DOVTORES EM AMORE DEDICAÇÃO!! 


\section{Dedicatórías}

\section{Ao Professor Doutor João Palermo-Neto}

Por ser o grande mestre e exemplo na arte de ensinar e orientar;

Doutor em sabedoria ao conduzir nossas mentes pelos caminhos da ciência;

Professor no sentido mais belo e amplo que a palavra pode ter: Alguém que com mente e coração planta as sementes da eterna busca pelo saber.

Obrigada por me permitir beber desta fonte, Por orientar meus passos e acreditar no meu potencial. Ao senhor, minha eterna admiração e gratidão. 


\section{Agradecimentos}

É importante dizer que não existem palavras para expressar minha gratidão por estas e por tantas outras pessoas que - por problemas de espaço ou de memória - não foram aqui citadas. A todas elas meu carinho e o meu muito obrigada!

Ao meu orientador, João Palermo-Neto, por me proporcionar orientação e apoio para meu desenvolvimento intectual e científico; por acreditar em mim e guiar meus passos nesta caminhada; um grande mestre a ser seguido;

Aos professores do Departamento de Patologia da Faculdade de Medicina Veterinária e Zootecnia da USP, em especial aos professores Luciano Felício, Jorge Camilo Flório e Frederico Azevedo, pelas discussões sempre tão amigáveis;

\section{À Fundação de Amparo à Pesquisa do Estado de São Paulo (FAPESP) e ao Conselho Nacional de Desenvolvimento Científico e Tecnológico (CNPq) pelo suporte financeiro concedido aos trabalhos do grupo;}

Ao Dr. Ricardo Lazzarini, por orientar o início da minha caminhada nos experimentos com inflamação;

Aos funcionários do Biotério, Cláudia, Herculano, D. Idalina, D. Rosires, Nelsinho, S. Luis e Mauro, sempre solícitos, alegres e prontos para auxilar. Obrigada pelo carinho e dedicação;

Aos técnicos do laboratório, Priscila, Ricardo e Magali, por nos proporcionarem apoio nos momentos mais necessários;

Às funcionárias das secretarias do VPT e do $\mathrm{NeC}$, e demais funcionários que direta ou indiretamente contribuíram com este trabalho

Ao Prof. Dr. Marcelo Muscará, não só pela colaboração nas dosagens de nitratos, mas pelo interesse e apoio sempre presentes na discussão dos meus resultados; 
Aos professores Sandra Farsky e Cristóforo Scavone por disponibilizarem seus laboratórios para a realização de meu trabalho;

À Cristina Hebeda e Graziela Ceravolo, pela colaboração tão carinhosa;

Ao Cláudio e Luciano da histopatologia e à Luciana da Patologia, sempre dispostos a auxiliar;

Ao laboratório de microbiologia do VPT por ceder o $S$. aureus utilizado neste trabalho;

Ao Rodrigo (secretário do Dr. João), pela paciência e simpatia de sempre;

À Glaucie Alves e Milena Lobão, pelo apoio nos experimentos, pelos infindáveis bate-papos, pela amizade e companheirismo;

Ao casal Alison e Viviane, meus afilhados, têm um lugar especial no meu coração. Obrigada pelo carinho e apoio sempre presentes;

Aos companheiros da pós-graduação Mônica Sakai (pelas ajudas, discussões e apoio sempre presente), Renato Moraes (que com a Milena me ajudaram na escolha do título da tese), Denise, Natô (e suas discussões filosóficas), Bel, Domênica, Andréa Latorre, Bia, Wanderley, Fabio Silva, Elaine, Daniel, Dudu, Evelise, Cris Massoco, Portela, Vanessa, Camila, Lucianas (sim, no plural), Adriano Zager, Eduardo "Márcio", Bárbara e Karina, Julia, Karin, Thiago, Ana Paula Ligeiro, Altamir e João Paulo, por darem alegria e leveza ao dia-a-dia;

Às amigas de todas as horas, Luciane de Souza e Lídia Cristine: os tantos anos passados apenas fortaleceram as raízes de nossa amizade. Obrigada por vocês existirem em minha vida;

Ao meu irmão Lúcio e Simone, que me acompanharam nesta longa caminhada, compartilhando ansiedades e sonhos; 
Aos amigos da Uninove, em especial Adriana Grosso e Alice, pelas infindáveis e alegres conversas;

À coordenação/diretoria da Uninove, por confiarem e apoiarem meu trabalho;

Aos meus alunos, por me mostrarem minha condição irreversível de SER e não apenas estar como professora. Que com suas dúvidas, muito têm me ensinado; Que com suas dificuldades, me ajudam a buscar um caminho sempre melhor. Vocês são e sempre serão uma grande motivação em minha carreira;

Aos animais de experimentação, que com suas vidas permitiram 0 desenvolvimento deste e de tantos outros trabalhos;

E, acima de tudo, à Deus, que me deu forças e condições de chegar até aqui. "Se o SENHOR não edificar a casa, em vão trabalham os que a edificam.."SI 127:1 
"O temor do SENHFORé o princípio do conhecimento; os loucos desprezam a sabedoria e a instrução."

Provérbios 1:7

"Ainda que eu tenha o dom de profetizar e conheça todos os mistérios e toda a ciência;

ainda que eu tenha tamanha fé, a ponto de transportar montes, se não tiver amor, nada serei."

I Coríntios, 13:2 


\section{RESUMO}

VISMARI, L. Papel do antidepressivo amitriptilina sobre a resposta inflamatória aguda em ratos. [Role of the antidepressant amitriptyline in the acute inflammatory response in rats]. 2010. 143f. Tese de Doutorado. Instituto de Psicologia, Universidade de São Paulo, São Paulo, 2010.

Diversos estudos têm sugerido uma ação anti-inflamatória para o antidepressivo amitriptilina; a presente investigação pretende analisar os mecanismos envolvidos com esta resposta. Mais especificamente, o objetivo do presente estudo é avaliar os efeitos da amitriptilina sobre a resposta inflamatória induzida pela carragenina em ratos e investigar os prováveis mecanismos relacionados a estes efeitos. Num primeiro momento, utilizando-se o modelo do edema de pata induzido pela carragenina, avaliamos o efeito anti-inflamatório da amitriptilina após administração em diferentes doses e intervalos de tempo, isto é, de forma aguda ou em múltiplas doses, por diferentes vias de administração. Verificamos que o tratamento com amitriptilina $10 \mathrm{mg} / \mathrm{kg}$, administrada a cada tempo de meia-vida de eliminação, produziu redução significante do edema de pata nos diversos tempos avaliados. Não houve reversão deste efeito anti-inflamatório quando os animais foram pré-tratados com um antagonista de receptores de glicocorticoides (RU-486); houve potencialização do efeito anti-inflamatório pelo pré-tratamento com antagonista de receptores alfa-1-adrenérgicos (prazosina). A administração de amitriptilina juntamente com um inibidor inespecífico de síntese de óxido nítrico (L-NAME) levou a uma potencialização do efeito anti-inflamatório avaliado pelo modelo do edema de pata; produziu, ainda, uma redução significante na concentração de leucócitos e no número total de leucócitos do exsudato peritoneal induzido por carragenina e uma redução significante do total de nitratos circulantes, quando comparados aos animais do grupo controle. Este efeito anti-inflamatório avaliado pelo edema de pata não foi revertido pela administração de um precursor da síntese de NO. O tratamento com amitriptilina ou L-NAME isoladamente ou em conjunto não produziu alterações significantes na expressão das moléculas de adesão ICAM-1, PECAM-1, L-selectina e MAC-1 por leucócitos do sangue periférico. Quando avaliamos o comportamento dos leucócitos por microscopia intravital, observamos que a amitriptilina produziu uma redução significante no rolamento, adesão e transmigração de leucócitos avaliados em condição inflamatória. A administração de amitriptilina isoladamente ou em conjunto com L-NAME também mostrou produzir redução significante nos níveis 
de IL-1beta e TNF-alfa no soro de ratos. Podemos assim concluir que a amitriptilina apresentou um efeito anti-inflamatório na maioria dos modelos avaliados. Os mecanismos parecem envolver a participação dos receptores alfa-1-adrenérgicos, a inibição da NOS - com consequente redução na síntese de NO e das ações próinflamatórias a ele associadas - e a diminuição nos níveis das citocinas IL-1beta e TNF-alfa. Considerando-se a teoria que implica a depressão como um fenômeno inflamatório, a compreensão dos mecanismos envolvidos no efeito anti-inflamatório da amitriptilina poderia contribuir nas investigações envolvendo esta teoria.

Palavras-chave: Drogas antidepressivas. Inflamação. Moléculas de adesão celular. Neuroimunomodulação. Citocinas. Microscopia. Óxido Nítrico 


\begin{abstract}
VISMARI, L. Role of the antidepressant amitriptyline in the acute inflammatory response in rats. [Papel do antidepressivo amitriptilina sobre a resposta inflamatória aguda em ratos]. 2010. XXXf. Tese de Doutorado. Instituto de Psicologia, Universidade de São Paulo, São Paulo, 2010.
\end{abstract}

Several studies have suggested an anti-inflammatory action to the antidepressant amitriptyline; the present investigation intend to analyze the mechanisms involved in this response. More specifically, the objective of the present study is to evaluate the effects of amitriptyline in the carrageenan-induced inflammatory response and investigate the possible mechanisms related to these effects. At first, with the carrageenan-induced paw edema model, we evaluated the anti-inflammatory effect of amitriptyline administrated in different doses, intervals, acute or chronically, by different routes of administration. We verified that amitriptyline $10 \mathrm{mg} / \mathrm{kg}$, administrated each elimination half-life, produced a significant reduction on paw edema in several times evaluated. It was not reverted with the pretreatment with an glicocorticoid antagonist (RU-486); it was potentiated with the pretreatment with an alpha-1- antagonist (prazosin). The co-administration of amitriptyline and an unspecific inhibitor of nitric oxide synthesis (L-NAME) produced a potentialization of the anti-inflammatory effect, evaluated in the paw edema model, a decrease in the leukocyte concentration and total number in the carrageenan-induced peritoneal exsudate and a significant reduction in the total serum nitrate, when compared to the control group. This anti-inflammatory effect evaluated by the paw edema was not reverted with a NO precursor administration. The only amitriptyline or L-NAME treatment didn't produce significant alterations in the adhesion molecules expression ICAM-1, PECAM-1, L-selectin e MAC-1 by leukocytes of the peripheral blood. When the leukocyte behavior was evaluated by intravital microscopy, we verified that amitriptyline produced significant reduction in the rolling, adhesion and transmigration of leukocytes evaluate in inflammatory condition. Amitriptyline and/or L-NAME administration produced a significant reduction on IL-1beta and TNF-alpha levels in rat's serum. We may conclude that amitriptyline presented an anti-inflammatory effect in the most models evaluated. Mechanisms seem to involve alpha-1-adrenergic 
receptors, NOS inhibition - and consequent reduction in NO synthesis and its proinflammmatory actions - and reduction on cytokines IL-1beta and TNF-alpha levels. Considering the theory that implicates depression as an inflammatory phenomenon, the comprehension of the anti-inflammatory effects of amitriptyline could contribute in the investigations about this theory.

Key-words: Antidepressants. Inflammation. Cellular adhesion molecules. Neuroimmunomodulation. Cytokines. Microscopy. Nitric Oxide 


\section{LISTA DE FIGURAS}

Figura 1 - Representação esquemática do comportamento leucocitário frente a um estímulo inflamatório local. As principais etapas envolvem o rolamento de leucócitos (rolling), seguido pela sua adesão e transmigração. No esquema encontram-se representadas as principais moléculas de adesão envolvidas em cada processo. (Modificado de COTRAN; KUMAR; COLLINS, 2000)

Figura 2 - Efeitos de diferentes doses de amitriptilina sobre o edema inflamatório induzido pela carragenina $1 \%$ em ratos. $O$ volume da pata é dado pela diferença de cada medida em relação ao volume basal $(\mathrm{mL})$. Os valores referem-se à média \pm desvio padrão. *: $p<0,05$ em relação ao grupo controle. (ANOVA de uma via seguida pelo teste de Student-NewmanKeuls). Controle: $\mathrm{n}=9$; Amitrip 3 (amitriptilina $3,0 \mathrm{mg} / \mathrm{kg}$ ): $\mathrm{n}=8$; Amitrip 6 (amitriptilina 6,0mg/kg): $\mathrm{n}=8$; Amitrip 10 (amitriptilina $10,0 \mathrm{mg} / \mathrm{kg}):=10$

Figura 3 - Influência do tempo de administração nos efeitos da amitriptilina sobre o edema de pata induzido pela carragenina $1 \%$ em ratos. O volume da pata é dado pela diferença de cada medida em relação ao volume basal $(\mathrm{mL})$. Os valores referem-se à média \pm desvio padrão. *: $p<0,05$ em relação ao respectivo grupo controle. (ANOVA de duas vias seguida pelo teste de Tukey). $n=10$ por grupo

Figura 4 - Efeitos do tratamento prolongado (15 dias) com imipramina e amitriptilina no edema de pata induzido pela carragenina $1 \%$ em ratos. O volume da pata é dado pela diferença de cada medida em relação ao volume basal $(\mathrm{mL})$. Os valores referem-se à média \pm desvio padrão. *: $p<0,05$ em relação ao controle. (ANOVA de duas vias seguida pelo teste de Tukey). $\mathrm{n}=10$ por grupo

Figura 5 - Efeitos do tratamento prolongado (16 dias) com imipramina e amitriptilina sobre a atividade de neutrófilos. A- Burst oxidativo de neutrófilos estimulados pelo DCFH, S.aureus + DCFH ou PMA; B- Porcentagem e intensidade de fagocitose de neutrófilos de ratos. Os valores referem-se à média \pm desvio padrão. *: $p<0,05$ em relação ao respectivo grupo controle; \# $p<0,05$ em relação ao grupo amitriptilina. $n=8$ por grupo. 
Figura 6 - Efeito do tratamento com amitriptilina durante 7 e 14 dias (A) ou 28 dias (B) no edema de pata induzido pela carragenina $1 \%$ em ratos. O volume da pata é dado pela diferença de cada medida em relação ao volume basal $(\mathrm{mL})$. Os valores referem-se à média \pm desvio padrão. *: $p<0,05$ em relação ao respectivo grupo controle. (ANOVA de duas vias seguida pelo teste de Tukey). C7: controle 7 dias, $n=9$; E7: amitriptilina 10,0mg/kg, 7 dias, $\mathrm{n}=10$; C14: controle 14 dias, $\mathrm{n}=7 ; \mathrm{E} 14$ : amitriptilina 10,0mg/kg, 14 dias, $n=10 ; C 28$ : controle 28 dias, $\mathrm{n}=8$; E28: amitriptilina $10 \mathrm{mg} / \mathrm{kg}, 28$ dias, $\mathrm{n}=9$.

Figura 7 - Efeitos de injeções intraperitoneais, subcutâneas e a cada tempo de meia-vida de amitriptilina sobre o edema de pata induzido pela carragenina em ratos. O volume da pata é dado pela diferença de cada medida em relação ao volume basal $(\mathrm{mL})$. Os valores referem-se à média \pm desvio padrão. *: $\mathrm{p}<0,05$ em relação ao grupo controle. (ANOVA de duas vias seguida pelo teste de Tukey). $n=10$ por grupo.

Figura 8 - $\quad$ Patas de ratos 24 horas depois de terem sido injetadas com carragenina $(A)$, amitriptilina $(B)$ e amitriptilina + carragenina (C)

Figura 9 - Efeito do pré-tratamento com um antagonista de receptores de glicocorticoides (RU-486) nas ações da amitriptilina administrada a cada tempo de meia-vida sobre o edema de pata induzido por carragenina $1 \%$ em ratos. $O$ volume da pata é dado pela diferença de cada medida em relação ao volume basal $(\mathrm{mL})$. Os valores referem-se à média \pm desvio padrão. *: $p<0,05$ em relação ao grupo controle. (ANOVA de duas vias seguida pelo teste de Tukey). controle e ru: $n=9$ por grupo; ami e ru-ami: $n=8$ por grupo

Figura 10 - Efeito do pré-tratamento com um antagonista de adrenoceptores alfa-1 (prazosina) nas ações da amitriptilina administrada a cada tempo de meia-vida sobre o edema de pata induzido por carragenina $1 \%$ em ratos. $O$ volume da pata é dado pela diferença de cada medida em relação ao volume basal $(\mathrm{mL})$. Os valores referem-se à média \pm desvio padrão. *: $p<0,05$ em relação ao grupo controle. (ANOVA de duas vias seguida pelo teste de Tukey). Controle: $n=8$; ami: $n=9$; demais grupos: $n=10$

Figura 11 - Efeitos do pré-tratamento com um inibidor da síntese de óxido nítrico (L-NAME) nas ações da amitriptilina sobre o edema de pata induzido pela carragenina $1 \%$ em ratos. $O$ volume da pata é dado pela diferença de cada medida em relação ao volume basal $(\mathrm{mL})$. Os valores referem-se à média \pm desvio 
padrão. *: $p<0,05$ em relação ao grupo controle. (ANOVA de duas vias seguida pelo teste de Tukey). Grupos controle, ami (amitriptilina 10,0mg/kg) e I-name: $n=9$; I-name-ami: $n=8$.

Figura 12 - Efeitos do pré-tratamento com um precursor da síntese de óxido nítrico (L-arginina) nas ações da amitriptilina sobre o edema de pata induzido pela carragenina $1 \%$ em ratos. $O$ volume da pata é dado pela diferença de cada medida em relação ao volume basal $(\mathrm{mL})$. Os valores referem-se à média \pm desvio padrão. *: $p<0,05$ em relação ao grupo controle. (ANOVA de duas vias seguida pelo teste de Tukey). Controle: $\mathrm{n}=9$; ami (amitriptilina 10,0mg/kg): $\mathrm{n}=8$; I-arg: $\mathrm{n}=10$; I-arg-ami: $\mathrm{n}=11$

Figura 13 - Efeitos do pré-tratamento com um inibidor da síntese de óxido nítrico (L-NAME) nas ações da amitriptilina administrada a cada tempo de meia-vida sobre o edema de pata induzido por carragenina $1 \%$ em ratos. $O$ volume da pata é dado pela diferença de cada medida em relação ao volume basal $(\mathrm{mL})$. Os valores referem-se à média \pm desvio padrão. * : $p<0,05$ em relação ao grupo controle. (ANOVA de duas vias seguida pelo teste de Tukey). Controle: $n=10$, ami $n=8$, I-name: $n=7 ;$ name-ami: $n=8$.

Figura 14 - Efeitos do pré-tratamento com um precursor da síntese de óxido nítrico (L-arginina) nas ações da amitriptilina administrada a cada tempo de meia-vida sobre o edema de pata induzido por carragenina $1 \%$ em ratos. $O$ volume da pata é dado pela diferença de cada medida em relação ao volume basal $(\mathrm{mL})$. Os valores referem-se à média \pm desvio padrão. *: $p<0,05$ em relação ao grupo controle. (ANOVA de duas vias seguida pelo teste de Tukey). $n=10$ por grupo.

Figura 15 - Efeitos da administração de amitriptilina e L-NAME sobre a produção de nitratos em ratos. Os valores referem-se à média \pm desvio padrão. *: $p<0,05$ em relação ao grupo controle. (ANOVA de uma via seguida pelo teste de Tukey). L-NAMEamitriptilina: $n=4$; demais grupos: $n=6$.

Figura 16 - Efeitos da amitriptilina sobre as características do exsudato inflamatório produzido pela injeção intraperitoneal de carragenina. A-número de células por $\mathrm{mL}$ (ANOVA de uma via seguida pelo teste de Tukey; naive: $n=7$; controle: $n=9$, ami: $n=10$ ); B- número total de células (Teste de KruskalWallis seguido pelo teste de Dunn; naive: $n=7$; controle: $n=8$, ami: $n=9)$; C- volume do exsudato. Os valores referem-se à média \pm desvio padrão. *: $p<0,05$ em relação ao grupo controle (Teste de Kruskal-Wallis; $n=10$ por grupo). 
Figura 17 - Efeito do pré-tratamento com L-NAME nas ações da amitriptilina sobre as características do exsudato inflamatório produzido pela injeção intraperitoneal de carragenina. Anúmero de células por $\mathrm{mL}$; B- número total de células; Cvolume do exsudato. Os valores referem-se à média \pm desvio padrão. *: $p<0,05$ em relação ao grupo controle; $\# p<0,05$ em relação ao grupo L-NAME (ANOVA de uma via seguida pelo teste de Tukey; controle: $n=5$, ami: $n=6$, L-NAME: $n=9$, LNAME-ami: $n=8$ )

Figura 18 - Efeitos da amitriptilina sobre o comportamento de leucócitos em condição não-inflamatória. A-número de leucócitos em rolling por minuto; B- número de leucócitos aderidos em 100 $\mu \mathrm{m}$ de vênula; C- tempo para percorrer $100 \mu \mathrm{m}$ de vênula por minuto. Os valores referem-se à média \pm desvio padrão. * $\mathrm{p}<0,05$ em relação ao grupo naive. (A e B: ANOVA de uma via seguida pelo teste de Tukey; C: Teste de Kruskal-Wallis; naive: $n=7$, controle e amitriptilina: $n=6$ cada).

Figura 19 - Efeitos da amitriptilina sobre o comportamento de leucócitos em condição inflamatória. A-número de leucócitos em rolling por minuto; B- número de leucócitos aderidos em $100 \mu \mathrm{m}$ de vênula; C-número de leucócitos transmigrados em $200 \mu \mathrm{m}$ de área; D- tempo para percorrer $100 \mu \mathrm{m}$ de vênula por minuto. Os valores referem-se à média \pm desvio padrão. * $p<0,05$ em relação ao grupo controle; $t=$ tendência $(p<0,1)$ comparada ao grupo controle. (teste t, exceto em D 30', onde utilizou-se o teste de Mann-Whitney; A: controle: $n=9$, ami: $n=8$; $B$ : controle: $n=9$, ami: $n=7 ;$ C: $n=9$ /grupo; D: controle: $n=11$, ami: $n=9)$.

Figura 20- Efeitos da amitriptilina sobre a concentração de (A) IL-1beta e (B) TNF-alfa no soro de ratos em condição inflamatória. Os valores referem-se à média \pm desvio padrão. * $p<0,05$ em relação ao grupo controle $(\mathrm{pg} / \mathrm{mL})$. (ANOVA de uma via seguida pelo teste de Tukey; A: controle, ami e L-NAME-ami: $n=7$, L-NAME: $n=6$; B: controle e L-NAME-ami: $n=7$, ami e LNAME: $\mathrm{n}=8$ )

Figura 21 - Interrelações entre hipótese inflamatória da depressão, IDO, NO, receptores NMDA e o uso de antidepressivos (ATD). Adaptado de STONE; DARLINGTON (2002) e MAES (2009).. 


\section{LISTA DE TABELAS}

Tabela 1 - Algumas das principais moléculas de adesão envolvidas no processo inflamatório (Adaptado de BRASILEIRO-FILHO, 2006 e JANEWAY, 2000).

Tabela 2 - Áreas sob a curva (ASC) do volume da pata em função do tempo de animais tratados com veículo (controle) ou diferentes doses de amitriptilina. Os valores referem-se à média \pm desvio padrão. * $p<0,01 \mathrm{em}$ relação ao grupo controle (ANOVA de uma via seguida pelo teste de Newman-Keuls)

Tabela 3 - Áreas sob a curva (ASC) do volume da pata em função do tempo de animais tratados ou não com L-NAME e amitriptilina. Os valores referem-se à média \pm desvio padrão. * $p<0,01$ em relação ao grupo controle (Teste de Kruskal-Wallis seguido pelo teste de Dunn)...............

Tabela 4 - Áreas sob a curva (ASC) do volume da pata em função do tempo de animais tratados ou não com L-arginina e amitriptilina. Os valores referem-se à média \pm desvio padrão. (ANOVA de uma via não encontrou diferenças entre os grupos; $p>0,05$ )

Tabela 5 - Áreas sob a curva (ASC) do volume da pata em função do tempo de animais tratados ou não com L-NAME e amitriptilina (a cada meia-vida). Os valores referem-se à média \pm desvio padrão. * $\mathrm{p}<0,01$ em relação ao grupo controle (ANOVA de uma via seguida pelo teste de Tukey)

Tabela 6 - Expressão de moléculas de adesão em leucócitos do sangue periférico. Dados representam intensidade média de fluorescência (média geométrica), obtida pela análise por citometria de fluxo. Os valores referem-se à média \pm desvio padrão. (ANOVA de uma via não encontrou diferenças entre os grupos, $p>0,05)$. 
1- INTRODUÇÃO ............................................................. 27

2- $\quad$ REVISÃO DA LITERATURA............................................. 28

2.1- A NEUROIMUNOMODULAÇÃO..................................................... 28

2.2- OS PSICOFÁRMACOS NO CONTEXTO DA NEUROIMUNOMODULAÇÃO.......................................................... 34

2.3- OS ANTIDEPRESSIVOS NO CONTEXTO DA NEUROIMUNOMODULAÇÃO ……............................................... 38

2.4- $\quad$ PRINCIPAIS ASPECTOS DA INFLAMAÇÃO..................................... 42

3- OBJETIVOS

3.1- OBJETIVOS GERAIS ............................................................ 53

3.2- OBJETIVOS ESPECÍFICOS .......................................................... 53

4- MATERIAL E MÉTODOS.......................................................... 55

4.1- ANIMAIS........................................................................... 55

4.2- FÁRMACOS, REAGENTES.E ANTICORPOS..................................... 55

4.3- PROCEDIMENTOS EXPERIMENTAIS............................................. 58

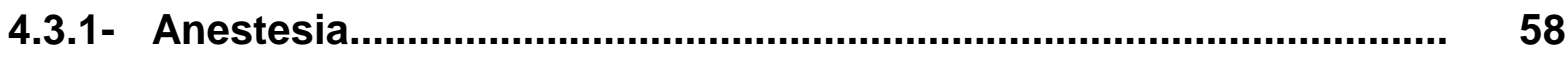

4.3.2- Modelo do Edema de Pata induzido por carragenina........................ 58

4.3.3- Avaliação do exsudato inflamatório peritoneal induzido por

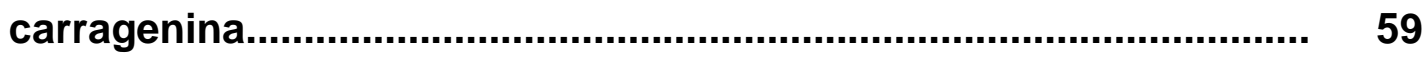

4.3.4- Avaliação da microcirculação "in vivo" e "in situ": estudo por microscopia intravital direta......................................................... 59

4.3.5- Avaliação de nitratos e nitritos........................................................ 60

4.3.6- Citometria de Fluxo..................................................................... 61

4.3.7- Enzyme-linked Immunoabsorbent Assay (ELISA) para determinação de citocinas no soro de ratos.................................... 
5- DELINEAMENTO EXPERIMENTAL E RESULTADOS........................ 65

5.1- AVALIAÇÃO DO EFEITO DA AMITRIPTILINA SOBRE A INFLAMAÇÃO..

Experimento 1 - Avaliação da administração aguda de diferentes doses de amitriptilina (3,0; 6,0 e 10,0 mg/kg) sobre o edema inflamatório induzido pela carragenina a $1 \%$.

Experimento 2 - Influência do intervalo de tempo entre administrações agudas de amitriptilina $e$ de carragenina sobre o edema de pata induzido pela carragenina $1 \%$

Experimento 3 - Avaliação da influência de um tratamento prolongado com amitriptilina e imipramina no edema de pata induzido pela carragenina e no burst oxidativo de neutrófilos e fagocitose.

Experimento 4 - Avaliação dos efeitos da administração aguda $e$ prolongada (7, 14 e 28 dias) de amitriptilina sobre $o$ edema inflamatório induzido pela carragenina a $1 \%$.

Experimento 5 - Avaliação dos efeitos de injeções intraperitoneais e subcutâneas em dose única e de injeções intraperitoneais realizadas a cada tempo de meiavida de amitriptilina sobre o edema de pata induzido pela carragenina em ratos.

Experimento 6 - Avaliação dos efeitos da administração de amitriptilina no coxim esquerdo sobre o edema de pata induzido pela carragenina.

5.2- AVALIAÇÃO DA PARTICIPAÇÃO DOS GLICOCORTICOIDES NO EFEITO ANTI-INFLAMATÓRIO DA AMITRIPTILINA.

Experimento 7 - Influência do pré-tratamento com antagonista de receptores glicocorticoides ( $R U$ 486) nos efeitos da amitriptilina sobre o edema de pata induzido por carragenina $1 \%$ 
Experimento 8 - Influência do pré-tratamento com antagonista de adrenoceptores alfa-1 (prazosina) nos efeitos da amitriptilina administrada a cada meia-vida sobre $o$ edema de pata induzido por carragenina $1 \%$.

5.4- AVALIAÇÃO DA PARTICIPAÇÃO DO ÓXIDO NÍTRICO NO EFEITO ANTI-INFLAMATÓRIO DA AMITRIPTILINA.

Experimento 9 - Efeito do pré-tratamento com um inibidor da síntese de óxido nítrico nas ações da amitriptilina sobre o edema de pata induzido por carragenina $1 \%$ em ratos.

Experimento 10 - Efeito do pré-tratamento com um precursor da síntese de óxido nítrico (L-arginina) nas ações da amitriptilina sobre o edema de pata induzido por carragenina $1 \%$ em ratos.

Experimento 11 - Influência do pré-tratamento com um inibidor da síntese de óxido nítrico (L-NAME) nas ações da amitriptilina administrada a cada tempo de meia-vida sobre o edema de pata induzido por carragenina $1 \%$ em ratos.

Experimento 12 - Influência do pré-tratamento com um precursor da síntese de óxido nítrico (L-arginina) nas ações da amitriptilina administrada a cada tempo de meia-vida sobre o edema de pata induzido por carragenina $1 \%$ em ratos.

Experimento 13 - Avaliação da influência da administração de amitriptilina e L-NAME sobre a produção de nitratos em ratos.

5.5- AVALIAÇÃO DOS EFEITOS DA AMITRIPTILINA SOBRE O EXSUDATO INFLAMATÓRIO PERITONEAL INDUZIDO PELA CARRAGENINA 
Experimento 14 - Influência da amitriptilina sobre as características do exsudato inflamatório produzido pela injeção intraperitoneal de carragenina.

Experimento 15 - Influência do pré-tratamento com L-NAME nas ações da amitriptilina sobre as características do exsudato inflamatório produzido pela injeção intraperitoneal de carragenina.

5.6- EFEITOS DA AMITRIPTILINA SOBRE O COMPORTAMENTO DE LEUCÓCITOS: AVALIAÇÃO POR MICROSCOPIA INTRAVITAL..........

Experimento 16 - Avaliação do rolling, adesão e velocidade de leucócitos em condições não-inflamatórias.

Experimento 17 - Avaliação do rolling, adesão, velocidade e transmigração de leucócitos em condições inflamatórias.

5.7- EFEITOS DA AMITRIPTILINA SOBRE A EXPRESSÃO DE MOLÉCULAS DE ADESÃO: AVALIAÇÃO POR CITOMETRIA DE FLUXO.

Experimento 18 - Influência do tratamento com amitriptilina na expressão de L-selectina, MAC-1, ICAM-1 e PECAM-1 em leucócitos de sangue periférico.

5.8- EFEITOS DA AMITRIPTILINA SOBRE A CONCENTRAÇÃO DE CITOCINAS PRÓ-INFLAMATÓRIAS NO SORO DE RATOS.

Experimento 19 - Influência do tratamento com amitriptilina na concentração de IL-1beta e TNF-alfa no soro de ratos.

6- DISCUSSÃO. 


\section{1- INTRODUÇÃO'}

Os estudos pertinentes às interações entre os sistemas nervoso, endócrino e imune tiveram seu início nos anos 70 , em especial com o trabalho pioneiro de Bartrop et al (1977) que demonstrou a existência de alterações imunes em pessoas que vivenciaram uma situação de estresse emocional. No entanto, bem antes disso, em 1936, Hans Selye já havia verificado ocorrência de hipertrofia das glândulas adrenais e outras alterações imunes decorrentes de situações estressoras de diferentes tipos. Neste contexto, apesar de ser a neuroimunomodulação enquanto ciência um produto do século passado, já no século XVII Molière afirmava em seus escritos que os males do corpo tinham origem na mente.

Neste sentido, apesar dos avanços e dos inúmeros estudos baseados na Teoria Monoaminérgica, ainda não se encontrou explicação definitiva e satisfatória para a depressão. Esta realidade incentivou a busca por novas teorias, sendo uma delas a que analisa a depressão do ponto de vista de um fenômeno neuroimunológico, isto é, como tendo perfil pró-inflamatório. Apoiando esta hipótese, diversos estudos têm demonstrado um efeito anti-inflamatório para diversos fármacos antidepressivos. No entanto, os mecanismos que explicam tais efeitos ainda não foram totalmente elucidados, assim como a eventual relação que possam ter com a depressão.

Sendo assim, pareceu-nos relevante analisar os mecanismos envolvidos no efeito anti-inflamatório da amitriptilina - fármaco antidepressivo clinicamente importante pelos efeitos que tem na depressão e em diversas condições dolorosas. Para isto, utilizamos o modelo de inflamação aguda induzida pela carragenina; em especial, avaliamos o edema de pata e o exsudato produzidos, após o uso de amitriptilina associada ou não a outros fármacos com ação na inflamação. Técnicas de microscopia intravital e avaliação de moléculas de adesão por citometria de fluxo e de citocinas por ELISA também foram empregadas.

As referências bibliográficas encontram-se citadas no item 2 Revisão de Literatura. 


\section{2- REVISÃO DA LITERATURA}

\section{1 - A NEUROIMUNOMODULAÇÃO}

A Neuroimunomodulação, também chamada de psiconeuroimunologia ou, menos frequentemente, de neuroimunoendocrinologia é uma área da ciência que busca o estudo das complexas interações bidirecionais existentes entre 0 Sistema Neuroendócrino e o Sistema Imune (BLALOCK, 1984; FISCHLER, 1987). Fisiologicamente, ambos os sistemas apresentam uma série de semelhanças, já que são capazes de responder a um grande número de estímulos externos e internos, além de desenvolver um comportamento adaptativo baseado em experiência e memória (BLALOCK, 1994; CROSS et al, 1986). Uma série de descobertas apoia a existência destas interações (BLALOCK, 1984, 1994; DUNN, 1995):

- Linfócitos: possuem receptores adrenérgicos, colinérgicos e para outros mediadores químicos do Sistema Nervoso Central (SNC) e são capazes de sintetizar Hormônio Adenocorticotrópico (ACTH), Hormônio Liberador de Corticotropina $(\mathrm{CRH})$, Hormônio do Crescimento $(\mathrm{GH})$, Hormônio Liberador de Tireotropina (TRH), endorfinas, entre outros;

- Inervação simpática de estruturas imunes, tais como medula óssea, timo e linfonodos;

- A regulação da atividade de células natural killer (NK) por catecolaminas;

- A IL-6 e a IL-1 regulam a liberação de $\mathrm{CRH}$;

- Interleucinas são secretadas no SNC, onde existem receptores para as mesmas;

- Interleucinas produzem alterações comportamentais;

- O sistema nervoso autônomo promove modulação da resposta inflamatória (TRACEY, 2002).

No entanto, até que fosse atingido o nível de conhecimento que se tem hoje a respeito destas interações, o surgimento da neuroimunomodulação foi direcionado por visões intuitivas e dedutivas dos resultados obtidos em diversos laboratórios.

O impulso inicial para o estudo das relações entre o SNC e o sistema imune adveio de um trabalho clássico do húngaro Hans Selye (1936, republicado em 
1998). Nele o autor apresenta o conceito da Síndrome Geral de Adaptação, que consiste em uma série de alterações orgânicas -divididas em três estágios- que se seguem à exposição do indivíduo a um estressor não-específico. Dentre as alterações, encontram-se aumento de tamanho da glândula supra-renal e atrofia do timo, baço e outros órgãos linfoides. Com estas observações, Selye demonstrou, pela primeira vez, que os efeitos do SNC sobre as funções neurovegetativas durante o estresse podem influenciar estruturas que fazem parte do sistema imune. No entanto, foi apenas o trabalho pioneiro de Bartrop et al (1977) que consolidou esta relação, ao mostrar pela primeira vez que uma situação de luto produzia uma diminuição da resposta de linfócitos à mitógenos. Posteriormente, outros estudos também verificaram que o estado físico e psicológico de humanos - tais como períodos que antecedem as provas, problemas em família e desemprego - são capazes de afetar a atividade de neutrófilos e de macrófagos, produzindo ainda, entre outros, redução na atividade de células NK e na resposta de linfócitos a mitógenos (revisto por DANTZER; KELLEY, 1989; MILLER, 1998, ALVES; PALERMO-NETO, 2007). Neste mesmo sentido, a observação do que acontecia na depressão - um modelo clínico excelente para mostrar a existência de relações entre cérebro-comportamento-imunidade - já há quase três décadas indicava que pacientes deprimidos apresentavam um aumento no número de leucócitos sanguíneos periféricos e uma diminuição do número de linfócitos e da atividade de células NK, além outras alterações, conforme revisão de Irwin e Miller (2007).

Até 1987, no entanto, as informações sobre as relações neuroimunes eram relativamente poucas e baseavam-se, por exemplo, no efeito da manipulação de regiões cerebrais e mecanismos hormonais sobre o sistema imune e, também, nos resultados, ainda escassos, da existência de receptores para alguns neurotransmissores e hormônios em células imunes. Outro achado também importante foi o de Ader e Cohen (1975), que mostraram ser a imunossupressão passível de condicionamento (revisto por BESEDOVSKY; DEL REY, 2007). Estes foram alguns dos passos iniciais mais relevantes para a formulação da hipótese de que as respostas imunes são sujeitas a regulação neuro-endócrina.

Neste sentido, uma série de estudos passou a ser realizada em animais a fim de se avaliar influências do SNC sobre a imunidade. A dominância em ratos e camundongos demonstrou acompanhar-se de um aumento na imunidade celular e humoral. A separação de um filhote de sua mãe, por sua vez, produziu alterações 
profundas no sistema imunológico, desde redução na resposta dos linfócitos a mitógenos até diminuição na capacidade de produção de anticorpos contra um desafio viral (DANTZER; KELLEY, 1989). Em um artigo de revisão recente, COSTAPINTO et al (2009) correlacionaram o comportamento animal ao tipo de resposta imune por ele apresentada. Camundongos dominantes, devido à sua posição hierárquica, podem priorizar o comportamento doentio frente à aplicação de LPS. Animais submissos, por sua vez, buscam primariamente o comportamento defensivo, mesmo sob efeito de LPS, já que estão na presença do animal dominante (COHN; DE SÁ-ROCHA, 2006). Isto sugere que a resposta imune é modulada pelo contexto ambiental.

Ainda neste sentido, a convivência com um animal doente tem demonstrado produzir no animal saudável alterações em seu padrão imune, tais como um prejuízo no estabelecimento de hipersensibilidade do tipo tardia produzida por ovalbumina e alterações no fenótipo de células dendríticas (TOMIYOSHI et al, 2009). Em outro trabalho, camundongos que conviveram com um companheiro inoculado com tumor de Ehrlich apresentaram uma diminuição na intensidade e porcentagem de fagocitose por macrófagos estimulados com Onco-BCG ou tumor de Ehrlich e um aumento no burst oxidativo na presença de $S$. aureus. Também foi observada uma diminuição da resistência ao crescimento do tumor de Ehrlich neste grupo (ALVES; VISMARI; PALERMO-NETO, 2007).

Palermo-Neto et al (2008) avaliaram em camundongos o efeito do alojamento individual sobre 0 crescimento do tumor de Ehrlich. Animais mantidos individualmente em gaiolas apresentaram um aumento no volume do fluido ascítico e no número de células tumorais, além de uma menor sobrevida quando comparados aos animais mantidos em caixas coletivas. Houve também um aumento do comportamento do tipo ansioso nos animais isolados, como avaliado pelo teste do labirinto em cruz-elevado. Os dados sugeriram que animais mantidos sozinhos apresentaram uma menor resistência ao crescimento do tumor de Ehrlich. Foi proposto que esta correlação entre comportamento e alterações imunes envolveria a ativação do eixo Hipotálamo-Hipófise-Adrenal (HHA).

No entanto, evidências apontam para uma resposta bifásica do sistema imune em situações estressoras, com uma tendência para um aumento nas reações imunes no pico do estresse, seguida por uma resposta diminuída no período pósestresse. Sabe-se, portanto, que a influência dos estressores nas respostas 
imunológicas é complexa, e depende não somente das características deste estressor, mas também do tempo no qual este é aplicado em relação ao curso da resposta imune avaliada (DANTZER; KELLEY, 1989; MILLER, 1998, COSTA-PINTO et al, 2009).

Além do eixo HHA, o sistema neuroendócrino também utiliza o sistema nervoso autônomo para regular as respostas imunes. A divisão autonômica simpática é conhecida pela liberação de noradrenalina pelos neurônios pós-ganglionares e de adrenalina pela medula supra-renal, particularmente em situações conhecidas como de "luta ou fuga", mas também na regulação homeostática geral do organismo. Imunologicamente, o simpático inerva diversos órgãos linfoides primários e secundários, como o baço, sendo que macrófagos alveolares e leucócitos circulantes apresentam alta densidade de receptores beta-2 adrenérgicos. Inclusive, vale ressaltar o efeito modulatório exercido pela noradrenalina na produção de citocinas. Neste sentido, Selmeczy et al (2003) demonstraram que a produção das citocinas IL-1 e TNF-alfa é prejudicada em camundongos deficientes de transportadores de noradrenalina ou com os mesmos bloqueados por desipramina; mostraram, ainda, que a concentração extracelular de noradrenalina e a duração da exposição a este neurotransmissor estão entre os reguladores chave da produção de citocinas evocada por LPS.

Em relação ao sistema nervoso autônomo parassimpático, seus neurônios pósganglionares são conhecidos por liberarem acetilcolina; um de seus principais componentes, o nervo vago, inerva os principais órgãos, incluindo-se aqui aqueles do sistema reticuloendotelial (fígado, pulmões, baço, rins. e intestino). Tracey (2002) propôs a existência de uma via anti-inflamatória colinérgica, onde a estimulação do nervo vago leva à diminuição da inflamação. A sinapse entre nervos colinérgicos e o sistema imune requer o receptor nicotínico do tipo sensível à alfa-bungarotoxina, expresso em macrófagos e outras células imunocompetentes que modulam ou participam da resposta inflamatória (CZURA; TRACEY, 2005).

Em contrapartida, pelo fato de ser uma interação neuroimune e bidirecional, não apenas o sistema imune pode ser controlado pelo eixo neuro-endócrino como, também, o caminho inverso pode ser observado. De fato, em experimento realizado por Besedovsky et al (1977), ratos imunizados apresentaram um aumento da atividade elétrica de neurônios do hipotálamo ventromedial, o que não foi observado em animais que não responderam ao antígeno. Estes resultados mostraram, pela 
primeira vez, um fluxo de informações entre sistema imune ativado e sistema nervoso.

Em 1984, J. Edwin Blalock, em um ensaio pioneiro para uma revista de imunologia, propôs que o sistema imune teria o papel de um órgão sensorial, podendo, portanto, ser considerado como um sexto sentido. E, como um componente do sistema sensorial, ele serviria para detectar informações que os outros sentidos não seriam capazes de perceber, tais como a presença de patógenos, tumores e alérgenos, mobilizando o corpo para responder de forma adequada a estes desafios. Dentre os exemplos de vias sensoriais aferentes utilizadas por esta informação imunossensorial poderíamos citar, conforme BLALOCK (1984) e BLALOCK; SMITH (2007):

- neuropeptídeos derivados de linfócitos, como a beta-endorfina, modulariam a dor via nervos sensoriais periféricos;

- hormônios derivados de leucócitos, como o MSH (hormônio estimulador de melanócitos) atravessariam a barreira hemato-encefálica e afetariam a sinalização do sistema nervoso simpático;

- a IL-1, primeira citocina identificada como sendo capaz de ativar o eixo HHA (BESEDOVSKY et al 1986), agiria nas aferências do nervo vago para causar as alterações comportamentais que serão posteriormente discutidas;

Este achado de que a IL-1 era capaz de ativar o eixo HHA foi posteriormente reforçado pela descoberta de uma rede citocinérgica com este mesmo papel, que incluia IL-2, IL -3, IL -6, IL -8, IL -11, IL -12, TNF, INF-gama e GM-CSF, mostrando aí o importante papel regulador do sistema imune sobre o sistema neuroendócrino (revisto por BESEDOVSKY; DEL REY, 2007).

A principal produção de citocinas se faz por células do sistema imune periférico, e elas podem adentrar no cérebro através de regiões onde a barreira hematoencefálica está ausente (ex: órgãos circunventriculares), menos restritiva, como na eminência mediana ou em situações onde ela esteja comprometida (ex. esclerose múltipla). Existem, também, sistemas transportadores para citocinas, além de liberação de citocinas pró-inflamatórias por neurônios e células da glia dentro do próprio SNC, como, por exemplo, no hipotálamo, hipocampo, núcleos da base e outros, com a presença de receptores funcionalmente ativos para citocinas em neurônios dessas regiões (KULMATYCKI; JAMALI, 2006; MÜLLER; ACKENHEIL, 1998; SZELENYI; VIZI, 2007). Existem duas vias pelas quais se acredita que as 
citocinas interfiram com o comportamento animal, (CZURA; TRACEY, 2005; KONSMAN; PARNET; DANTZER, 2002):

- via neural: mais rápida, onde as informações seriam levadas ao SNC por vias nervosas aferentes, como as do nervo vago, cujas terminações nervosas encontramse em íntimo contato com as células dos órgãos peritoneais; importante no comportamento doentio;

- via humoral: mais lenta, envolvendo a produção de citocinas e de mediadores inflamatórios por células endoteliais, como a prostaglandina E2 (PGE2); importante na regulação de febre e alterações endócrinas.

Particularmente em relação à IL-1, além do seu papel na inflamação como citocina pró-inflamatória, já foi citado o fato de que sua injeção produz no indivíduo uma série de respostas comportamentais, coletivamente denominadas como comportamento doentio (sickness behavior).

Em um artigo de revisão recente, Goshen e Yirmiya (2009) classificaram a IL1 como um regulador central das respostas ao estresse. Sua liberação pelo cérebro em condições de estresse leva à liberação de glicocorticoides, o que em conjunto produz os efeitos do estresse na memória e plasticidade neural, sendo estes benéficos ou deletérios dependendo dos níveis produzidos e da duração de sua produção. A liberação de IL-1 e glicocorticoides também foi envolvida no desenvolvimento dos sintomas depressivos associados à exposição ao estresse. Thomas et al (2005) verificaram que pacientes com depressão maior apresentavam níveis sanguíneos de IL-1beta 170\% maiores que indivíduos saudáveis da mesma idade (maiores de 60 anos), sendo que estes níveis correlacionaram-se fortemente com a severidade da depressão.

Neste contexto, Vismari, Alves e Palermo-Neto (2008) relataram, em um artigo de revisão, que pacientes vítimas de estresse crônico e depressão apresentam ativação das respostas imuno-inflamatórias - com um padrão próinflamatório - e do eixo HHA, os quais, direta ou indiretamente, influenciam a neurotransmissão. Além do fato de se conhecer que pacientes não responsivos aos antidepressivos possuem um sistema imune-inflamatório mais ativo.

Em função desses achados, diversas teorias têm implicado a depressão como um fenômeno psiconeuroimunológico. Essas incluem desde modelos ligados ao Sistema Imune-Inflamatório, passando pela Hipótese Citocinérgica da Depressão até a chamada Teoria Macrofágica (SMITH, 1991). Todas essas teorias se baseiam na 
ideia de que o aumento na produção de citocinas pró-inflamatórias observado na depressão resultaria nos sintomas a ela relacionados, isto é, a depressão seria um tipo especial de "comportamento doentio". Nesse sentido, as citocinas próinflamatórias atuariam como neuromoduladores, mediando os aspectos neuroquímicos, neuroendócrinos e comportamentais dos transtornos depressivos (LEONARD, 2001, 2007, 2009; SCHIEPERS et al., 2005; YIRMIYA et al, 2000). No entanto, há uma série de dados controversos na literatura, havendo indícios de um perfil imune diferente de acordo com o tipo de depressão.

Sugere-se, com isso, que os sistemas nervoso e endócrino desempenhem um papel relevante na patofisiologia de doenças que envolvem o sistema imunológico. Paralelamente ao aparecimento de alterações imunológicas em diversos transtornos psiquiátricos, tem sido de grande interesse o estudo da contribuição potencial do sistema imunológico para os comportamentos ditos anormais. A interação entre estes sistemas não é surpreendente, já que eles constituem elementos-chave na manutenção da homeostase corporal e da resistência orgânica às doenças (MILLER, 1998).

Neste momento, um olhar mais atento para a modulação farmacológica das ações do SNC levará o leitor a refletir que os psicofármacos, por atuarem primariamente no sistema nervoso, poderiam gerar consequências imunes. Além disso, suas ações farmacológicas conhecidas poderiam também depender destes mecanismos imunes, muitos deles ainda desconhecidos, conforme será discutido a seguir.

\section{2- OS PSICOFÁRMACOS NO CONTEXTO DA NEUROIMUNOMODULAÇÃO}

Diversos estudos têm buscado avaliar os efeitos de psicofármacos sobre a resposta imune/inflamatória (ABDEL-SALAM et al, 2004; BIANCHI et al, 1995; DE PAULA et al, 2009; KLEEB, 1999; KULMATYCKI; JAMALI, 2006; YARON et al, 1999).

Particularmente em nosso laboratório, diversos psicofármacos testados mostraram a capacidade de influenciar a resposta imune/inflamatória em diferentes modelos avaliados. Kleeb et al (1997) inocularam Tumor de Ehrlich sólido na pata de 
camundongos $\left(1,5 \times 10^{6}\right.$ células) seguido da administração de haloperidol $2,0 \mathrm{mg} / \mathrm{kg}$ s.c. Após 13 dias foi observado que animais tratados apresentavam uma menor área necrótica e menor invasão tumoral. Em trabalho posterior, eles verificaram que o haloperidol induzia um aumento na produção de óxido nítrico (NO) e na porcentagem de espraiamento de macrófagos peritoneais de animais com Tumor Ascítico de Ehrlich, o que poderia explicar os resultados anteriormente observados (KLEEB et al, 1999).

Em outro estudo mais recente, ratos machos e fêmeas receberam doses agudas $(2,0 \mathrm{mg} / \mathrm{kg})$ ou prolongadas (2,0 mg/kg - 21 dias) de haloperidol, a fim de avaliar seu efeito sobre a atividade de macrófagos. Os resultados mostraram que 0 tratamento prolongado produziu um aumento no espraiamento de macrófagos, na fagocitose e na liberação de $\mathrm{NO}$ em machos e fêmeas, não havendo efeito significativo após dose aguda. Além disso, houve um aumento nos níveis de prolactina e corticosterona após o tratamento com haloperidol de forma aguda e prolongada. Sendo assim, os resultados sugerem que ativação dos macrófagos tenha se dado por meio da elevação dos níveis de prolactina ou como consequência de sua ação direta sobre receptores dopaminérgicos macrofágicos (LOURENÇO et al, 2005).

O diazepam, por sua vez, tradicionalmente conhecido por sua atividade psicotrópica, induziu alterações imunológicas em vários modelos animais (DOMINGUES-JÚNIOR et al, 2000; LAZZARINI et al, 2003; MASSOCO; PALERMONETO, 1999; RIGHI et al, 1999; SAKAl et al, 2006; DA SILVA et al, 2003; UGAZ et al, 1999).

Massoco e Palermo-Neto (1999) investigaram os efeitos do diazepam (1,5 $\mathrm{mg} / \mathrm{kg} / \mathrm{dia}, 7$ dias) na atividade de macrófagos e nos níveis séricos de corticosterona em camundongos. Os resultados mostraram que o tratamento com diazepam diminuiu o espraiamento de macrófagos, a fagocitose, e as concentrações de água oxigenada (peróxido de hidrogênio $-\mathrm{H}_{2} \mathrm{O}_{2}$ ) liberada espontaneamente por estas células, além de aumentar os níveis séricos de corticosterona. Tais resultados foram explicados com base em uma possível ação agonista do diazepam em receptores benzodiazepínicos periféricos (PBRs), atualmente chamados de TSPO (translocator proteins) presentes nas glândulas adrenais, estimulando a produção de glicocorticoides, e/ou em macrófagos, alterando-se assim, direta ou indiretamente, a rede de citocinas produzidas pelos macrófagos. Posteriormente, foi observado que $o$ 
tratamento agudo e prolongado de ratos com diazepam produziu um aumento no burst oxidativo de neutrófilos (DA SILVA et al, 2003).

Lazzarini et al (1996) trataram ratos machos com diazepam de forma aguda (10 e $20 \mathrm{mg} / \mathrm{kg}$ ) e prolongada (10 mg/kg - $21 \mathrm{dias}$ ). Ao final dos tratamentos, os animais receberam o agente flogístico carragenina na pata posterior esquerda, a fim de se analisar o edema produzido. Os resultados mostraram que o tratamento agudo com diazepam reduziu o edema de pata, enquanto que o tratamento prolongado não produziu efeito significativo, tendo-se sugerido o desenvolvimento de tolerância após tratamento prolongado. Em outra série de experimentos, verificou-se que o tratamento agudo com diazepam induziu um aumento nos níveis séricos de corticosterona e redução no edema de pata, enquanto a administração prolongada não produziu efeitos significativos sobre estes parâmetros. Os níveis plasmáticos de diazepam não diferiram entre os tratamentos agudo e prolongado. Estes dados sugeriram um papel relevante da corticosterona no efeito anti-inflamatório do diazepam administrado em dose única, o que poderia se dar via ativação de PBRs presentes nas células do córtex adrenal, o que levaria a um aumento nos níveis séricos de corticosterona e conseqüentemente, a uma redução do edema de pata (LAZZARINI et al, 2003).

Quando se avaliou o efeito do diazepam em um modelo de tumor, a administração deste fármaco (3.0 mg/kg/dia, 7 dias) produziu um aumento no volume e no número de células do Tumor ascítico de Ehrlich, o que não foi observado em doses menores, mostrando um efeito dose-dependente. Além disso, a administração de diazepam $3.0 \mathrm{mg} / \mathrm{kg}$ por 2 dias reduziu a percentagem de macrófagos espraiados e seu nível de produção de NO (SAKAl et al, 2006).

Pensando de forma mais ampla, não apenas em psicofármacos, mas também em drogas de abuso, camundongos tratados com ecstasy (MDMA 10mg/kg), apresentaram diminuição no burst oxidativo e na porcentagem e intensidade de fagocitose por neutrófilos, além de alteração na distribuição de leucócitos no sangue, medula óssea e baço. Tais efeitos não foram observados in vitro, o que indica a participação do controle exercido provavelmente pelo eixo HHA ou pelo sistema noradrenérgico (DE PAULA et al, 2009).

Szuster-Ciesielska e colaboradores (2003) compararam a influência de antidepressivos tricíclicos (imipramina), heterocíclicos (mianserina) e do lítio na produção de citocinas por células mononucleares do sangue periférico de 
voluntários sadios. Os resultados mostraram que todos os antidepressivos regularam a produção de citocinas, aumentando a produção das citocinas anti-inflamatórias e inibindo aquela das pró-inflamatórias. Altas concentrações de imipramina e mianserina também inibiram o burst oxidativo de neutrófilos, sugerindo estes fatos um efeito imunorregulatório dos antidepressivos na função de leucócitos humanos.

Como a presente tese trata do efeito de um antidepressivo sobre a resposta inflamatória, esta classe de fármacos será melhor abordada no próximo capítulo. 


\subsection{OS ANTIDEPRESSIVOS NO CONTEXTO DA NEUROIMUNOMODULAÇÃO}

Os primeiros antidepressivos foram descobertos por acaso há mais de quarenta anos. No entanto, somente mais tarde determinou-se que a ação destes agentes se fazia pela inibição da enzima monoaminoxidase (MAO) ou pelo bloqueio da recaptação de noradrenalina ou de serotonina. Estas duas classes de antidepressivos - os inibidores da MAO e os antidepressivos tricíclicos, respectivamente - dominaram o tratamento da depressão durante quase 30 anos, até o final da década de 1980, quando foram introduzidos os inibidores seletivos de recaptação de serotonina. Posteriormente, outras classes de antidepressivos foram desenvolvidas, cujo mecanismo de ação difere dos demais. A venlafaxina, por exemplo, bloqueia a recaptação de serotonina, noradrenalina e dopamina, enquanto a mirtazapina é um antidepressivo antagonista alfa-2 - o que aumenta a neurotransmissão serotonérgica e noradrenérgica - além de antagonista de receptores 5- $\mathrm{HT}_{2}$, 5- $\mathrm{HT}_{3}$ e $\mathrm{H}_{1}$ (RANG et al, 1997; STAHL, 1998).

O mecanismo de ação dos antidepressivos tricíclicos (ATC) propõe inibições, de forma não-seletiva, da recaptação de noradrenalina e de serotonina. No entanto, tais fármacos também agem como antimuscarínicos, antagonistas adrenérgicos alfa1 e antihistamínicos $\left(H_{1}\right)$; estas ações são consideradas responsáveis por muitos dos efeitos colaterais destes medicamentos, tais como ganho de peso, sonolência, constipação, boca seca, visão borrada, hipotensão e vertigem.

Os vários tipos de ATC diferem entre si na seletividade de inibição da captação de noradrenalina e de serotonina, sendo os principais representantes do grupo a imipramina, a nortriptilina e a amitriptilina (RANG et al, 1997; STAHL, 1998).

A amitriptilina, em particular, tem papel especial na clínica, onde além de seu efeito antidepressivo é considerada como tratamento de escolha para diferentes tipos de dor crônica, incluindo-se enxaqueca e dor crônica miofascial. Este efeito analgésico, apesar de independente do efeito antidepressivo, parece envolver a inibição da recaptação de serotonina e noradrenalina (CASTELLS; DELGADO; ESCODA, 2008).

Diversos estudos têm demonstrado o papel de antidepressivos na resposta inflamatória, com resultados indicativos de uma downregulation na produção de citocinas pró-inflamatórias in vitro, e uma mudança de padrão $T h_{1}$ para $T h_{2}$, que são 
anti-inflamatórias e protetoras. Logo, a neuroproteção e as diversas formas de plasticidade neuronal, incluindo neurogênese e sinaptogênese no hipocampo, seriam os mais prováveis mecanismos moleculares da terapia antidepressiva, já que o tratamento crônico com antidepressivos também é responsável pelo aumento de fatores neurotróficos, como o BDNF (fator neurotrófico derivado do cérebro) (CASTRÉN et al, 2007; MULLER e SCHWARZ, 2007; NISHIDA et al, 2002).

Achar et al (2003) demonstraram que o tratamento com amitriptilina facilitou a eliminação de cálculos urinários em gatos, além de produzir melhora na sua função renal. Este efeito se deve a um potente relaxamento da musculatura lisa do trato urinário, mediado pelo bloqueio de canais de potássio voltagem-dependentes. Posteriormente, estes mesmos autores submeteram camundongos a um modelo de doença renal. Animais tratados com amitriptilina por 7 dias apresentaram redução da fibrose intersticial e da inflamação, com menor infiltração de macrófagos. Houve redução na expressão de genes dos marcadores de injúria tubulointersticial progressiva, como MCP-1, ICAM-1, and TGF- $\beta 1$, quando comparados aos animais do grupo controle. $O$ trabalho em questão propôs a amitriptilina como um importante agente terapêutico, não só por bloquear a inflamação e a fibrose renal, mas também pelas suas propriedades analgésicas, que auxiliaram no bem-estar e consequente ganho de peso dos animais (ACHAR et al, 2009).

O’Brien et al (2007) avaliaram os níveis de citocinas pró e anti-inflamatórias (IL6, TNF-a, sIL-6R, IL-8 e IL-10,) em três grupos: pacientes com depressão maior resistentes à terapêutica com ISRS, pacientes eutímicos resistentes à terapêutica com ISRS e controles saudáveis. Os pacientes deprimidos apresentaram níveis aumentados das citocinas pró-inflamatórias IL-6 e TNF- $\alpha$ quando comparados aos controles saudáveis. Dados dos pacientes eutímicos não diferiram daqueles do grupo controle. Não se encontraram diferenças nos níveis de citocinas antiinflamatórias entre os grupos. Os resultados sugeriram a necessidade de supressão das citocinas pró-inflamatórias para a recuperação de um quadro depressivo, mesmo em pacientes resistentes à terapêutica antidepressiva com ISRS.

As interações entre os sistemas catecolaminérgico e inflamatório se mostram importantes já que alguns anti-inflamatórios possuem efeitos antidepressivos, particularmente os inibidores da enzima ciclooxigenase do tipo 2 (COX-2), e a maioria dos antidepressivos podem modular a resposta imune, mostrando inclusive 
efeito anti-inflamatório (ABDEL-SALAM; NOFAL; EL-SHENAWY, 2003; BIANCHI et al, 1995; MULLER; SCHWARZ, 2007; SZELENYI; VIZI, 2007; SZUSTERCIESIELSKA et al, 2003; MÜLLER, 2010). Outros trabalhos também verificaram que a amitriptilina e a imipramina, dois antidepressivos tricíclicos, foram capazes de ativar em camundongos a enzima 15-hidroxiprostaglandina desidrogenase, responsável por degradar prostaglandinas, sendo este mais um possível mecanismo para explicar seu efeito anti-inflamatório (MAK; CHEN, 1986). Há evidências de que diferentes classes de antidepressivos também agiriam como inibidores da enzima ciclooxigenase (LEONARD, 2001).

Sendo assim, o tratamento com antidepressivos, por estimular a produção de citocinas anti-inflamatórias, inibindo aquelas com padrão $\mathrm{Th}_{1}$, levaria a uma diminuição na produção central de $\mathrm{NO}$ e $\mathrm{PGE}_{2}$; diminuiria a resistência dos receptores de glicocorticoides, restaurando a atividade do eixo HHA prejudicada pelas citocinas, além de inibir a ativação da enzima indolamina-2,3-dioxigenase (IDO). Tal enzima converte o triptofano em quinurenina e ácido quinolínico, este último uma substância neurotóxica implicada em transtornos neurodegenerativos e cuja via resulta na produção de metabólitos neurotóxicos presentes em indivíduos deprimidos. O ácido quinolínico é também um agonista de receptores NMDA que prejudica o feedback negativo de glicocorticóides, causa perda de receptores glicocorticóides e atrofia hipocampal (KULMATYCKI; JAMALI, 2006, MULLER; SCHWARZ, 2007). A inibição da IDO pelos antidepressivos elevaria a disponibilidade de triptofano e a neurotransmissão serotonérgica e catecolaminérgica, reduzindo, desta forma, a sintomatologia depressiva (CASTANON, 2002; LEONARD, 2001; SCHIEPPERS et al, 2005).

No entanto, existem diversas contradições na literatura que trata desse assunto. Marques-Deak et al (2007) selecionaram mulheres diagnosticadas com diferentes subtipos de transtorno depressivo maior e as avaliaram quanto aos níveis de citocinas pró-inflamatórias e cortisol. De maneira interessante, não se observaram diferenças entre os pacientes com depressão e indivíduos de um grupo controle saudável em relação a esses parâmetros. No entanto, após o tratamento com antidepressivos, houve aumento significativo dos níveis das citocinas próinflamatórias IL-1 $\beta$, IL-6 e IFN- $\gamma$, independentemente do subtipo de depressão (melancólico ou não melancólico, agudo ou crônico, episódico ou recorrente, severo ou moderado). De acordo com os autores, outros estudos deveriam ser realizados, 
padronizando-se o tipo de antidepressivo utilizado, a duração do tratamento e fatores que levem o paciente ao estresse, tais como a hospitalização.

Apesar das controvérsias da literatura, diversos estudos, conduzidos também com animais, têm demonstrado o papel anti-inflamatório dos antidepressivos. Bianchi et al (1994) observaram que a administração aguda de fluoxetina (2,5; 5,0 e $10,0 \mathrm{mg} / \mathrm{kg}$ - i.p.) reduziu significantemente o edema de pata induzido por levedura em ratos. Tal efeito anti-edema foi bloqueado por adrenalectomia e hipofisectomia, sendo que o uso de um antagonista de $\mathrm{CRH}$ não influenciou o efeito inicial observado. Estes resultados sugeriram aos autores a participação do eixo HHA, sem participação direta do $\mathrm{CRH}$, no efeito anti-edema induzido pela fluoxetina. Dados da literatura indicam também uma possível influência dos mecanismos neuronais espinais envolvendo receptores $G_{A B A}$ no desenvolvimento da inflamação periférica.

Outro trabalho, utilizando desta vez a clomipramina (10,0; 20,0 e 40,0 mg/kg i.p.) e a fluoxetina (5,0; 10,0 e 20,0 mg/kg - i.p.) também mostrou que estes dois antidepressivos reduziram o edema produzido pela implantação de carragenina no dorso de ratos, com diminuição do volume do exsudato, diminuição da concentração e da atividade de prostaglandinas $\mathrm{E}_{2}\left(\mathrm{PGE}_{2}\right)$; mostraram, ainda, que a clomipramina e a fluoxetina (esta última apenas na maior dose) inibiram a ação da substância $P$, a qual é fundamental para a inflamação neurogênica. Sabendo que a clomipramina, ao contrário da fluoxetina, é conhecida por diminuir a migração de polimorfonucleares, e que a fluoxetina está envolvida na ativação do eixo HHA, os autores sugeriram ser o efeito anti-inflamatório da fluoxetina mediado pela liberação de glicocorticoides produzidos via aumento de serotonina no SNC; sugeriram, ainda, que o efeito da clomipramina envolvia mecanismos neuro-imunes, via substância P (BIANCHI et al, 1995).

Por outro lado, a atividade anti-inflamatória da fluoxetina - um inibidor seletivo de recaptação de serotonina- foi estudada no modelo da inflamação induzida por carragenina. Houve uma diminuição significante do edema de pata com a utilização de fluoxetina (10-60 mg/kg i.p.) 30 minutos antes da carragenina, administrada tanto aguda como cronicamente. Tal efeito anti-edema foi parcialmente suprimido pelo antagonista opioide naloxona (ABDEL-SALAM et al, 2004). 
Neste contexto, para uma melhor compreensão dos experimentos que serão posteriormente apresentados, torna-se fundamental uma breve revisão dos principais aspectos envolvidos no processo inflamatório.

\section{4- PRINCIPAIS ASPECTOS DA INFLAMAÇÃO}

A exposição diária e contínua do organismo a uma variedade de patógenos ambientais e estímulos lesivos pode causar uma lesão celular e, como consequência um fenômeno complexo denominado "Processo Inflamatório ou Inflamação", cujas primeiras descrições remontam aos papiros egípcios em 3000 a.C. Muitos de seus componentes têm sido encontrados em todos os vertebrados estudados até 0 momento, além do fato de que algumas formas de resposta adaptativa às condições adversas, tais como lesões e infecções, ocorrerem em todos os animais e plantas (MEDZHITOV, 2008).

O evento inflamatório em si não é uma doença; sua função é destruir, diluir ou encerrar o agente lesivo, livrando o organismo das causas e consequências desta lesão, restaurando a função do tecido lesado. Este processo é desencadeado por inúmeros estímulos, como agentes infecciosos, alterações do sistema imune, interações antígeno-anticorpo e outros tipos de injúria, que levam o organismo a apresentar os quatro sinais clássicos de inflamação: rubor (vermelhidão), tumor (edema), calor e dor, como consequência de uma série de eventos quimicamente mediados. Entretanto, em algumas condições, o processo pode progredir para a cronicidade, levando o indivíduo ao quinto sinal, que é a perda da função, onde há alterações e destruição dos tecidos subjacentes (COTRAN; KUMAR; COLLINS, 2000; HAJJAR; PINHEIRO, 1999; MELLO; LAURINDO, 2000).

Diante do exposto, pode-se dividir didaticamente a inflamação em:

$\checkmark \quad$ Inflamação Aguda: onde há resposta imediata e precoce a um agente nocivo e um papel importante dos fenômenos vasculares;

$\checkmark$ Inflamação Crônica: considerada aquela de duração prolongada (semanas a meses), no qual inflamação ativa, destruição tecidual e tentativas de reparação estão acontecendo simultaneamente (COTRAN; KUMAR; COLLINS, 2000). 
A inflamação aguda, que será enfocada no presente trabalho, possui três componentes principais:

1) Alterações do calibre vascular, que acarretam um aumento do fluxo sanguíneo e consequente calor e rubor local;

2) Alterações estruturais da microvasculatura, com aumento de sua permeabilidade, que permitem que as proteínas plasmáticas e leucócitos deixem a circulação, levando à formação de um exsudato inflamatório agudo, típico da inflamação aguda;

3) Migração dos leucócitos da microcirculação e seu acúmulo no foco da lesão.

O exsudato formado é um líquido extravascular inflamatório com densidade maior que 1,020, rico em fluido (sais + proteínas), fibrina (proteína insolúvel de alto peso molecular), muitos neutrófilos (poliformonucleares (PMN)), poucos macrófagos e alguns linfócitos, além de restos celulares. A produção deste exsudato resulta em um aumento final do líquido extravascular, o qual é denominado edema, cuja composição exata é variável conforme o local e causa da inflamação (COTRAN; KUMAR; COLLINS, 2000; STEVENS; LOWE, 2002).

Em relação aos processos celulares na inflamação, sabe-se que os leucócitos desempenham papel fundamental na ativação e manutenção do estado inflamatório. Após um estímulo lesivo, os polimorfonucleares neutrófilos e os mononucleares circulantes se dispõem junto às paredes internas dos pequenos vasos para depois atravessarem-nas e atingirem a área lesada, sendo os neutrófilos as principais células do infiltrado em lesões agudas.

Mas para que isto seja possível, os seguintes passos são necessários (COTRAN; KUMAR; COLLINS, 2000; COUSSENS; WERB, 2002; MELLO; LAURINDO, 2000; STEVENS; LOWE, 2002; MEDZHITOV, 2008):

- Com a diminuição do fluxo sanguíneo no início da inflamação, graças ao aumento da permeabilidade vascular, ocorre a marginação dos leucócitos ao longo da superfície do endotélio;

- Há ativação de moléculas de adesão da família das selectinas (Selective Function Lectins), que facilitam o rolamento (rolling) destas células pelo endotélio vascular;

- Os leucócitos são ativados e aderem ao endotélio, sendo imobilizados com o auxílio das moléculas de adesão da família das integrinas e das imunoglobulinas; 
- Com o tempo, o endotélio passa a ser revestido de leucócitos (pavimentação)

- Estas células passam por transmigração pelo endotélio, com o auxílio de proteases extracelulares e de moléculas de adesão da família das imunoglobulinas, como a PECAM;

- Após este extravasamento, os leucócitos migram nos tecidos em direção ao local da lesão por um processo denominado quimiotaxia;.

- Ocorre acúmulo de leucócitos no foco inflamatório, seguido de fagocitose e liberação de enzimas lisossômicas, metabólitos ativos derivados do oxigênio e produtos do metabolismo do ácido araquidônico (prostaglandinas - PGs - e leucotrienos - LTs), para uma efetiva destruição do agente lesivo;

- Após a fagocitose, os neutrófilos vão à morte celular apoptótica e são removidos por macrófagos ou pelos vasos linfáticos.

A figura 1 ilustra este processo:

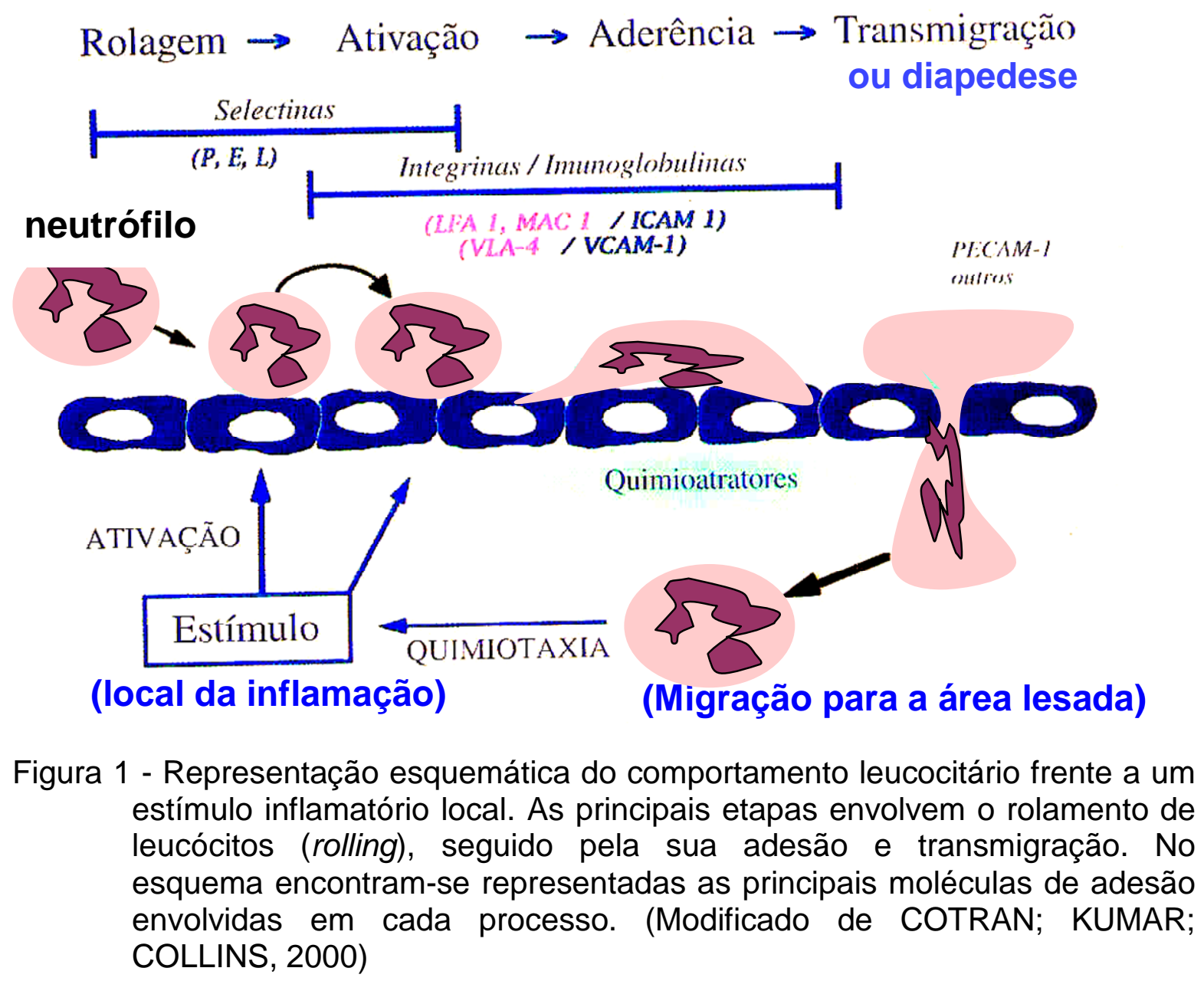


Diversas moléculas estão envolvidas na rolagem, adesão e transmigração leucócito/endotélio. Os leucócitos possuem moléculas de adesão da família das selectinas (L-selectina) e integrinas (VLAs, LFA-1, MAC-1), assim como glicoproteínas com resíduos de carboidratos. O endotélio, por sua vez, possui P e Eselectinas, imunoglobulinas e integrinas (BRASILEIRO-FILHO, 2006).

As selectinas são uma família de glicoproteínas transmembrana cálciodependentes. A P-selectina é constitutivamente sintetizada por células endoteliais e plaquetas, fica armazenada nos grânulos de Weibel-Palade, podendo ser rapidamente expostas frente à estímulos (TNF-alfa, IL-1, histamina, complemento), onde ficam por pouco tempo. Têm papel importante no recrutamento inicial de leucócitos na inflamação. A E-selectina, por sua vez, tem sua síntese no endotélio induzida por IL-1, TNF-alfa, LPS e IFN-gama (potencializador). Os ligantes destas duas selectinas são carboidratos das membranas dos leucócitos, especialmente os grupos sialil Lewis X. Estão envolvidas no rolamento de leucócitos (rolling) (BRASILEIRO-FILHO, 2006; Petri; Phillipson; Kubes, 2008). As principais imunoglobulinas do endotélio são as ICAM-1 e 2 (Intercellular adhesion molecule), VCAM (vascular CAM) e CD 31. Seus ligantes são as integrinas dos leucócitos. As ICAM-2 são constitutivamente expressas e armazenadas, sendo rapidamente expostas após serem estimuladas com IL-1, TNF-alfa e histamina. ICAM-1, VCAM-1 e CD-31, por sua vez, não são constitutivamente expressas, sendo sua produção induzida por IL-1, TNF-alfa, além de Interferon-gama e LPS (BRASILEIRO-FILHO, 2006).

As integrinas dos leucócitos, por sua vez, têm expressão estimulada por agentes quimiotáticos, como quimiocinas (IL-8 nos polimorfonucleares), PAF (fator ativador de plaquetas) e fração C5a do complemento; particulamente nos monócitos, isto se dá pela ação de citocinas (IL-1, TNF-alfa e IFN-gama) (BRASILEIRO-FILHO, 2006; PETRI; PHILLIPSON; KUBES, 2008).

A tabela 1 resume algumas das principais moléculas de adesão, bem como sua localização, função e principais ligantes. 
Tabela 1 - Algumas das principais moléculas de adesão envolvidas no processo inflamatório (Adaptado de BRASILEIRO-FILHO, 2006 e JANEWAY, 2000)

\begin{tabular}{|c|c|c|c|c|}
\hline Molécula de Adesão & Sinônimos & Localização & Função & $\begin{array}{l}\text { Alguns } \\
\text { ligantes }\end{array}$ \\
\hline \multicolumn{5}{|l|}{ SELECTINAS } \\
\hline L-selectina & CD-62L, & leucócitos & rolamento & $\begin{array}{c}\text { GlyCAM-1, } \\
\text { CD34 }\end{array}$ \\
\hline E-selectina & CD-62E & endotélio & rolamento & Sialil Lewis $\mathrm{X}$ \\
\hline P-selectina & CD-62P & $\begin{array}{l}\text { Endotélio e } \\
\text { plaquetas }\end{array}$ & rolamento & Sialil Lewis X \\
\hline \multicolumn{5}{|l|}{ IMUNOGLOBULINAS } \\
\hline ICAM-1 & CD54 & $\begin{array}{l}\text { Endotélio } \\
\text { ativado/leucócitos }\end{array}$ & adesão & $\begin{array}{c}\text { LFA-1, MAC- } \\
1\end{array}$ \\
\hline ICAM-2 & CD102 & $\begin{array}{l}\text { Endotélio em } \\
\text { repouso /leucócitos }\end{array}$ & adesão & LFA-1 \\
\hline VCAM-1 & CD106 & Endotélio ativado & adesão & VLA-4 \\
\hline PECAM & CD31 & $\begin{array}{l}\text { Endotélio/ } \\
\text { leucócitos }\end{array}$ & diapedese & CD-31 \\
\hline \multicolumn{5}{|l|}{ INTEGRINAS } \\
\hline$\alpha \mathrm{L} \beta 2$ & $\begin{array}{c}\text { LFA-1 } \\
\text { CD11a/CD18 }\end{array}$ & leucócitos & Adesão & ICAMs \\
\hline$\alpha M \beta 2$ & $\begin{array}{c}\text { MAC-1 } \\
\text { CD11b/CD18 }\end{array}$ & $\begin{array}{c}\text { Macrófagos, } \\
\text { monócitos e PMN }\end{array}$ & Adesão & $\begin{array}{l}\text { ICAM1. } \\
\text { fibrinogênio }\end{array}$ \\
\hline$A 4 \beta 1$ & $\begin{array}{c}\text { VLA-4 } \\
\text { CD49d/CD29 }\end{array}$ & $\begin{array}{l}\text { Linfócitos, } \\
\text { monócitos e } \\
\text { macrófagos }\end{array}$ & Adesão & $\begin{array}{l}\text { VCAM-1, } \\
\text { fibronectina }\end{array}$ \\
\hline
\end{tabular}

O desencadeamento e a manutenção do estado inflamatório dependem de inúmeras substâncias conhecidas como mediadores da inflamação. Provenientes do plasma ou secretados por células ativadas, eles são liberados concomitante ou sequencialmente nos sítios da lesão, em resposta a um fator etiológico (HAJJAR; 
PINHEIRO, 1999; MELLO; LAURINDO, 2000; MEDZHITOV, 2008). Tais mediadores podem ser divididos em:

- Proteoglicanas: servem como sítio de ligação dos mediadores, além de uma atividade regulatória;

- Mediadores enzimáticos como as proteases

- Mediadores Quimiotáxicos: como as citocinas, os leucotrienos, o sistema complemento e o Fator Ativador de Plaquetas (PAF);

- Mediadores com propriedades vasoativas: como histamina, PAF, óxido nítrico (NO), adenosina e os metabólitos do ácido araquidônico (prostaglandinas e leucotrienos)

Em relação aos mediadores quimiotáxicos, a quimiotaxia dos leucócitos pode ser iniciada por uma série de agentes que inclui produtos bacterianos, produtos da via da lipoxigenase (leucotrieno B4 - LTB4), citocinas como a IL-8, caseína e peptona. Além deles, existem inúmeras substâncias que, em contato com o soro, geram fatores quimiotáxicos via ativação do sistema complemento. Neste contexto, a fração C5a do sistema complemento está envolvida com a liberação de mediadores inflamatórios, incrementa a adesão e ativação leucocitária e é considerada o mais importante fator quimiotáxico para mastócitos, PMN e basófilos (MELLO; LAURINDO, 2000).

Outro agente quimiotáxico de grande importância no estudo de migração celular é o FMLP (N-formil-L-metionil-L-leucil-fenilalanina), um dos peptídeos sintéticos mais potentes em atrair PMN. Posteriormente, verificou-se que a própria parede mitocondrial pode promover a liberação desse agente e que, inclusive, há receptores específicos nas células humanas, ressaltando sua importância no processo inflamatório (CHEN; JAN, 2001; SELVATICl et al, 2006).

As citocinas são moléculas proteicas ou glicoproteicas solúveis secretadas por diversas células em resposta a uma variedade de estímulos. Suas ações são variadas, o que faz com que elas sejam classificadas em 3 grupos: citocinas antivirais (interferon- $\gamma$, interleucina 15 e 12 (IFN- $\gamma$, IL-15 e IL-12, respectivamente)); citocinas pró-inflamatórias (fator de necrose tumoral - TNF- $\propto$, IL-1, IL-6, quimiocinas); citocinas regulatórias, como a IL-10 (HAJJAR; PINHEIRO, 1999)

Dentre os mediadores com propriedades vasoativas, a histamina está entre as primeiras substâncias a serem liberadas na inflamação aguda, vinda da degranulação de mastócitos, além de basófilos e plaquetas circulantes. Tipicamente, 
a histamina provoca a dilatação de pequenos vasos sanguíneos, resultando em rubor, diminuição da resistência periférica total e aumento da permeabilidade capilar. A ativação dos receptores $\mathrm{H}_{1}$ e $\mathrm{H}_{2}$ pode causar vasodilatação máxima, apesar de os receptores $\mathrm{H}_{1}$ exibirem maior afinidade pela histamina, mediando uma resposta dilatadora rápida no seu início e de curta duração (HARDMAN; LIMBIRD, 2003).

Os receptores $\mathrm{H} 1$ são encontrados nas células endoteliais e sua estimulação leva à liberação de substâncias vasodilatadoras locais. Entre os principais efeitos da ativação de receptores $\mathrm{H}_{1}$ estão a contração da musculatura uterina, brônquica e intestinal, além do aumento da permeabilidade vascular em vênulas pós-capilares. Em contraste, a ativação de receptores $\mathrm{H}_{2}$ leva a um aumento da secreção gástrica de ácido e da secreção de muco nas vias aéreas, além de efeitos imunomodulatórios (STITES; TERR; PARSLOW, 1994; HARDMAN; LIMBIRD, 2003). Foi demonstrado que a ativação de receptores $\mathrm{H}_{2}$ leva à supressão da síntese de TNF- $\propto$ no local da inflamação, além de inibir a movimentação e exocitose de polimorfonucleares, o que paradoxalmente contribuiria para uma limitação das respostas inflamatórias e imunes locais (BRASILEIRO-FILHO, 2006; TANAKA; ICHIKAWA, 2006). A ligação a receptores $\mathrm{H}_{3}$, por sua vez, afeta a síntese e liberação de histamina e de alguns neurotransmissores, como a acetilcolina, dopamina, noradrenalina e serotonina, além de diversos estudos apontarem os agonistas $\mathrm{H}_{3}$ como potenciais agentes gastroprotetores, anti-inflamatórios e anticonvulsivantes (HARDMAN; LIMBIRD, 2003). O receptor de histamina mais recentemente identificado- receptor $\mathrm{H} 4$ mostrou ser primariamente expresso em leucócitos e parece estar implicado na ativação de linfócitos, eosinófilos e mastócitos in vitro, sendo que o antagonismo deste receptor preveniu a neutrofilia na cavidade pleural de camundongos que receberam zymosan, mas não daqueles que receberam carragenina (TAKESHITA et al, 2003).

A serotonina ou 5-hidroxitriptamina tem ações similares às da histamina sobre a permeabilidade vascular em vênulas pós-capilares na vigência de uma inflamação aguda. Está presente nas plaquetas e em células enterocromafins e sua liberação acontece quando agregados plaquetários entram em contato com colágeno, trombina, difosfato de adenosina (ADP) e complexos antígeno-anticorpo (MELLO; LAURINDO, 2000).

A bradicinina é um neuropeptídeo vasoativo produzido a partir do precursor plasmático chamado cininogênio pelas proteases conhecidas como calicreínas. Sua 
vida média é curta (cerca de 15 minutos) e sua formação se dá a partir de vários fatores, como lesão tecidual, reações alérgicas e outros eventos inflamatórios. Sua ação local produz dor, aumento da permeabilidade vascular e vasodilatação, esta última mediada pela produção de óxido nítrico e de prostaglandinas pelas células endoteliais vasculares (MELLO; LAURINDO, 2000; HARDMAN; LIMBIRD, 2003).

O ácido araquidônico é um ácido graxo de 20 carbonos liberado a partir de fosfolipídeos de membrana através da enzima fosfolipase $A_{2}$, a qual pode ser ativada por diversos estímulos (químico, inflamatório, traumático). O metabolismo do ácido araquidônico leva à produção dos eicosanoides pela ação de ciclooxigenases (COX), gerando prostaglandinas (PGs) e tromboxanos (TX)] ou pela ação de lipoxigenases, levando à produção de leucotrienos (LT) e lipoxinas (MEDZHITOV, 2008).

Diante de um trauma tissular, por exemplo, o acúmulo local destes mediadores leva à sensibilização periférica da dor, levando à hiperalgesia. Além disso, a prostaglandina $E_{2}\left(P E_{2}\right)$ e a prostaciclina $\left(P_{2}\right)$ são importantes na vasodilatação inflamatória e no incremento da permeabilidade vascular e quimiotaxia promovida por outros mediadores. O Tromboxano $A_{2}\left(T X A_{2}\right)$, por sua vez, é um potente agente de agregação plaquetária e vasoconstritor, rapidamente convertido à sua forma inativa TXB2. Além disso, as prostaglandinas também estão envolvidas na patogênese da febre e dor na inflamação.

A enzima COX possui duas isoformas denominadas COX-1 e COX-2. A atividade da COX-1 predomina em condições fisiológicas, agindo como citoprotetora gástrica e mantenedora da homeostase renal e plaquetária. A COX-2 é conhecida como uma enzima induzida em situações de trauma tissular e inflamação. A partir deste princípio, o mecanismo de ação das drogas anti-inflamatórias não-esteroidais baseia-se na inibição, cada vez mais seletiva, da COX-2, a fim de minimizar os efeitos colaterais relacionados a uma inibição não-seletiva. No entanto, a descoberta da presença constitutiva da COX-2 em tecidos humanos e animais levanta o questionamento sobre a real vantagem desta inibição específica a que buscam os mais recentes anti-inflamatórios (MELLO; LAURINDO, 2000; KUMMER; COELHO, 2002; FONSECA; VILORIA; REPETTI, 2002). Por outro lado, as lipoxinas (e as resolvinas derivadas de ácidos graxos ômega-3 da dieta e as protectinas) inibem a inflamação e promovem a resolução da inflamação e o reparo tecidual (MEDZHITOV, 2008) 
O óxido nítrico (NO) foi descrito inicialmente como fator relaxante derivado do endotélio (EDRF). A enzima óxido nítrico sintase (NOS) é a responsável pela conversão da L-arginina em NO e L-citrulina. Existem três tipos de NOS (MONCADA; HIGGS, 1991; TRIPATHI et al, 2007):

-Neuronal: também chamada de NOS I ou eNOS, é constitutivamente expressa via mecanismo cálcio/calmodulina-dependente. Foi originalmente caracterizada em neurônios;

-Endotelial: também chamada de NOS III ou eNOS, é constitutivamente expressa via mecanismo cálcio/calmodulina-dependente. Foi originalmente caracterizada em células endoteliais;

-Induzida: também chamada de NOS II ou iNOS, não é constitutiva, sendo expressa em células ativadas via mecanismo cálcio/calmodulina-independente; expressa por neutrófilos, hepatócitos e células epiteliais de vias aéreas, sua expressão é regulada por citocinas, e os fatores de transcrição que participam desta regulação incluem NF-kB, AP-1 e STAT-1.

Em presença de oxigênio, o NO é rapidamente metabolizado em radicais nitrito $\left(\mathrm{NO}_{2}{ }^{-}\right)$e nitrato (NO3-), podendo reagir também com ânion superóxido, originando os peroxinitritos, que são considerados responsáveis pela sua ação lesiva ao tecido. As ações do NO vão desde a influência sobre a função imune de macrófagos, ação como neurotransmissor no SNC e periférico e no relaxamento de vasos sanguíneos. (DAWSON; DAWSON, 1995; SAUTEBIN et al, 1998).

O NO possui uma série de ações consideradas pró-inflamatórias: é um potente vasodilatador, aumenta a permeabilidade vascular e induz a produção de prostaglandinas; no entanto, outras de suas propriedades podem ser consideradas anti-inflamatórias, tais como a redução da agregação de plaquetas e da adesão de leucócitos, apesar deste último parâmetro mostrar dados controversos na literatura (MELLO; LAURINDO, 2000).

O efeito da inibição crônica da biossíntese de NO foi investigado em dois modelos de inflamação aguda induzidos por carragenina (edema de pata e pleurisia). Foi demonstrado que a administração crônica (2 ou 4 semanas) do inibidor de NOs N-nitro-L-arginina-metil-éster (L-NAME) inibiu o edema de pata induzido por carragenina, sem contudo interferir na permeabilidade vascular e sem alterar a migração de leucócitos e a formação de exsudato na pleurisia, o que pode 
refletir uma diminuição no fluxo sanguíneo local e não um efeito sobre a permeabilidade vascular (MEDEIROS et al, 1995).

$\mathrm{Na}$ tentativa de elucidar estas questões, outro estudo verificou que a modulação da via L-arginina-NO em ratos com pleurisia induzida por carragenina resultou em uma modulação paralela da biossíntese de prostaglandinas no local da inflamação, provavelmente ativando a enzima ciclooxigenase por meio de um

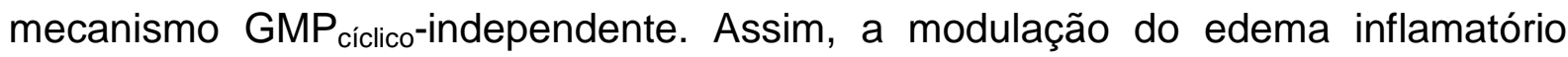
agudo pelo NO parece envolver não somente o aumento do fluxo local de sangue, mas também a estimulação da produção local de prostaglandinas (SAUTEBIN et al, 1998).

Um trabalho mais recente investigou a interação entre as vias de prostaglandinas e $\mathrm{NO}$ em células endoteliais microvasculares humanas e células endoteliais da veia umbilical in vitro. Os resultados mostraram que o aumento na disponibilidade de NO aumentou significantemente os níveis de PGs. No entanto, a mesma relação no sentido contrário não foi observada, ou seja, a redução nos níveis de PGs foi compensada com um aumento na liberação de $N O$, enquanto o tratamento com $\mathrm{PGE}_{2}$ não modificou o nível de nitratos/nitritos. Os resultados sugerem que tanto $\mathrm{NO}$ como PG tenham um papel chave na regulação da homeostase vascular (VASSALLE et al, 2003).

O NO também tem sido implicado na fisiopatologia de transtornos neurodegenerativos e psiquiátricos. Oliveira, Guimarães e Deakin (2008) observaram que pacientes com diagnóstico de depressão maior e depressão bipolar apresentaram maior número de neurônios hipocampais expressando nNOS; segundo os autores, este achado sugere a participação da via NMDA-NO na patofisiologia destes transtornos psiquiátricos. Artigo de revisão publicado por Joca, Ferreira e Guimarães (2007) mostra que a administração sistêmica da maior parte dos antidepressivos reduz a atividade da enzima óxido nítrico sintase no hipocampo, feito este que implica a participação do NO nos efeitos dos antidepressivos. Neste sentido, estudos in vitro mostraram que a amitriptilina e a fluoxetina, mesmo em presença de citocinas pró-inflamatórias, diminuíram a síntese de óxido nítrico e de prostaglandina E2 quando adicionados a uma cultura de células sinoviais humanas (YARON et al, 1999).

De acordo com artigo de revisão recente, RETTORI et al (2009), o NO também tem importante papel na liberação de $\mathrm{CRH}$ induzida por LPS, além de participar do 
estimulo à secreção de uma série de hormônios adrenocorticotrópicos promovida por citocinas como IL-1, TNF- $\alpha$, IL-6, e IL-2. Ou seja, além de seu papel no contexto inflamatório, o NO também pode ser visto como um elemento-chave nas interações neuroimunoendócrinas. 


\section{3- OBJETIVOS}

\section{1- OBJETIVOS GERAIS}

Avaliar os efeitos da amitriptilina sobre a resposta inflamatória induzida pela carragenina em ratos e investigar os prováveis mecanismos relacionados a estes efeitos.

\section{2- OBJETIVOS ESPECÍFICOS}

1 - Avaliar os efeitos anti-inflamatórios da amitriptilina no modelo do edema de pata induzido pela carragenina 1\% em ratos. Em seguida, investigar: diferentes intervalos de tempo para administração do fármaco; o efeito de administrações agudas e prolongadas; o efeito de injeções intraperitoneais e subcutâneas em dose única e de injeções intraperitoneais realizadas a cada tempo de meia-vida no mesmo modelo de inflamação; o efeito da administração de amitriptilina diretamente no coxim plantar. Nexte contexto, avaliar o efeito da amitriptilina sobre a atividade de neutrófilos, por citometria de fluxo.

2 - Avaliar a participação dos glicocorticoides nos efeitos anti-inflamatórios da amitriptilina sobre o edema de pata induzido por carragenina $1 \%$ em ratos, por meio da utilização de um antagonista de receptores de glicocorticoides (RU 486).

3 - Avaliar a participação dos receptores alfa-1-adrenérgicos nos efeitos antiinflamatórios da amitriptilina sobre o edema de pata induzido por carragenina $1 \%$ em ratos, por meio da utilização de um antagonista de receptores alfa-1 (prazosina). 
4 - Avaliar a participação do óxido nítrico (NO) nos efeitos anti-inflamatórios da amitriptilina sobre o edema de pata induzido por carragenina $1 \%$ em ratos, por meio da utilização de um inibidor da síntese de óxido nítrico (L-NAME) e de um precursor da síntese de óxido nítrico (L-arginina).

5 - Avaliar a influência da amitriptilina sobre as características do exsudato inflamatório produzido pela injeção intraperitoneal de carragenina, na ausência e presença de inibidor da síntese de NO (L-NAME).

6 - Avaliar a influência da amitriptilina no processo de "rolling", adesão e transmigração de neutrófilos por meio de microscopia intravital direta, em condições inflamatórias e não-inflamatórias.

7 - Avaliar a influência do tratamento com amitriptilina sobre a expressão de moléculas de adesão em leucócitos do sangue periférico, por citometria de fluxo.

8 - Avaliar a influência do tratamento com amitriptilina sobre a concentração das citocinas IL-1beta e TNF-alfa no soro de ratos, por ELISA. 


\section{4- MATERIAL E MÉTODOS}

\section{1- ANIMAIS}

Foram utilizados ratos Wistar, machos, com cerca de 90 dias de idade no início dos experimentos e provenientes do Biotério Central do Departamento de Patologia da Faculdade de Medicina Veterinária e Zootecnia da Universidade de São Paulo. Os animais foram mantidos em grupos de 5 em caixas de polipropileno, alojadas em sala exclusiva para a espécie, mantida a uma temperatura de $22 \pm 3^{\circ} \mathrm{C}$, com ventilação, exaustão e umidade (65-70\%) controladas, em um ciclo claro-escuro de 12 horas (6-18h), com acesso livre ao alimento e à água. Todos os experimentos deste trabalho foram aprovados pelo Comitê de Ética da Faculdade de Medicina Veterinária e Zootecnia da Universidade de São Paulo (protocolo n ${ }^{0.761 / 2005}$ ).

\section{2- FÁRMACOS, REAGENTES E ANTICORPOS}

- Amitriptilina (gentilmente cedido pela Cristália Produtos Químicos e Farmacêuticos Ltda, São Paulo, Brasil): fármaco objeto deste estudo;

- Anticorpos monoclonais anti-moléculas de adesão (BD Pharmingen, San Diego, CA, EUA):

$\checkmark$ Biotin Hamster Anti-Rat CD62L marcado com PE (anti-L-selectina),

$\checkmark$ Mouse Anti-Rat CD54 marcado com PE (anti ICAM-1),

$\checkmark$ Anti- Rat CD11b marcado com FITC (anti-MAC-1),

$\checkmark$ Mouse Anti-Rat CD31 marcado com PE (anti PECAM-1).

- Carragenina lambda (Sigma-Aldrich, St Louis, MO, USA): substância utilizada para induzir resposta inflamatória;

- Cloreto de sódio (Labsynth Produtos para Laboratório Ltda, São Paulo, Brasil): 0,2 e 1,6\%: soluções utilizadas na lise de hemácias por choque hipotônico. 
- DCFH-DA: Diacetato de 2'7'diclorofluoresceína (Molecular Probes, Eugene, OR, USA): fluorocromo utilizado na citometria de fluxo;

- EDTA (Sigma-Aldrich, St Louis, MO, USA): utilizado na citometria de fluxo para interromper a reação dos tubos com $S$. aureus; também utilizado como anticoagulante;

- Heparina sódica (Liquemine ${ }^{\circledR}$, Produtos Roche Químicos e Farmacêuticos S.A., Rio de Janeiro, RJ, Brasil);

- lodeto de Propídeo (PI) (Sigma-Aldrich, St Louis, MO, USA): fluorocromo utilizado na citometria de fluxo conjugado a $S$. aureus;

- L-arginina (Sigma-Aldrich, St Louis, MO, USA): precursor da síntese de óxido nítrico;

- L-NAME (Sigma-Aldrich, St Louis, MO, USA): inibidor inespecífico da síntese de óxido nítrico;

- Lauril sulfato de sódio (Labsynth Produtos para Laboratório Ltda, Diadema, SP, Brasil): constituinte da solução utilizada no pletismógrafo;

- Líquido de Turk: corante utilizado para contagem de leucócitos;

- PBS- (Phosfate Buffered Saline): tampão de pH 7,2-7,4, utilizado como diluente

- PMA: miristato-acetato de forbol (Calbiochem, San Diego, CA, USA): utilizado na citometria como ativador de neutrófilos;

- Prazosina (Minipress ${ }^{\circledR}$ - Pfizer, São Paulo, Brasil): antagonista alfa-1 adrenérgico

- quetamina cloridrato 10\% (Dopalen ${ }^{\circledR}$ - SESPO Indústria e Comércio Ltda, São Paulo, Brasil): anestésico;

- RU-486 ou mifepristona (Sigma-Aldrich, St Louis, MO, USA): antagonista de receptores glicocorticoides e antiprogestagênico;

- Salina: Cloreto de sódio 0,9\% ( $\mathrm{NaCl}$ 0,9\%, Labsynth Produtos para Laboratório Ltda, Diadema, SP, Brasil): constituinte da solução utilizada no pletismógrafo e também veículo de diversos fármacos;

- Solução de Ringer (Aster Produtos Médicos Ltda, São Paulo, Brasil): diluente da carragenina; também utilizada para manutenção do tecido durante a avaliação da microcirculação "in vivo" e "in situ";

- S. aureus (Staphylococcus aureus) Cepa ATCC 25923 (DIFCO, Detroit, MI, USA): bactéria marcada com iodeto de propídeo (Sigma-Aldrich, St Louis, MO, USA) utilizada para avaliar a atividade de fagócitos sanguíneos, por citometria de fluxo; 
- xilazina cloridrato 2\% (Calmiun ${ }^{\circledR}$ - União Química Farmacêutica Nacional S.A., São Paulo, Brasil): anestésico

- Reagentes utilizados na determinação do total de nitratos (Sigma Chemical Co. St Louis, Mo):

$\checkmark$ Nitrato redutase de Aspergillus

$\checkmark$ FAD;

$\checkmark \mathrm{NADPH}$;

$\checkmark$ tampão TRIS-HCl pH 7,6;

$\checkmark$ lactato desidrogenase;

$\checkmark$ ácido pirúvico;

$\checkmark$ reagente de Griess.

- Reagentes utilizados no ELISA para determinação de citocinas no soro de ratos (DuoSet ELISA, R\&D System, Inc, Minneapolis, USA)

$\checkmark$ anticorpo de captura;

$\checkmark$ tampão de lavagem;

$\checkmark$ tampão de bloqueio;

$\checkmark$ padrões $(4000,2000$ 1000, 500, 250, 125 e $62,5 \mathrm{pg} / \mathrm{mL})$;

$\checkmark$ anticorpo de detecção biotinilado;

$\checkmark$ Streptavidina-HRP;

$\checkmark$ solução substrato;

$\checkmark$ solução de parada. 


\section{3- PROCEDIMENTOS EXPERIMENTAIS}

\subsection{1- Anestesia}

Em todos os experimentos em que houve a necessidade de anestesia, foram utilizadas soluções de quetamina $10 \%$ e xilazina $2 \%$, na proporção de 1:1, empregando-se $1 \mathrm{~mL} / \mathrm{kg}$ da mistura, por via i.p.

\subsection{2- Modelo do Edema de Pata induzido por carragenina}

-Indução da Resposta Inflamatória Aguda

O edema inflamatório foi induzido no coxim plantar esquerdo do rato por meio da injeção de carragenina a $1 \%$, preparada imediatamente antes do uso. Para minimizar eventuais agressões ao tecido, todas as injeções foram realizadas com agulhas finas descartáveis $(13,0 \mathrm{~mm} \times 0,3 \mathrm{~mm})$. A concentração da carragenina usada foi determinada com base em dados da literatura e em experiências prévias de nosso laboratório. (LAZZARINI et al, 1996; LAZZARINI et al, 2003).

\section{- Medida do Edema Inflamatório}

O edema de pata foi avaliado utilizando-se um pletismógrafo digital (Plethysmometer - Ugo Basile $^{\circledR}$, Comerio VA, Italy) antes da injeção desta substância e em diversos horários após a mesma (1, 2, 3, 4, 6 e 8h). A leitura se deu pela inserção da pata do animal em uma cubeta do aparelho contendo solução de $\mathrm{NaCl}$, lauril sulfato de sódio e água destilada. O deslocamento do líquido produzido pela pata - proporcional ao seu volume - é informado pelo visor digital do Pletismógrafo. Os resultados foram obtidos pela diferença entre os volumes medidos antes e depois das injeções, em mililitros $(\mathrm{mL})$. 


\subsection{3- Avaliação do exsudato inflamatório peritoneal induzido por carragenina}

A inflamação peritoneal foi induzida pela injeção de $500 \mu \mathrm{g}$ de carragenina dissolvida em $2 \mathrm{~mL}$ de Ringer por animal. Após 2 e 3 horas, os animais que foram previamente anestesiados com quetamina-xilazina (i.p.) receberam uma injeção i.p de $5 \mathrm{~mL}$ de PBS; em seguida, procedeu-se à massagem da região abdominal e coleta subsequente do exsudato para avaliação do volume e do número de células, o que se fez com o auxílio de uma câmara de Neubauer.

\subsection{4- Avaliação da microcirculação "in vivo" e "in situ": estudo por microscopia intravital direta}

Os animais foram anestesiados e, logo em seguida, submetidos à exteriorização do mesentério para observação da microcirculação in situ, de acordo com protocolo descrito previamente por FORTES et al (1991). É importante ressaltar que o tecido foi fixado de forma tal a não prejudicar a rede microcirculatória, sendo que os movimentos respiratórios do animal não perturbaram a observação. Os animais foram mantidos sobre uma placa de acrílico transparente aquecida a $37^{\circ} \mathrm{C}$ (que permitia a transiluminação do tecido) montada sobre o "charriot" de um microscópio binocular Nikon Eclipse 80-i equipado com uma câmera Sony, ao qual estão acoplados um fototubo, com sistema de lentes ampliadoras superpostas e um monitor de vídeo, para a visualização da imagem ampliada. Os vasos selecionados para estudo foram vênulas pós-capilares com diâmetro entre 15 e $30 \mu \mathrm{m}$, as quais foram medidas por meio do programa ACT-1C for DXM 1200 (FORTES et al, 1991; FARSKY, SANNOMIYA, GARCIA-LEME, 1995; MARTINEZ et al, 2004).

Estudou-se a interação dos leucócitos circulantes com a superfície luminal do endotélio venular, considerando-se as células na periferia da corrente sanguínea em contato com o endotélio e que rolaram sobre este (comportamento de rolamento ou "rolling", sendo estes leucócitos considerados "rollers"). Como a velocidade de rolamento destas células costuma ser baixa, foi possível visualizá-las individualmente a fim de que pudessem ser contadas. Assim, avaliou-se o número 
de "rollers" que passaram por um determinado ponto do vaso e o número de células que ficaram aderidas (>30s) em 100 $\mu$ m de extensão de endotélio venular ("stickers") durante 1 hora, isto é, nos tempos 0, 15, 30, 45 e 60 minutos. Em cada horário fizeram-se três medidas de 1 minuto com intervalos de 1 minuto entre elas; considerou-se como resultado de cada intervalo a média das três medidas, de acordo com protocolo adaptado de SANS et al (2002). O número de leucócitos que transmigraram e se acumularam em área padrão de $2000 \mu \mathrm{m}^{2}$ de tecido conectivo adjacente à vênula pós-capilar estudada foi determinado no tempo zero e 1 hora após o início da avaliação. Estimulou-se a velocidade de rolamento destes leucócitos com base no tempo gasto para percorrer $100 \mu \mathrm{m}$ de vênula.

Cada segmento vascular foi examinado uma única vez. Os procedimentos aconteceram em condições não-inflamatórias e inflamatórias (FORTES et al, 1991; FARSKY, SANNOMIYA, GARCIA-LEME, 1995, MARTINEZ et al, 2004).

\subsection{5- Avaliação de nitratos e nitritos}

Os animais dos diferentes grupos foram mantidos em jejum por 12 horas, isolados das próprias fezes e recebendo apenas água destilada como bebida, a fim de se evitar o contato dos mesmos com compostos nitrogenados. Em seguida, os ratos foram pré-tratados e tratados de acordo com o delineamento experimental, sendo anestesiados para coleta de sangue por punção cardíaca. O material coletado foi centrifugado a 4000rpm por 15 minutos, separado o soro e levado para análise, de acordo com trabalho de Muscara e De Nucci (1996). Em resumo, o nitrato da amostra foi reduzido a nitrito, de acordo com o método modificado de Grisham e colaboradores (1996), sendo determinado pela reação de Griess, onde $100 \mu \mathrm{l}$ do soro era incubado por $1 \mathrm{~h}$ a $37^{\circ} \mathrm{C}$ na presença de $0.2 \mathrm{U} / \mathrm{mL}$ de nitrato redutase de Aspergillus (Sigma Chemical Co. St Louis, Mo), $5 \mu \mathrm{M}$ FAD, $100 \mu \mathrm{M}$ NADPH e $20 \mathrm{mM}$ de tampão TRIS-HCl pH $7.6 \mathrm{em}$ um total de $160 \mu \mathrm{L}$. Após incubação, $20 \mu \mathrm{L}$ de lactato desidrogenase $(135 \mathrm{U} / \mathrm{mL}$, Sigma Chemical Co. St Louis, Mo) e $20 \mu \mathrm{L}$ of $90 \mathrm{mM}$ de ácido pirúvico (Sigma Chemical Co. St Louis, Mo) foram adicionados a fim de se oxidar o NADPH. Após incubação adicional de 30 
min a $37^{\circ} \mathrm{C}, 100 \mu \mathrm{L}$ de reagente de Griess foi adicionado a cada tubo e após 10 minutos em temperatura ambiente a absorbância foi determinada a $540 \mathrm{~nm}$. Os níveis de nitrito foram determinados na ausência de nitrato redutase. A concentração de nitrato foi calculada pela diferença entre os valores obtidos na presença e ausência de nitrato redutase. Todo material utilizado neste procedimento foi previamente lavado com água bidestilada, a fim de remover resíduos de compostos nitrogenados.

\subsection{6- Citometria de Fluxo}

Um citômetro de fluxo (FACSCalibur, Becton Dickinson Immunocytometry Systems, San Jose, CA, USA), em interface com computador Macintosh G4 foi utilizado para avaliação da atividade de neutrófilos (burst oxidativo e fagocitose) e da expressão das moléculas de adesão por leucócitos. Os dados de 10.000 eventos foram coletados e analizados no CellQuestPro (Becton Dickinson Immunocytometry Systems). As populações celulares foram identificadas baseadas em suas propriedades no gráfico de forward scatter (FSC)/side scatter (SSC), mecanicamente separados (FACScan, Becton Dickinson Immunocytometry Systems). Os dados de neutrófilos e monócitos foram coletados construindo-se janelas (gates) em torno destas populações.

\section{- Burst oxidativo}

A quantificação do burst oxidativo de neutrófilos foi estimada por meio da fluorescência de DCFH, mensurada em $530 \pm 30$ nM (detector FL1) e analisada após a compensação de fluorescência para corrigir qualquer interferência entre os dois sinais. Em resumo, de cada animal foram preparados 4 tubos de propileno com $100 \mu \mathrm{L}$ de sangue total heparinizado (coletado por decapitação), aos quais foram adicionados: 1- PBS; 2- $200 \mu \mathrm{L}$ de DCFH-DA (0,3mM) e PBS; 3- $200 \mu \mathrm{L}$ de DCFHDA (0,3mM), $100 \mu \mathrm{L}$ de $S$. aureus marcado com PI e PBS; 4- $100 \mu \mathrm{L}$ de PMA, 200 $\mu \mathrm{L}$ de DCFH-DA (0,3mM) e PBS. As amostras foram incubadas sob agitação por 30 
minutos a $37^{\circ} \mathrm{C}$. As reações foram paradas adicionando-se $2 \mathrm{~mL}$ de solução de EDTA gelado $(3 \mathrm{mM})$ aos tubos que contivessem bactéria. Após a centrifugação (1200rpm - 10 minutos) os eritrócitos de todas as amostras foram lisados com $2 \mathrm{~mL}$ de cloreto de sódio 0,2\% (choque hipotônico), seguido após 20 segundos por cloreto de sódio a 1,6\% (para restaurar a isotonicidade), centrifugando-se mais 10 minutos, a 1200 rpm. Tal procedimento de lise foi realizado duas vezes em cada amostra. Após a última centrifugação, os leucócitos foram ressuspendidos em PBS para leitura em citômetro de fluxo. As medidas diretas da fluorescência média do canal verde foram gravadas como burst oxidativo, como proposto por Hasui e cols (1989).

\section{- Fagocitose}

Com relação à atividade fagocítica de neutrófilos, verificou-se a porcentagem e a intensidade de fagocitose. A porcentagem de fagocitose foi calculada pelo número de neutrófilos que fagocitaram $S$. aureus marcado com $\mathrm{Pl}$ e que emitiram fluorescência vermelha, divido pelo número total destas células vezes 100. A intensidade de fagocitose, por sua vez, representou o total de bactérias fagocitadas; foi medida pela média geométrica da intensidade de fluorescência emitida pelos neutrófilos.

- Análise da expressão de moléculas de adesão por leucócitos

Os animais foram anestesiados com quetamina-xilazina $(1: 1$; i.p.), para serem submetidos a uma coleta de sangue por punção cardíaca, sendo este sangue trasnferido para um tubo com EDTA $(20 \mu \mathrm{L})$. Após a lise de $200 \mu \mathrm{L}$ deste sangue por choque hipotônico ( $\mathrm{NaCl}$ 0.2\% e 1.6\%-2mL; 20 segundos) e centrifugação, o sangue foi ressuspenso em $100 \mu \mathrm{L}$ de PBS e $1 \mu \mathrm{L}$ de anticorpo (Anti-Rat CD62L marcado com PE, Anti-Rat CD54 marcado com PE, Anti-Rat CD11b marcado com FITC ou Anti-Rat CD31 marcado com PE) e levado para incubação por 1 hora no escuro em temperatura ambiente. Após este período, houve centrifugação, retirada do sobrenadante, sendo os leucócitos resssuspendidos em $500 \mu \mathrm{L}$ de paraformaldeído $0,5 \%$ para leitura posterior. No dia da leitura, o material foi centrifugado e ressuspenso em PBS para leitura no citômetro de fluxo (FACSCalibur, Becton Dickinson Immunocytometry Systems, San Jose, CA, USA). Foram analisados 10.00 
eventos, sendo consideradas as médias geométricas de fluorescência emitidas pelas células avaliadas.

\subsection{7- Enzyme-linked Immunoabsorbent Assay (ELISA) para determinação de citocinas no soro de ratos}

Neste ensaio, a concentração das citocinas IL-1beta e TNF-alfa em soro de ratos foi avaliada, de acordo com protocolo sugerido pelo fabricante (DuoSet ELISA, R\&D System, Inc, Minneapolis, USA). Brevemente, iniciou-se o ensaio com o preparo da placa de poliestireno de 96 poços, adicionando-se $100 \mu \mathrm{L} /$ poço do respectivo anticorpo de captura, seguida por incubação no escuro, a temperatura ambiente, por cerca de $12 \mathrm{~h}$. Ao final deste período, os poços foram lavados com tampão de lavagem, sendo adicionado $300 \mu \mathrm{L} /$ poço de tampão de bloqueio, sendo incubado por mais $1 \mathrm{~h}$ no escuro em temperatura ambiente. Após nova lavagem, deu-se início o ensaio propriamente dito, adicionando-se, em duplicata, $100 \mu \mathrm{L} /$ poço dos respectivos padrões (4000, 2000 1000, 500, 250, 125 e 62,5 pg/mL) e amostras, sendo levado às mesmas condições de incubação por $2 \mathrm{~h}$. Após a lavagem, adicionou-se o anticorpo de detecção biotinilado, seguido, após $2 \mathrm{~h}$ horas de incubação, por nova lavagem e adição de $100 \mu \mathrm{L} /$ poço de Streptavidina-HRP. Vinte minutos depois, procedeu-se nova lavagem e adicionou-se $100 \mu \mathrm{L} /$ poço de solução substrato, ficando incubado por mais vinte minutos no escuro a temperatura ambiente. Ao final, adicionou-se $50 \mu \mathrm{L} /$ poço de solução de parada. A leitura da densidade óptica de cada poço foi realizada por meio de um leitor de ELISA, sendo que o resultado foi determinado subtraindo-se as leituras realizadas no comprimento de onda $540 \mathrm{~nm}$ daquelas obtidas a $450 \mathrm{~nm}$. Tal subtração visa corrigir quaisquer imperfeições ópticas das placas. Os valores obtidos foram submetidos à análise de regressão com interpolação de valores a partir de uma curva padrão, sendo expressos em picogramas por mililitro $(\mathrm{pg} / \mathrm{mL})$. 


\section{4-ANÁLISE ESTATÍSTICA}

Os dados foram inicialmente analisados por meio dos testes de KolmogorovSmirnov e de Bartlet para verificar sua adequação ou não aos testes paramétricos. Quando a distribuição dos dados foi normal e houve homocedasticidade, eles foram analisados por meio por meio do teste $t$ (comparação entre dois grupos) ou da análise de variância (ANOVA) de uma ou duas vias $(\mathrm{p}<0.05)$, seguidos pelos testes pos hoc de Tukey-Kramer (muitas vezes referido no texto apenas como teste de Tukey) ou Newman-Keuls (também chamado de Student-Newman-Keuls), para verificação de possíveis diferenças entre os grupos. Não havendo distribuição normal ou homocedasticidade, os dados foram avaliados pelos testes não-paramétricos mais adequados (Teste de Mann-Whitney ou teste de Kruskal-Wallis seguido pelo teste de Dunn). O software de estatística utilizado foi o SigmaStat $3.0^{\circledR}$.

O cálculo da área sob a curva do volume da pata em função do tempo foi realizada pelo método dos trapezóides, do tempo 1 ao tempo 8h. O software de estatística utilizado foi o GraphPad Prism 5.0 $0^{\circledR}$.

As absorbâncias obtidas na dosagem de citocinas por ELISA passaram por um análise de regressão com interpolação dos dados a partir de uma curva padrão, para obter os seus correspondentes em $\mathrm{pg} / \mathrm{mL}$. As concentrações de citocinas de cada grupo foram comparadas por meio da ANOVA de uma via seguida pelo teste de Tukey. O software de estatística utilizado foi o GraphPad Prism $5.0^{\circledR}$. 


\section{5- DELINEAMENTO EXPERIMENTAL E RESULTADOS}

\section{1- AVALIAÇÃO DO EFEITO DA AMITRIPTILINA SOBRE A INFLAMAÇÃO}

Experimento 1 - Avaliação da administração aguda de diferentes doses de amitriptilina (3,0;6,0 e 10,0 mg/kg) sobre o edema inflamatório induzido pela carragenina a $1 \%$.

Quarenta ratos foram divididos aleatoriamente em quatro grupos iguais: 1 controle (salina) e 3 experimentais tratados com Amitriptilina (3,0;6,0;10,0 mg/kg). Todos os ratos receberam uma dose aguda dos respectivos tratamentos $(1,0 \mathrm{~mL} / \mathrm{Kg}$; i.p.) e, 1 hora após, foram submetidos aos procedimentos para indução de edema de pata, conforme descrito anteriormente. Segue abaixo o esquema do protocolo experimental:

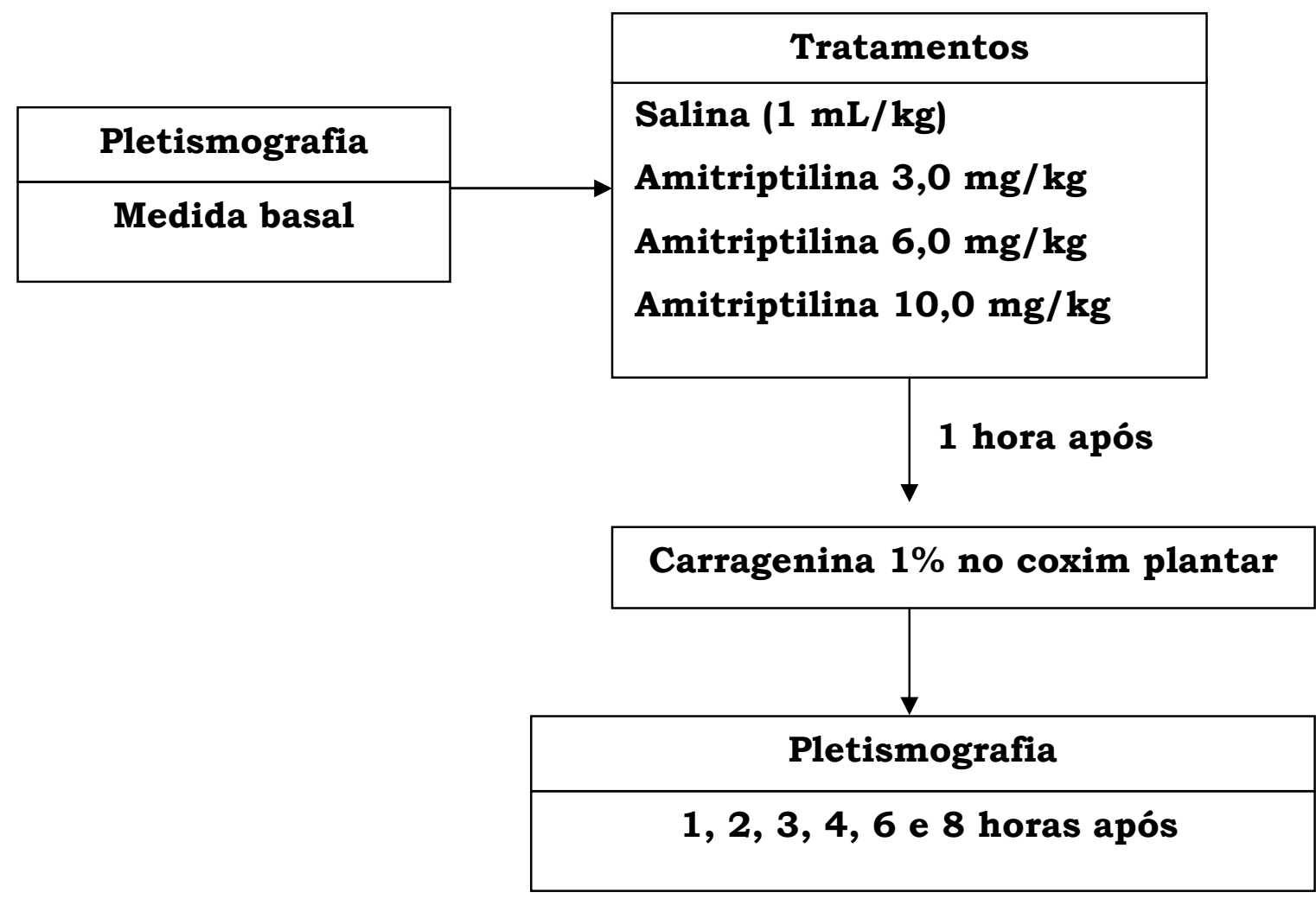


A ANOVA de uma via mostrou a existência de diferenças significantes entre os grupos nos tempos $2\left(F_{3,30}=5,447 ; p<0,05\right), 3\left(F_{3,30}=3,845 ; p<0,02\right), 4\left(F_{3,30}=3,177\right.$; $p<0,05)$, e 6 horas $\left(F_{3,30}=6,027 ; p<0,005\right)$ após a injeção de carragenina. $O$ teste pos hoc de Student-Newman-Keuls indicou que o grupo tratado com amitriptilina 3,0 $\mathrm{mg} / \mathrm{kg}$ apresentou redução significante no edema de pata, quando comparado aos dados obtidos no grupo controle nos tempos 2 ( $p<0,01), 3(p<0,05), 4(p<0,05)$ e $6 \mathrm{~h}$ $(p<0,005)$. Os animais tratados com amitriptilina $6 \mathrm{mg} / \mathrm{kg}$ mostraram redução significante no edema de pata nos tempos 3 e $6 \mathrm{~h}(\mathrm{p}<0,05)$. O grupo tratado com amitriptilina $10 \mathrm{mg} / \mathrm{kg}$ teve redução significante no edema de pata nos tempos 2 $(p<0,005) 3(p<0,02)$ e $6 h(p<0,01)$. Os grupos tratados com amitriptilina não apresentaram diferenças significantes entre si. A figura 2 ilustra estes dados.

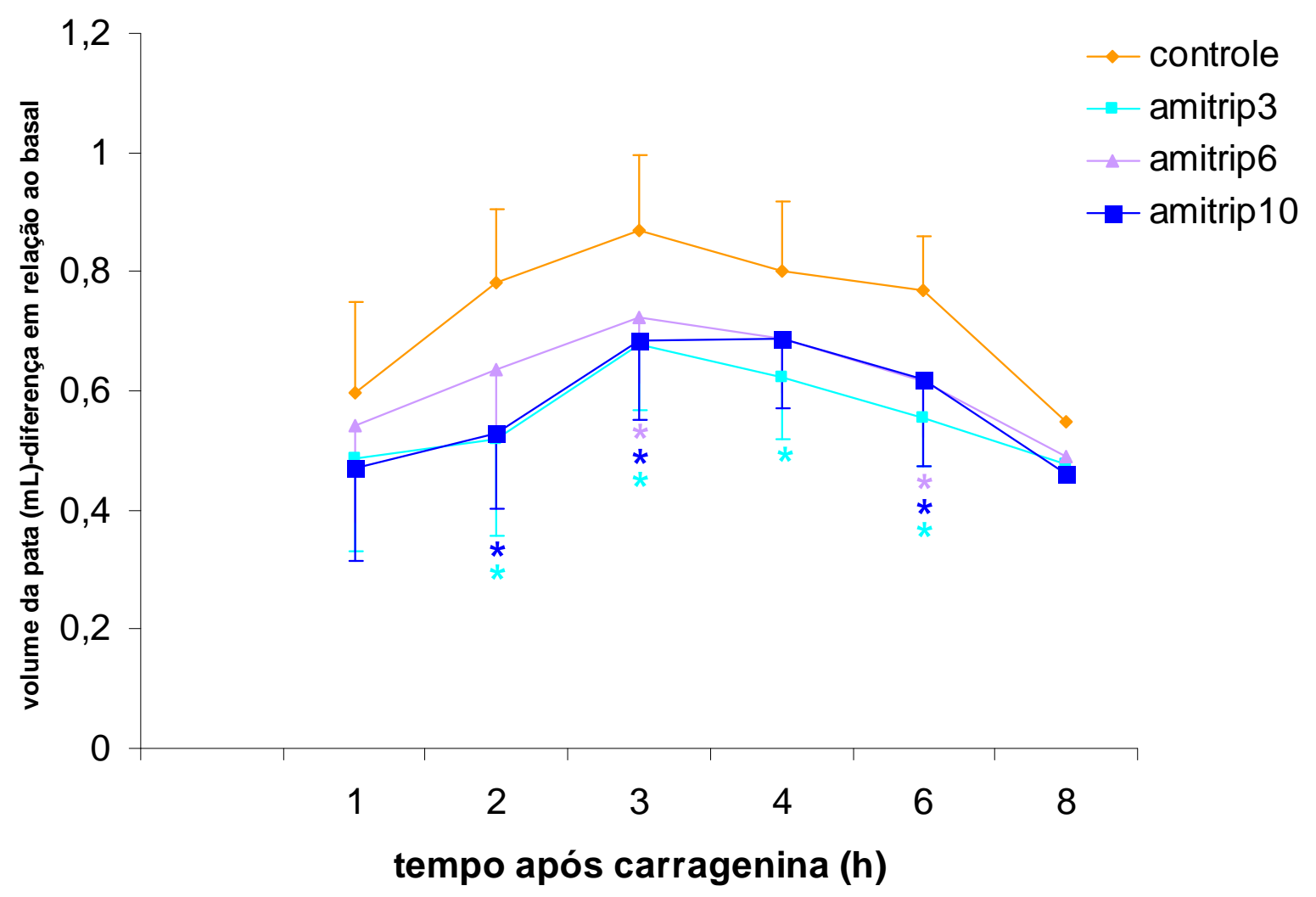

Figura 2 - Efeitos de diferentes doses de amitriptilina sobre o edema inflamatório induzido pela carragenina $1 \%$ em ratos. O volume da pata é dado pela diferença de cada medida em relação ao volume basal $(\mathrm{mL})$. Os valores referem-se à média \pm desvio padrão. *: $p<0,05$ em relação ao grupo controle. (ANOVA de uma via seguida pelo teste de Student-NewmanKeuls). Controle: $\mathrm{n}=9$; Amitrip 3 (amitriptilina 3,0mg/kg): $\mathrm{n}=8$; Amitrip 6 (amitriptilina 6,0mg/kg): $\mathrm{n}=8$; Amitrip 10 (amitriptilina 10,0mg/kg): $n=10$ 
O cálculo da área sob a curva (ASC) do volume da pata em função do tempo foi realizado com os dados obtidos de cada animal. As médias e desvios-padrões de cada grupo, apresentadas na tabela 2, foram comparadas por meio de uma ANOVA de uma via, que indicou existência de diferenças significantes entre os grupos $\left(F_{3,30}=4,565 ; p<0,01\right)$. O teste pos hoc de Student-Newman-Keuls indicou que os grupos tratados com amitriptilina, independente da dose, diferem dos dados obtidos do grupo controle.

Tabela 2 - Áreas sob a curva (ASC) do volume da pata em função do tempo de animais tratados com veículo (controle) ou diferentes doses de amitriptilina. Os valores referem-se à média \pm desvio padrão. * $p<0,01$ em relação ao grupo controle (ANOVA de uma via seguida pelo teste de Newman-Keuls)

\begin{tabular}{ccccc}
\hline & controle & $\begin{array}{c}\text { Amitriptilina } \\
3,0 \mathrm{mg} / \mathrm{kg}\end{array}$ & $\begin{array}{c}\text { Amitriptilina } \\
6,0 \mathrm{mg} / \mathrm{kg}\end{array}$ & $\begin{array}{c}\text { Amitriptilina } \\
10,0 \mathrm{mg} / \mathrm{kg}\end{array}$ \\
\hline \multirow{2}{*}{ ASC } & $5,24 \pm 0,76$ & $3,96 \pm 0,78^{\star}$ & $4,38 \pm 0,66^{\star}$ & $4,18 \pm 0,84^{\star}$ \\
\hline
\end{tabular}


Experimento 2 - Influência do intervalo de tempo entre administrações agudas de amitriptilina e de carragenina sobre o edema de pata induzido pela carragenina $1 \%$.

Quarenta ratos foram divididos ao acaso em 4 grupos iguais: 2 controles (salina) e 2 experimentais (amitriptilina $10 \mathrm{mg} / \mathrm{kg}$ ). Uma hora após os respectivos tratamentos (20 animais), ou duas horas depois (20 animais), os animais foram injetados com carragenina $1 \%$ no coxim esquerdo $(0,1 \mathrm{~mL})$ para obtenção do edema. Segue abaixo o esquema do experimento:

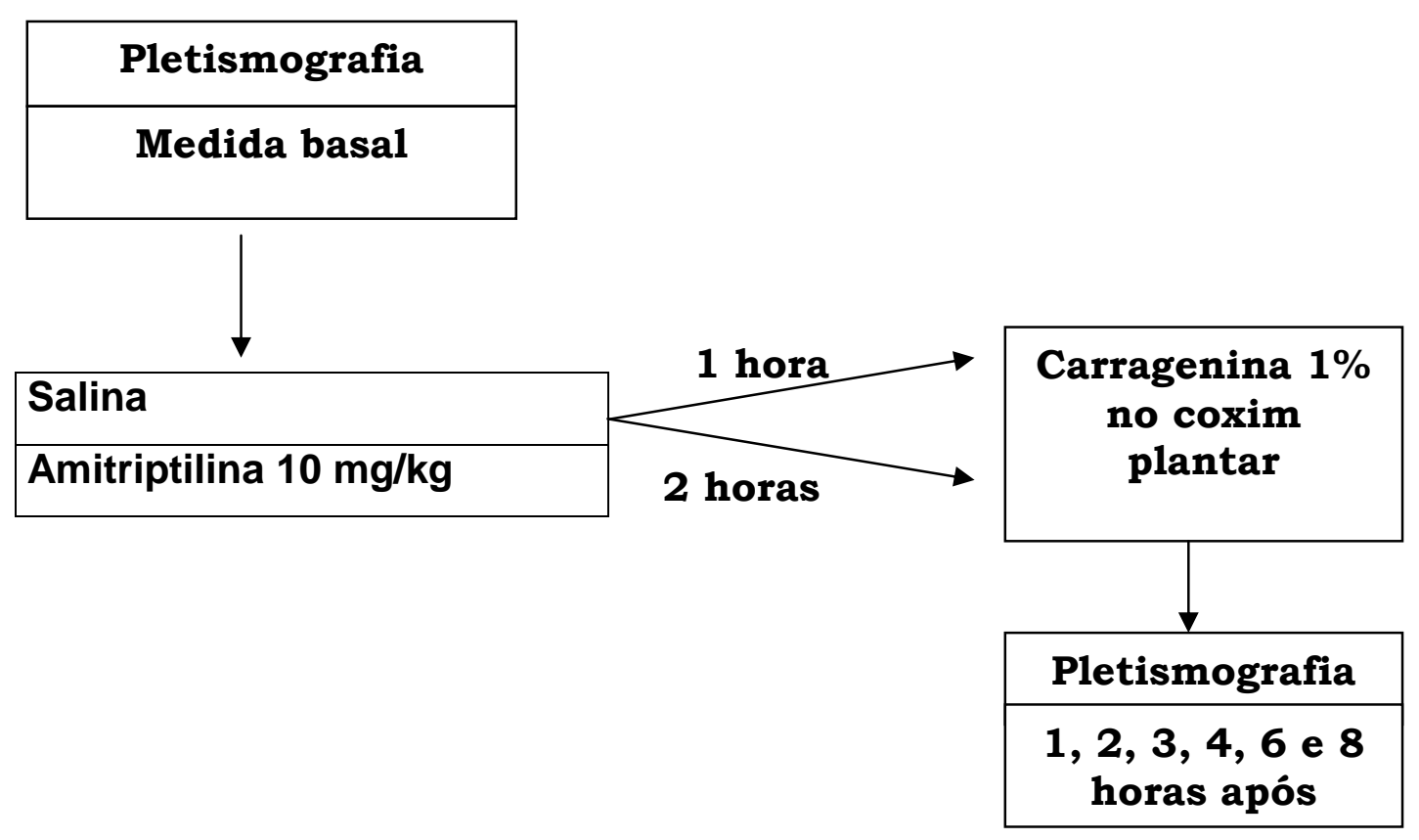

A análise dos resultados pela ANOVA de duas vias mostrou existência de diferenças significantes entre os tratamentos $\left(F_{3,135}=10,051 ; p<0,001\right)$ e entre os tempos $\left(F_{5,135}=38,11 ; p<0,0001\right)$ e uma interação entre os fatores tratamento e tempo $\left(F_{15,135}=1,89 ; p<0,05\right)$. O teste pos hoc de Tukey não revelou diferenças estatísticas entre os grupos controle 1 hora e controle 2 horas $(p>0,05)$, nem entre os grupos amitriptilina administradas 1 ou $2 \mathrm{~h}$ antes da carragenina (amitrip1h e amitrip2h, respectivamente). Quando comparados aos respectivos grupos controles, o grupo amitrip1h produziu redução significante no edema de pata em todos os horários (1 $\mathrm{h}$ : $p<0,001 ; 2 h: p<0,0001 ; 3 h: p<0,0001 ; 4 h: p<0,0001 ; 6 h: p<0,0001$ e $8 h: p<0,05)$. $O$ grupo amitrip2h, por sua vez, mostrou-se diferente do grupo controle em cinco das 
seis medidas (1h: $p<0,01$; $2 h: p<0,0001$; 3h: $p<0,0001$; $4 h: p<0,01$; $6 h: p<0,05$; $8 h$ : $p>0,05)$. Esses resultados estão ilustrados na figura 3 .

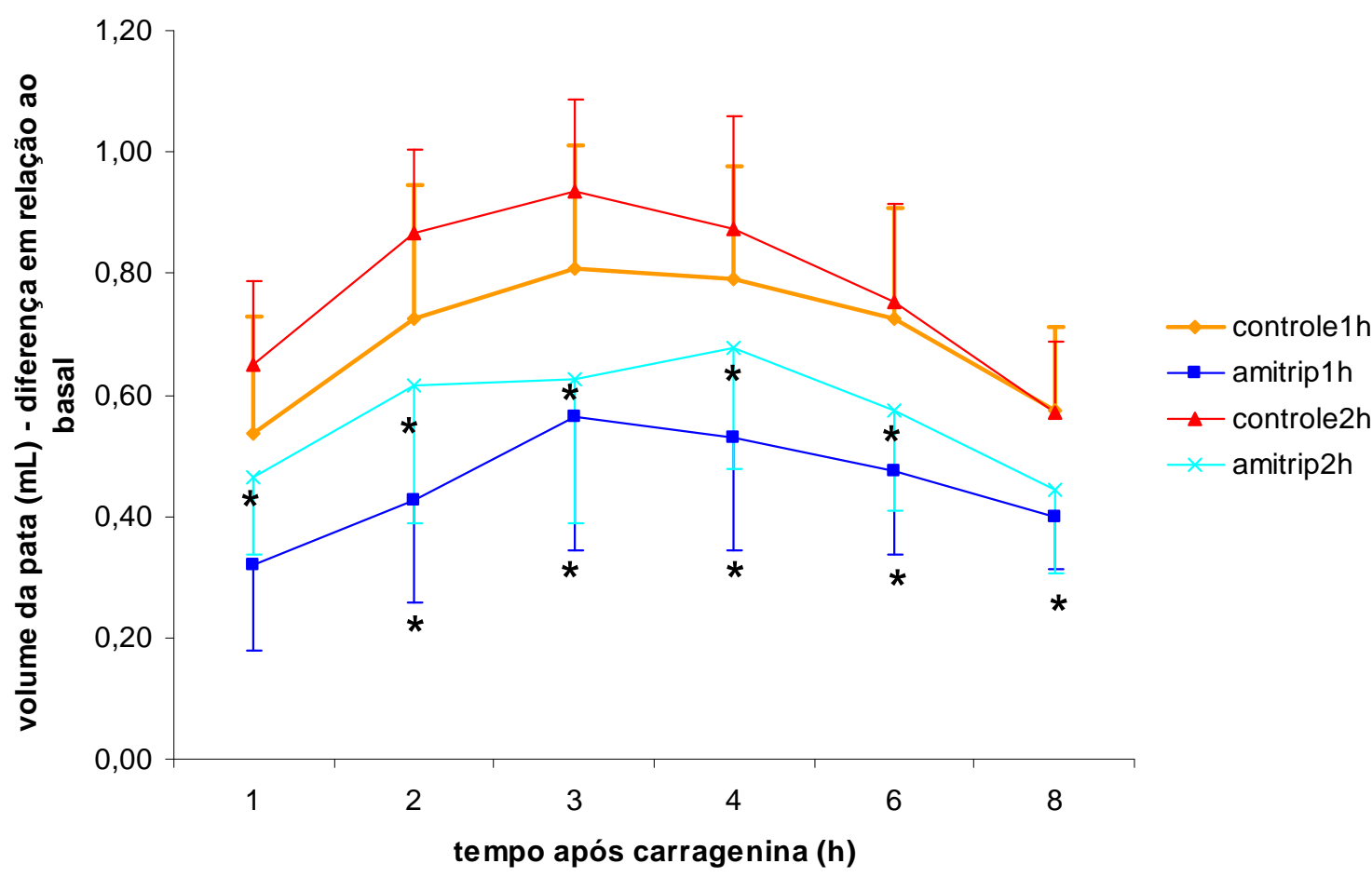

Figura 3 - Influência do tempo de administração nos efeitos da amitriptilina sobre o edema de pata induzido pela carragenina $1 \%$ em ratos. O volume da pata é dado pela diferença de cada medida em relação ao volume basal $(\mathrm{mL})$. Os valores referem-se à média \pm desvio padrão. ${ }^{*}: p<0,05$ em relação ao respectivo grupo controle. (ANOVA de duas vias seguida pelo teste de Tukey). $n=10$ por grupo

- Com estes resultados, optou-se por administrar amitriptilina 1 hora antes da injeção de carragenina.

- Considerando-se a importância dos neutrófilos em um processo inflamatório agudo, optou-se por avaliar sua atividade frente ao tratamento prolongado com amitriptilina. 
Experimento 3 - Avaliação da influência de um tratamento prolongado com amitriptilina e imipramina no edema de pata induzido pela carragenina e no burst oxidativo de neutrófilos e fagocitose.

Os animais foram divididos ao acaso em três grupos: um controle (salina), e dois experimentais: imipramina 6,0 mg/kg (IMI 6) e amitriptilina 6,0 mg/kg (AMITRIP 6).

Os animais de cada grupo receberam uma injeção intraperitoneal diária dos respectivos tratamentos $(1,0 \mathrm{~mL} / \mathrm{Kg})$ ao longo de 15 dias. No décimo quinto dia e 1 hora após a administração dos fármacos, eles foram injetados com o agente flogístico carragenina $1 \%$ no coxim esquerdo $(0,1 \mathrm{~mL})$. A primeira medida do volume da pata foi realizada imediatamente antes da injeção da carragenina e as demais 1 , 2, 3, 4, 6 e 8 horas após. Os resultados obtidos foram expressos em termos da diferença entre os volumes medidos antes e depois das injeções.

No dia seguinte (16․ dia), os animais receberam uma nova injeção dos respectivos tratatamos e, uma hora depois, foram eutanasiados e seu sangue coletado para avaliação do burst oxidativo e da fagocitose realizada por neutrófilos. O protocolo experimental encontra-se esquematizado abaixo:

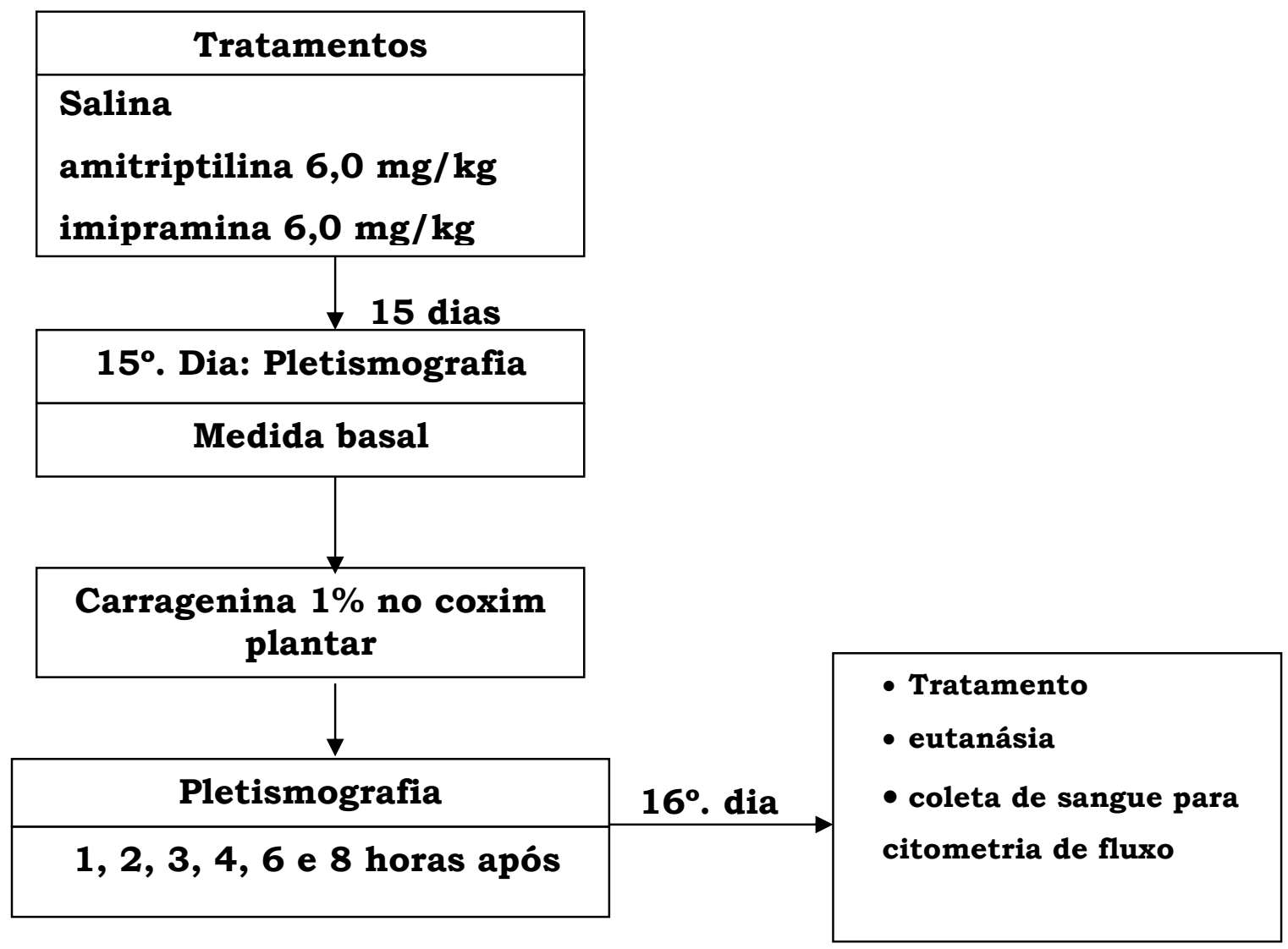


Em relação ao edema de pata produzido pela carragenina, a ANOVA de duas vias mostrou uma diferença significante entre os tratamentos $\left(F_{2,162}=17,949 ; p<0,001\right)$ e tempos $\left(F_{5,162}=18,208 ; p<0,001\right)$, sem apontar feito de interação $\left(F_{10,162}=1,437\right.$; $\mathrm{p}>0,05)$. O teste pos hoc de Tukey indicou que o grupo tratado com imipramina 6 $\mathrm{mg} / \mathrm{kg}$ (IMI6) apresentou redução significante no edema de pata nos tempos 2 e 6 horas $(p<0,001)$. O tratamento com amitriptilina $6 \mathrm{mg} / \mathrm{kg}$ (AMI6), por sua vez, produziu redução significante no edema nos tempos $2(p<0,001), 3(p<0,05)$ e 6 horas $(p<0,01)$, quando comparados ao grupo controle, como pode ser observado na figura 4.

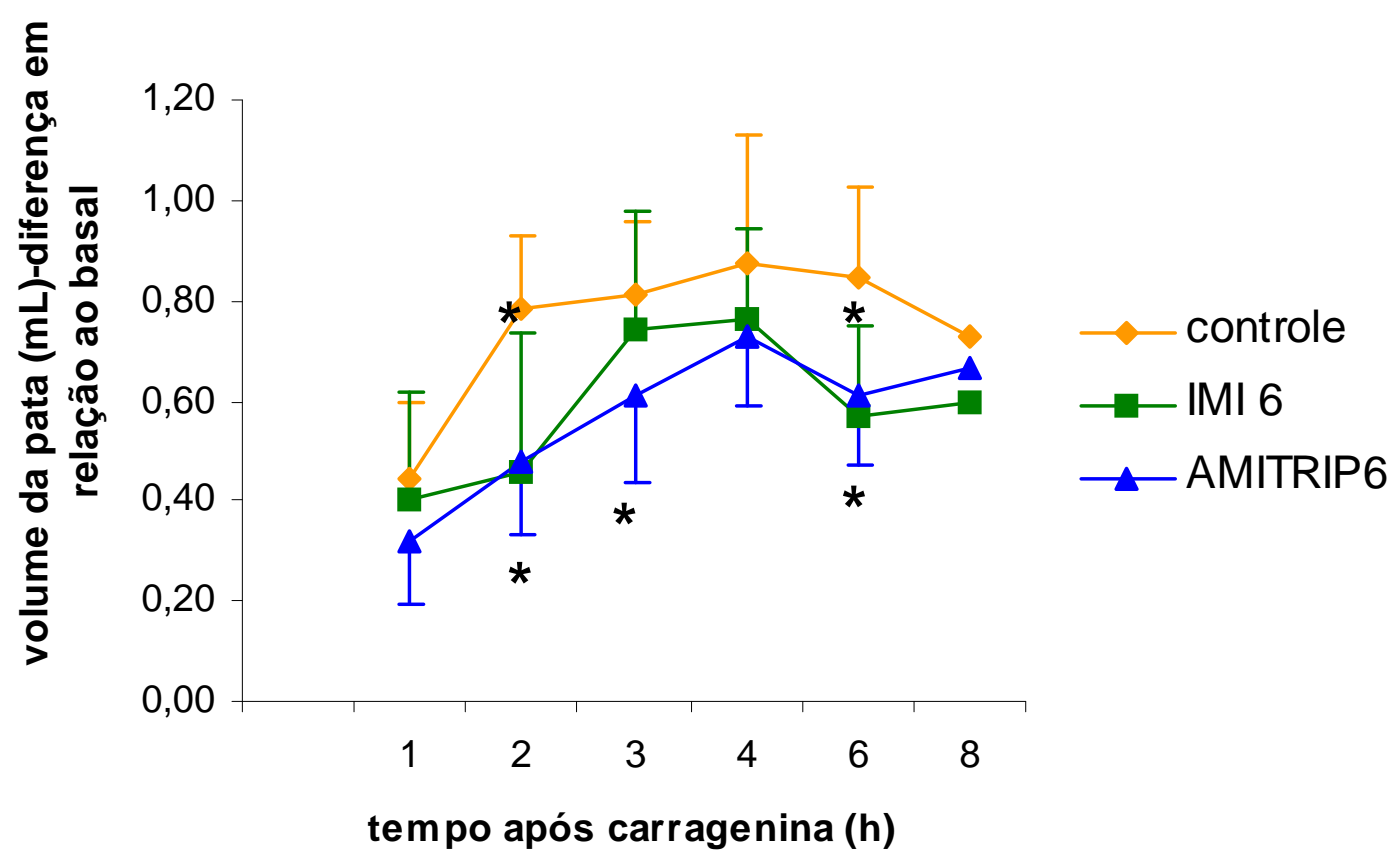

Figura 4 - Efeitos do tratamento prolongado (15 dias) com imipramina e amitriptilina no edema de pata induzido pela carragenina $1 \%$ em ratos. $O$ volume da pata é dado pela diferença de cada medida em relação ao volume basal $(\mathrm{mL})$. Os valores referem-se à média \pm desvio padrão. * $: p<0,05$ em relação ao controle. (ANOVA de duas vias seguida pelo teste de Tukey). $n=10$ por grupo 
Em relação à atividade de neutrófilos, a ANOVA de uma via revelou diferenças significantes entre os grupos no que concerne aos neutrófilos estimulados com DCFH $\left(F_{2,15}=15,591 ; p<0,001\right)$ e DCFH + S.aureus $\left(F_{2,19}=7,997 ; p<0,005\right)$. O teste de Tukey mostrou que o grupo tratado com imipramina produziu um aumento significativo da atividade de neutrófilos estimulados com DCFH $(p<0,001)$ e com S.aureus + DCFH, quando comparados aos grupos amitriptilina e controle $(p<0,005$ e $\mathrm{p}<0,05$ respectivamente). O teste de Kruskal-Wallis não apontou diferenças significantes entre os grupos em relação aos neutrófilos estimulados com PMA (KW $=4,257 ; p>0,05)$, como pode ser observado na figura $5 \mathrm{~A}$.

Adicionalmente, a análise não-paramétrica de Kruskal-Wallis mostrou diferenças significantes entre os grupos quanto ao parâmetro porcentagem de fagocitose $(K w=28,264 ; p<0,01)$. O teste de comparações múltiplas de Dunn indicou que o tratamento com amitriptilina produziu uma redução significante na porcentagem de fagocitose dos neutrófilos, quando comparado ao grupo controle $(p<0,01)$. Não houve diferenças significantes quanto ao parâmetro intensidade de fagocitose $(p>0,05)$. Os dados relativos à fagocitose por neutrófilos estão ilustrados na figura $5 \mathrm{~B}$. 


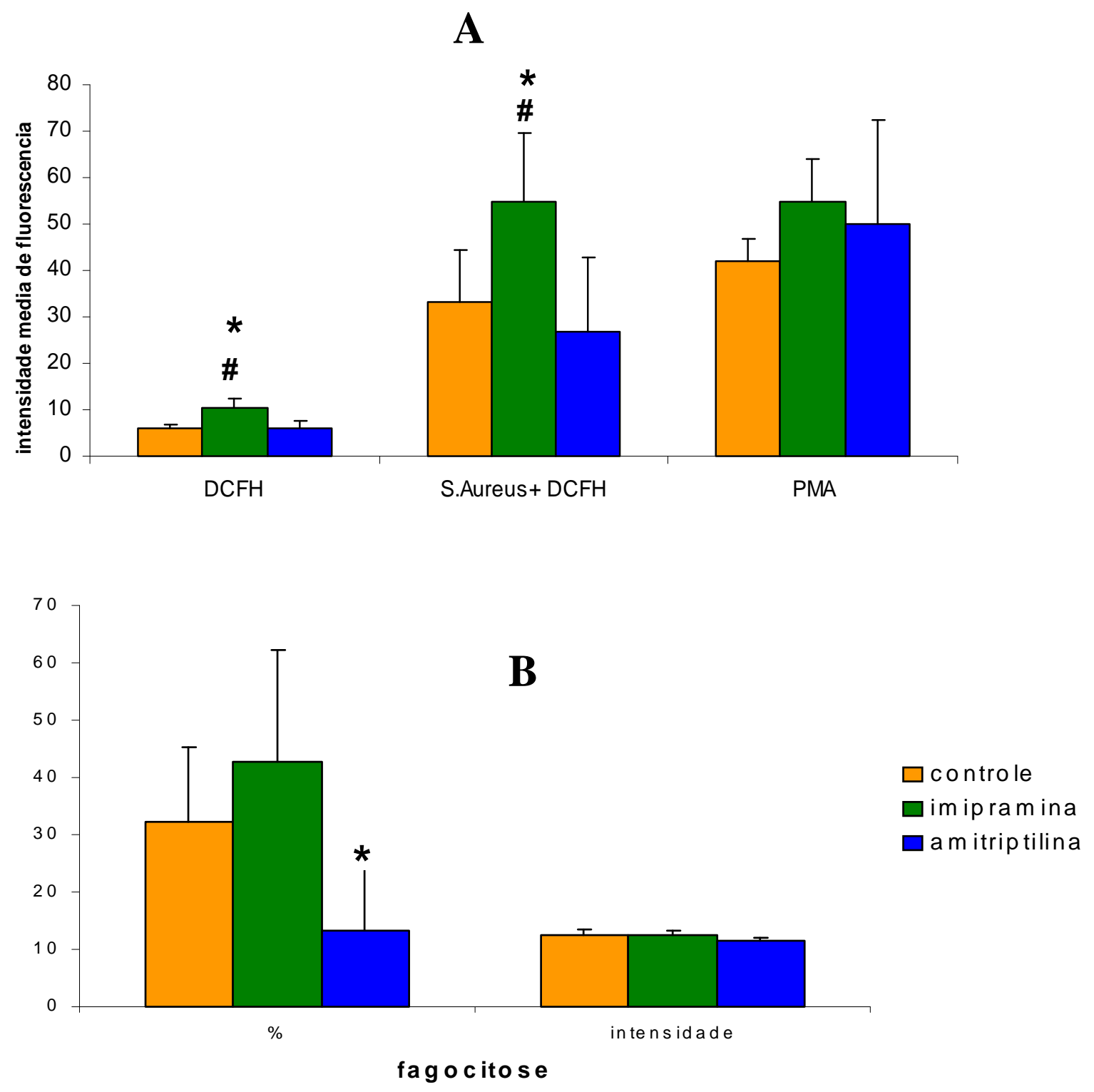

Figura 5 - Efeitos do tratamento prolongado (16 dias) com imipramina e amitriptilina sobre a atividade de neutrófilos. A- Burst oxidativo de neutrófilos estimulados pelo DCFH, S.aureus + DCFH ou PMA; B- Porcentagem e intensidade de fagocitose de neutrófilos de ratos. Os valores referem-se à média \pm desvio padrão. *: $p<0,05$ em relação ao respectivo grupo controle; \# $p<0,05$ em relação ao grupo amitriptilina. $n=8$ por grupo 
Experimento 4 - Avaliação dos efeitos da administração aguda e prolongada (7, 14 e 28 dias) de amitriptilina sobre o edema inflamatório induzido pela carragenina a $1 \%$.

Quarenta ratos foram divididos aleatoriamente em quatro grupos iguais: dois controles tratados com salina e dois experimentais tratados com amitriptilina 10 $\mathrm{mg} / \mathrm{kg}(1,0 \mathrm{~mL} / \mathrm{Kg})$. A administração dos respectivos tratamentos aconteceu ao longo de 7 dias (controle:C7 e amitriptilina:E7) ou 14 dias (controle:C14 e amitriptilina:E14). No último dia, todos os animais receberam o agente flogístico carragenina $1 \%$ no coxim plantar $(0,1 \mathrm{~mL}), 1$ hora após os respectivos tratamentos. A primeira medida do volume da pata foi realizada imediatamente antes da injeção da carragenina e as demais 1, 2, 3, 4, 6 e 8 horas depois.

O mesmo procedimento foi realizado em momento posterior, efetuando-se os respectivos tratamentos por 28 dias (controle:C28 e amitriptilina:E28). O esquema abaixo ilustra o protocolo:

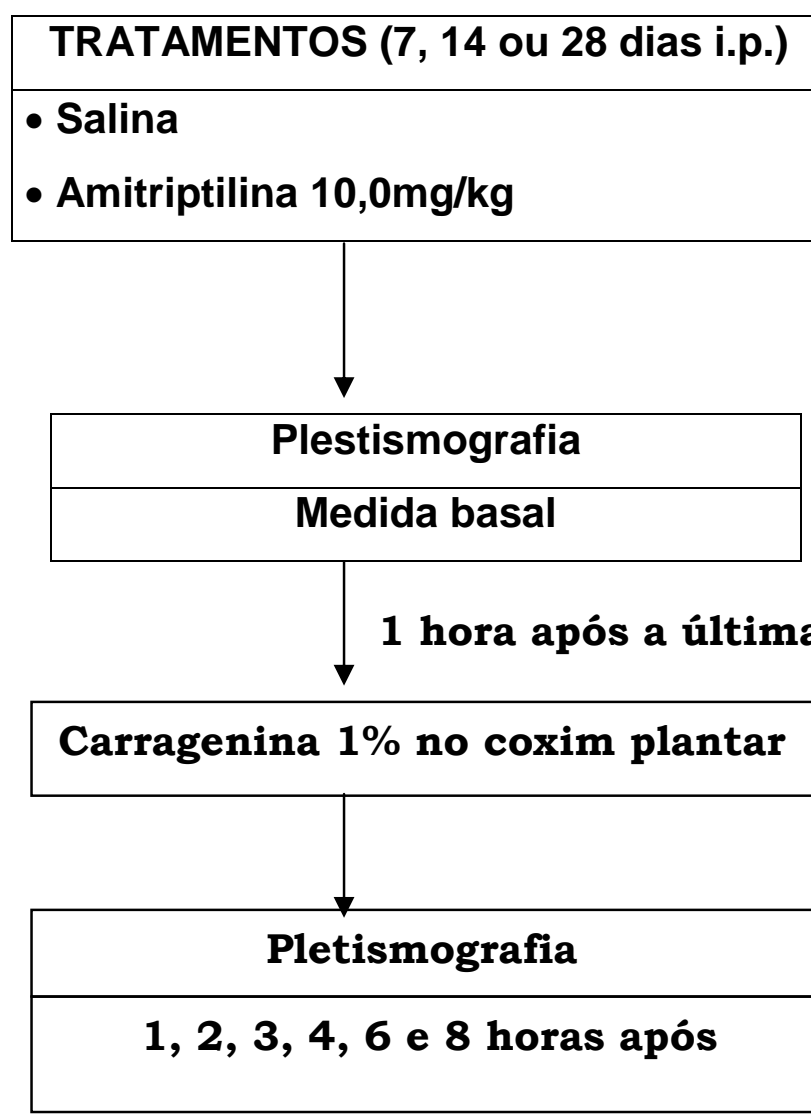


A ANOVA de duas vias dos dados obtidos com os tratamentos durante 7 ou 14 dias indicou a existência de diferenças significantes entre os tratamentos $\left(F_{3,192}=30,104\right.$; $p<0,001)$, tempos $\left(F_{5,192}=75,569 ; p<0,001\right)$ e na interação entre estes fatores $\left(F_{15,192}=2,12 ; p<0,05\right)$. O teste pos hoc de Tukey mostrou que 0 tratamento com amitriptilina durante 7 ou 14 dias produziu uma redução significante no edema de pata nos tempos 1 (respectivamente $p<0,01$ e $p<0,05), 2$ ( $p<0,001$ e $p<0,01)$, e 3 horas $(p<0,001$ e $p<0,05)$, quando comparados aos respectivos controles. Na quarta hora, apenas o tratamento feito durante 7 dias foi capaz de reduzir o edema de forma significante, quando comparado ao controle $(p<0,01)$. Não se observaram diferenças significantes entre dados dos grupos tratados com amitriptilina durante 7 ou 14 dias $(p>0,05)$. Estes dados encontram-se representados na figura 6 .

Quanto ao tratamento durante 28 dias, a ANOVA de duas vias mostrou diferenças significantes entre os tratamentos $\left(F_{1,90}=52,798 ; p<0,001\right)$, tempos $\left(F_{5,90}=49,962\right.$; $p<0,001)$ e na interação entre estes fatores $\left(F_{5,90}=9,805 ; p<0,001\right)$. $O$ teste de Tukey indicou que o tratamento com amitriptilina $10 \mathrm{mg} / \mathrm{kg}$ durante 28 dias produziu uma redução no edema de pata nos tempos $1,2,3$ horas $(p<0,001)$, quando comparado aos animais tratados com salina, como pode ser observado na figura 6 . 

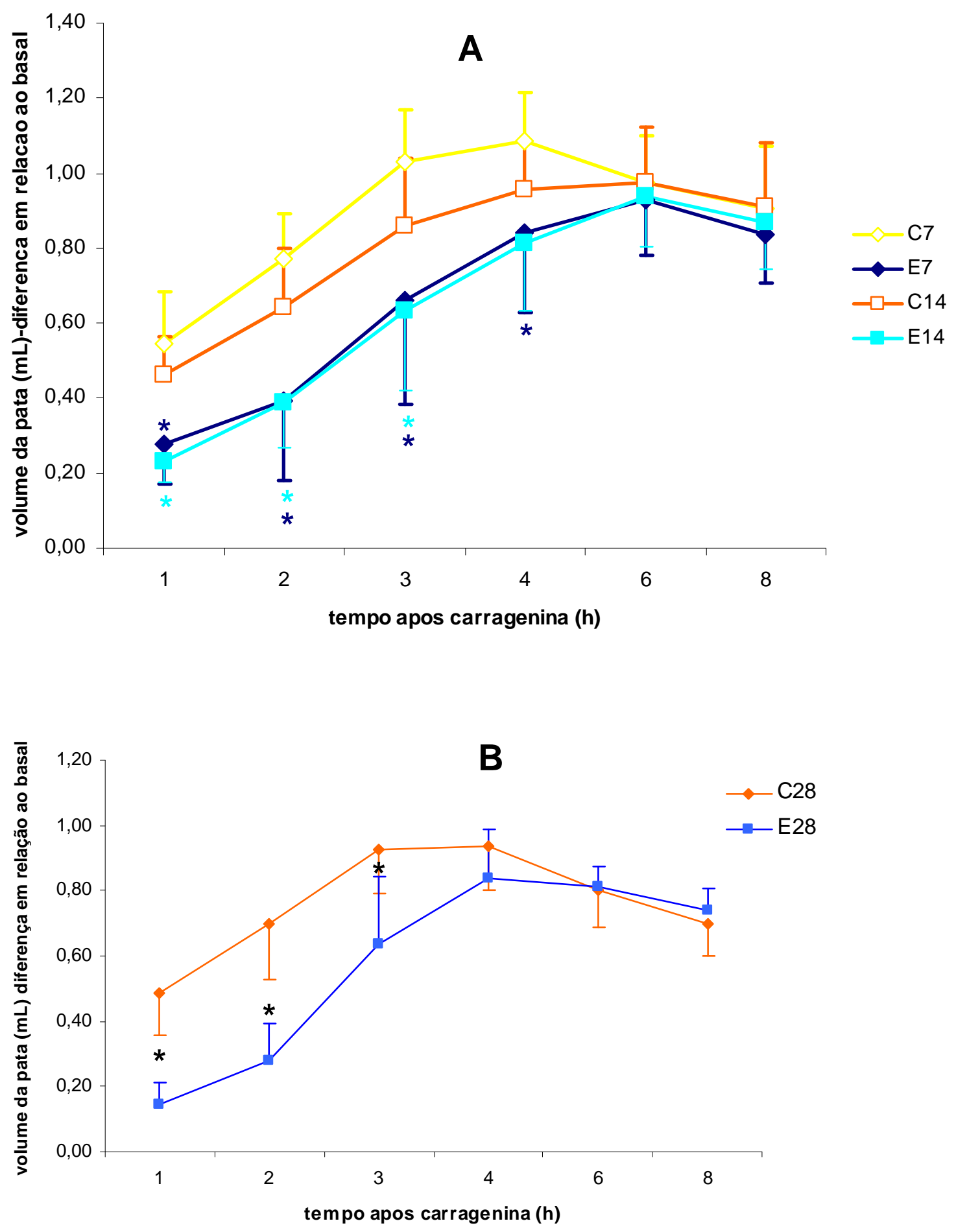

Figura 6 - Efeito do tratamento com amitriptilina durante 7 e 14 dias (A) ou 28 dias (B) no edema de pata induzido pela carragenina $1 \%$ em ratos. O volume da pata é dado pela diferença de cada medida em relação ao volume basal $(\mathrm{mL})$. Os valores referem-se à média \pm desvio padrão. ${ }^{*}: p<0,05$ em relação ao respectivo grupo controle. (ANOVA de duas vias seguida pelo teste de Tukey). C7: controle 7 dias, $n=9$; E7: amitriptilina 10,0mg/kg, 7 dias, $n=10$; C14: controle 14 dias, $\mathrm{n}=7$; E14: amitriptilina $10,0 \mathrm{mg} / \mathrm{kg}, 14$ dias, $\mathrm{n}=10$; C28: controle 28 dias, $\mathrm{n}=8$; E28: amitriptilina $10 \mathrm{mg} / \mathrm{kg}, 28$ dias, $\mathrm{n}=9$ 
- Verifica-se, portanto, que o tratamento prolongado com amitriptilina por 7, 14 ou 28 dias produziu uma redução significante do edema de pata no máximo até a quarta hora, não se observando efeitos após este horário.

- Sendo assim, o próximo passo foi avaliar a injeção de amitriptilina respeitando-se a meia-vida de eliminação deste fármaco em ratos (2,5-3h)

Experimento 5 - Avaliação dos efeitos de injeções intraperitoneais e subcutâneas em dose única e de injeções intraperitoneais realizadas a cada tempo de meia-vida de amitriptilina sobre o edema de pata induzido pela carragenina em ratos.

Quarenta ratos foram divididos ao acaso em 5 grupos:

- um controle tratado por via i.p. com $\mathrm{NaCl} 0,9 \%$ (controle I.P., $n=5$ );

- um controle tratado por via S.C. com $\mathrm{NaCl} 0,9 \%$ (controle S.C., $n=5$ );

- um grupo experimental tratado i.p. com amitriptilina $10 \mathrm{mg} / \mathrm{kg}$ (AMI I.P., $\mathrm{n}=10$ );

- um grupo experimental tratado S.C. com amitriptilina $10 \mathrm{mg} / \mathrm{kg}$ (AMI S.C., $n=10)$;

- um grupo tratado com amitriptilina $10 \mathrm{mg} / \mathrm{kg}$ i.p. a cada 2,5-3 horas (AMI I.P.1/2, $n=10$ ).

Uma hora após os respectivos tratamentos, os ratos foram injetados com carragenina $0,5 \%$ no coxim esquerdo $(0,1 \mathrm{~mL})$. A primeira medida do volume da pata foi realizada imediatamente antes da injeção da carragenina e as demais 1, 2, 3, 4, 6 e 8 horas depois.

Esta alteração na concentração da carragenina de 1 para $0,5 \%$ baseou-se em experimento prévio (dados não mostrados), onde verificou-se que a amitriptilina reduziu de forma mais intensa o edema produzido por carragenina quando usada nesta concentração de $0,5 \%$. Segue abaixo esquema do protocolo experimental: 


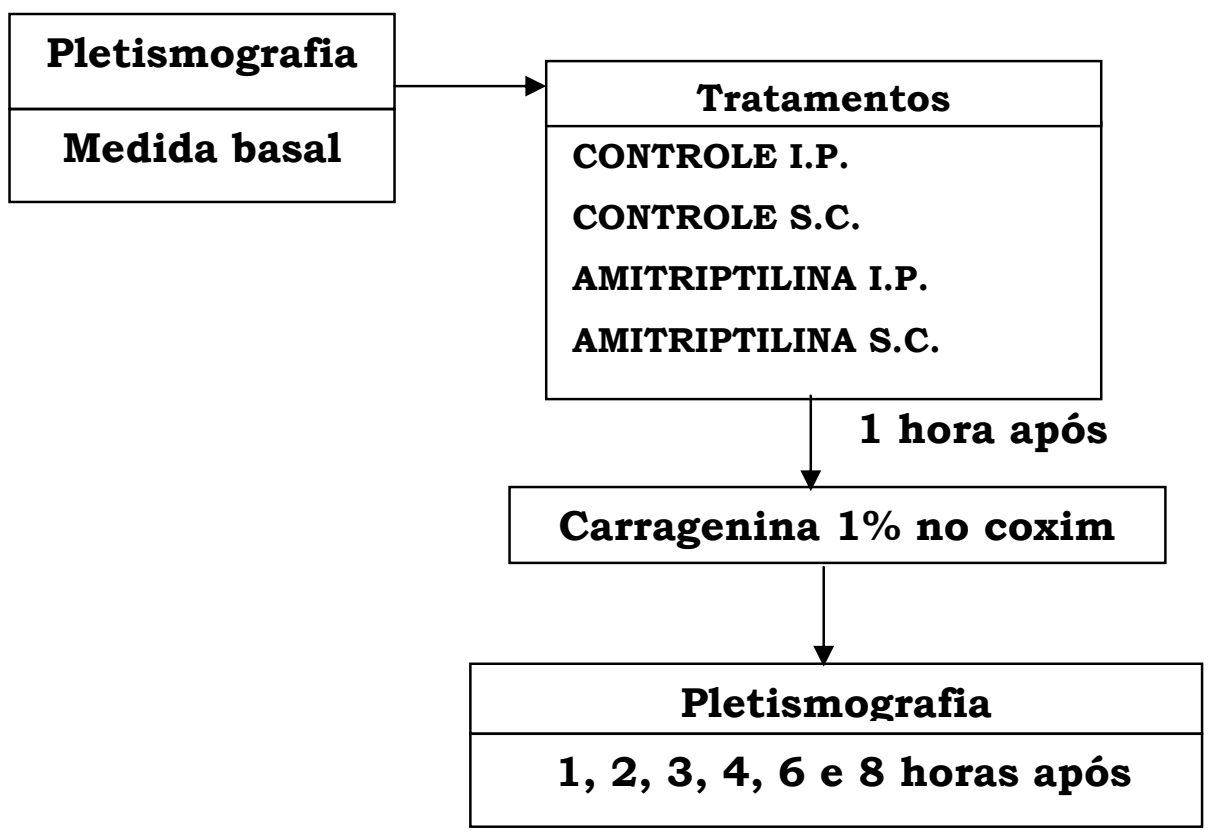

A aplicação do teste-t não mostrou diferenças significantes entre os dois grupos controle em todos os tempos analisados $(t=0,419 ; p>0.05)$. Assim, nas análises subsequentes os dados agrupados foram considerados como parte de um único grupo controle. A ANOVA de duas vias mostrou uma diferença significante entre os tratamentos $\left(F_{3,216}=42.337, p<0.001\right)$ e os tempos $\left(F_{5,216}=35.307, p<0.001\right)$. Não houve efeito de interação entre os fatores tratamento e tempo $\left(F 1_{5,216}=0,667\right.$; $p>0,05)$. O teste pos hoc de Tukey mostrou que na primeira hora os grupos AMI IP $1 / 2$ vida $(p<0.001)$ e AMI SC $(p<0.005)$ apresentaram uma diminuição no edema de pata comparados ao grupo controle. Nos tempos 2 e 3 horas, todos os animais que receberam amitriptilina apresentaram redução no edema de pata $(p<0.05)$. Entretanto, somente o grupo AMI IP1/2 mostrou um edema de pata menor em todos os tempos avaliados, ou seja, $1,2,3,4,6 \mathrm{~h}(\mathrm{p}<0.01)$ and $8 \mathrm{~h}(\mathrm{p}<0.01)$ quando comparado aos animais do grupo controle, como pode ser observado na Figura 7. 


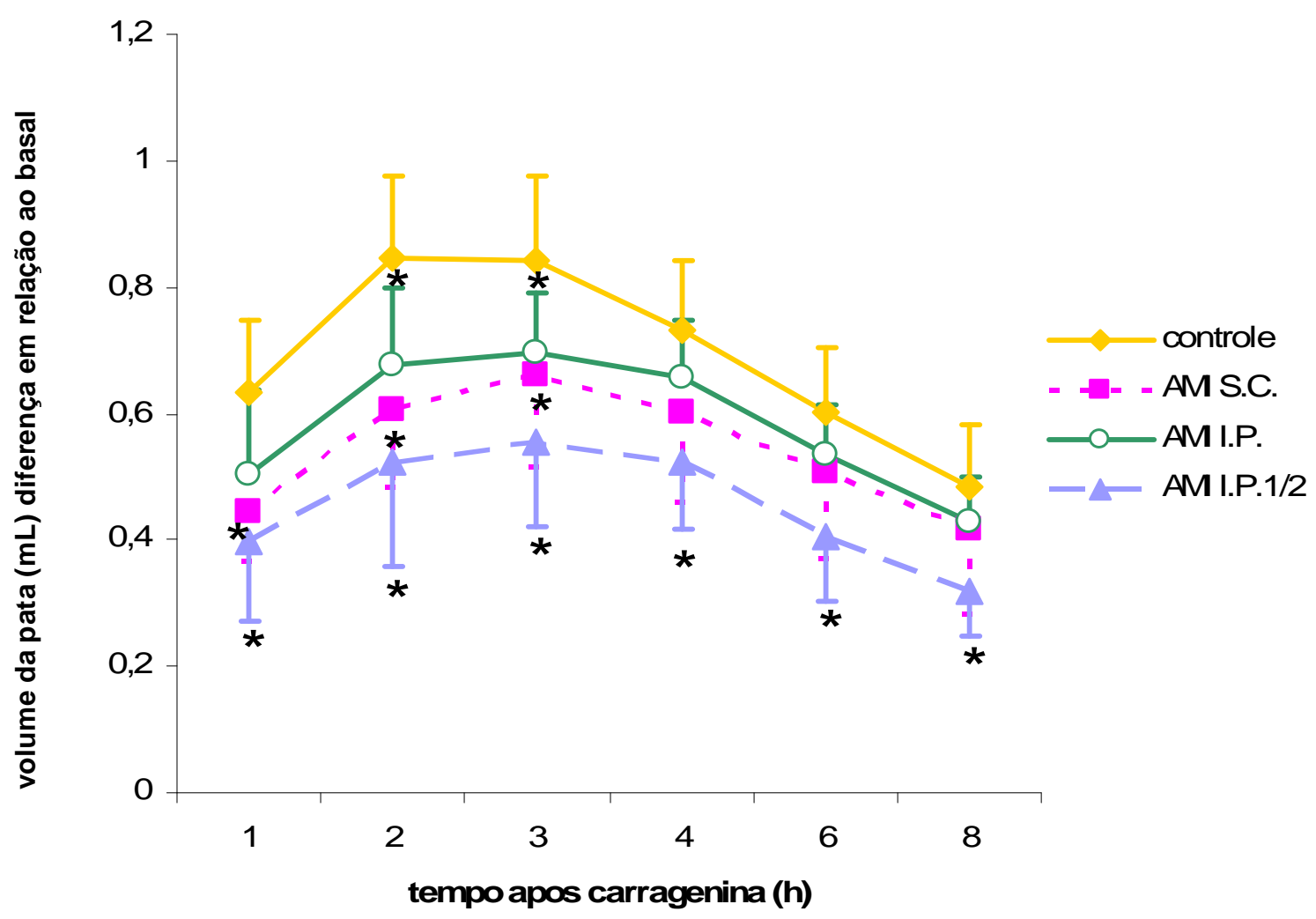

Figura 7 - Efeitos de injeções intraperitoneais, subcutâneas e a cada tempo de meia-vida de amitriptilina sobre o edema de pata induzido pela carragenina em ratos. O volume da pata é dado pela diferença de cada medida em relação ao volume basal $(\mathrm{mL})$. Os valores referem-se à média \pm desvio padrão. *: $p<0,05$ em relação ao grupo controle. (ANOVA de duas vias seguida pelo teste de Tukey). $n=10$ por grupo 
Experimento 6 - Avaliação dos efeitos da administração de amitriptilina no coxim esquerdo sobre o edema de pata induzido pela carragenina.

Seis ratos foram aleatoriamente divididos ao acaso em 3 grupos:

- 2 animais receberam o veículo da amitriptilina ( $\mathrm{NaCl}$ 0,9\%) e uma hora depois carragenina $(0,05 \mathrm{~mL}$ cada), diretamente no coxim esquerdo.

- 2 animais receberam amitriptilina $(10 \mathrm{mg} / \mathrm{kg})$ diretamente no coxim esquerdo $(0,1 \mathrm{~mL})$,

- 2 animais receberam amitriptilina $(10 \mathrm{mg} / \mathrm{kg})$ e depois de uma hora carragenina $1 \%(0,05 \mathrm{~mL}$ cada), diretamente no coxim esquerdo,

Os animais foram observados durante 72 horas para avaliação do aspecto geral da pata. Na figura 8 é possível verificar as patas dos animais 24 horas após a injeção de salina + carragenina (A), amitriptilina (B) e amitriptilina + carragenina (C).

Ao final das 72 horas, os animais que receberam a carragenina já tinham suas patas com seu volume original. No entanto, a injeção de amitriptilina (com ou sem carragenina) fez com que as patas permanecessem edemaciadas e com aparência hiperêmica até além das 72 horas observadas. Sendo assim, como a amitriptilina per se produziu um efeito pró-edema na pata, não foi possível avaliar o efeito dessa administração local sobre a resposta inflamatória.

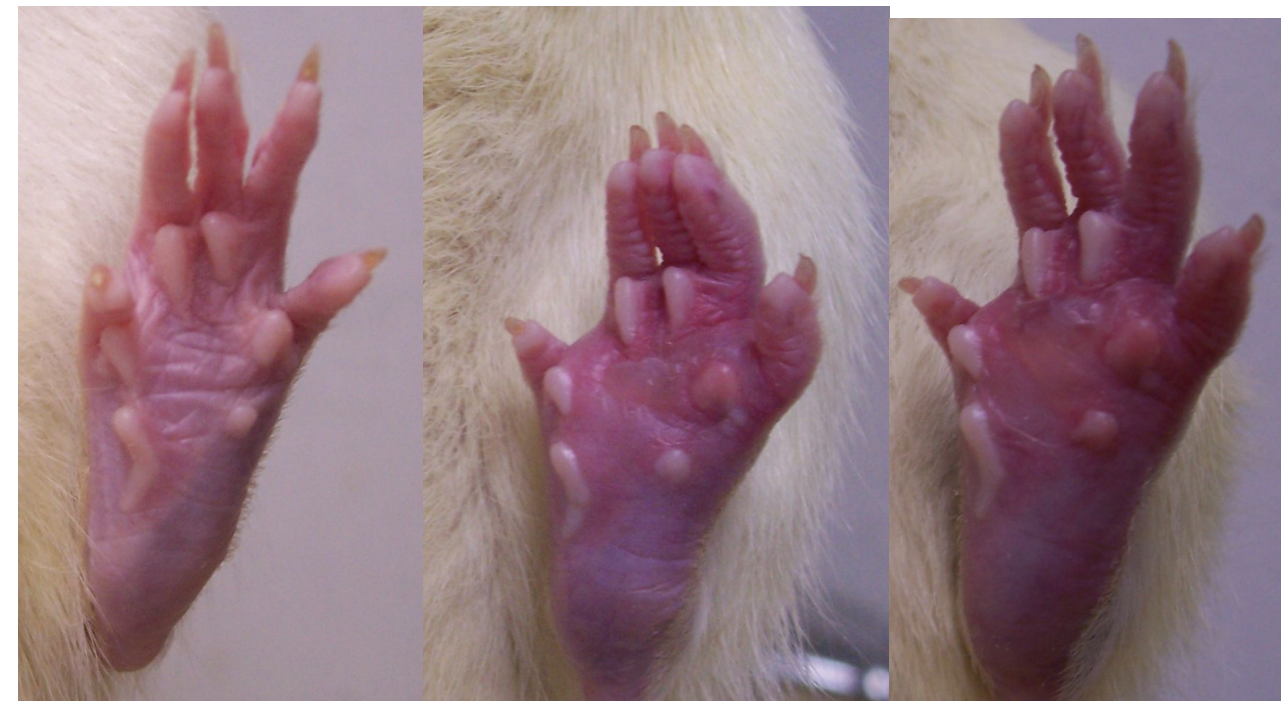

A

B

C

Figura 8 - Patas de ratos 24 horas depois de terem sido injetadas com carragenina (A), amitriptilina (B) e amitriptilina + carragenina (C) 
O próximo passo foi, então, avaliar a influência dos glicocorticoides sobre o efeito anti-inflamatório da amitriptilina administrada a cada tempo de meia-vida.

\section{2- AVALIAÇÃO DA PARTICIPAÇÃO DOS GLICOCORTICOIDES NO EFEITO ANTI-INFLAMATÓRIO DA AMITRIPTILINA.}

Experimento 7 - Influência do pré-tratamento com antagonista de receptores glicocorticoides ( $R U$ 486) nos efeitos da amitriptilina sobre o edema de pata induzido por carragenina $1 \%$

Quarenta animais foram divididos aleatoriamente em 4 grupos iguais, sendo 1 controle e 3 experimentais. Os animais do grupo controle foram pré-tratados com o veículo de RU-486 (álcool 70 a 5\% + propilenoglicol), após 12 horas receberam nova dose do veículo e após uma hora receberam salina (1 mL/kg, i.p.). Os grupos experimentais foram: 1)pré-tratados com veículo de RU-486 (10mg/kg, i.p.), após 12 horas com nova dose do veículo e após uma hora com amitriptilina $10 \mathrm{mg} / \mathrm{kg}$ (grupo amitriptlina); 2) pré-tratados com RU-486 (10 mg/kg, i.p.), após 12 horas com nova dose de RU-486 e após uma hora com salina (grupo RU-486); 3) pré-tratados com RU-486 (10 mg/kg, i.p.), após 12 horas com nova dose de RU-486 e após uma hora com amitriptilina $10 \mathrm{mg} / \mathrm{kg}$ (grupo RU-486-amitriptilina).

Uma hora depois da primeira administração de amitriptilina ou seu veículo - que foram administrados a cada 2,5-3 horas - todos os animais foram injetados com carragenina $1 \%$, sendo o volume das patas avaliado conforme experimentos anteriores. $\mathrm{O}$ esquema abaixo ilustra o protocolo experimental: 


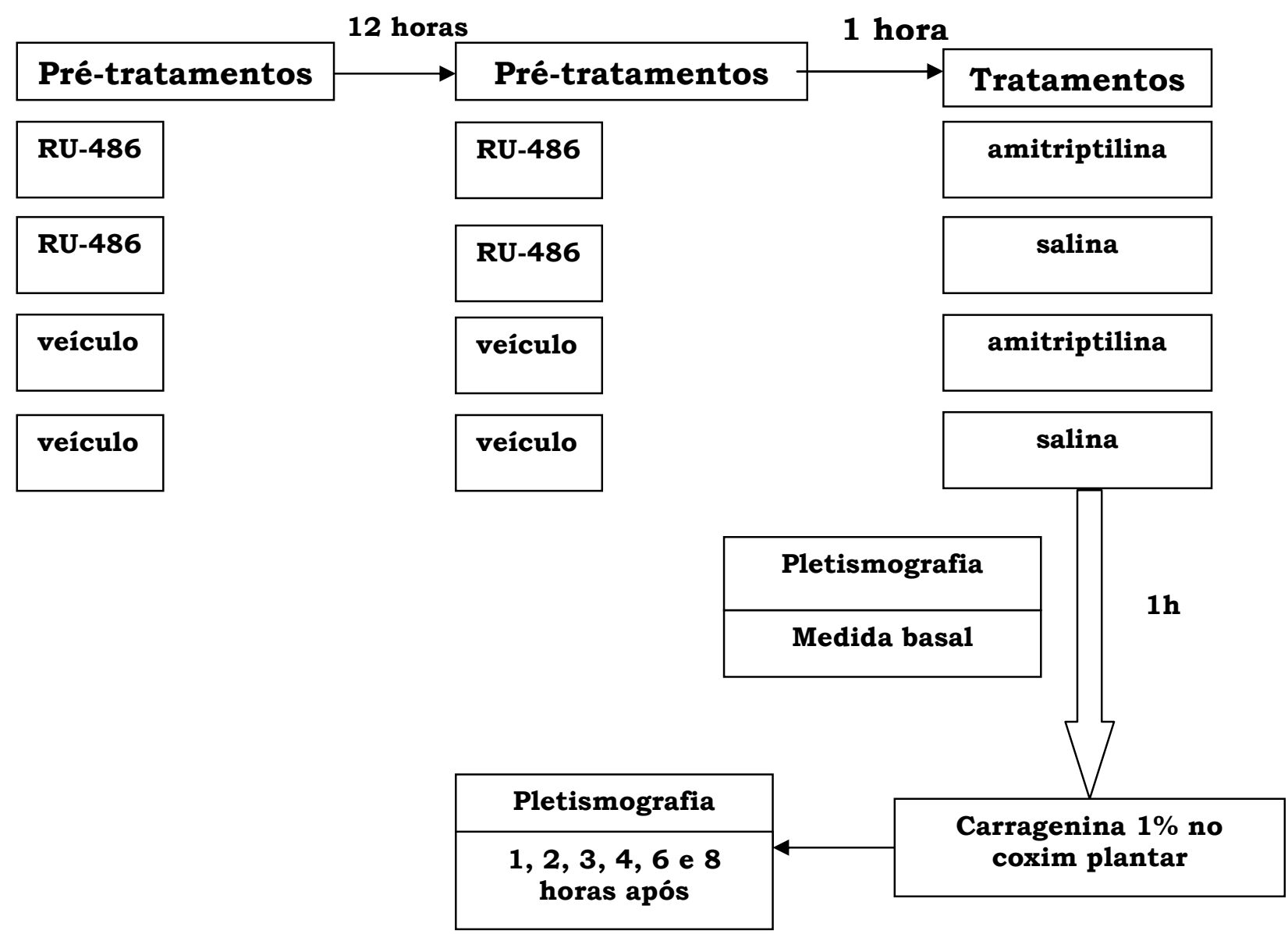

A ANOVA de duas vias mostrou a existência de diferenças significantes entre os tratamentos $\left(F_{3,180}=50,64, p<0,001\right)$ e entre os tempos $\left(F_{5,180}=28,44, p<0,001\right)$, sem efeito interação $\left(F_{15,180}=0,9, p>0,05\right)$. A análise pos hoc de Tukey mostrou que a administração de amitriptilina $10 \mathrm{mg} / \mathrm{kg}$ a cada tempo de meia-vida produziu uma redução significante no edema de pata nos tempos 2, 3, $4(p<0,001), 6(p<0,005)$ e 8 horas $(p<0,005)$, quando comparado ao grupo controle. Resultado semelhante foi observado no grupo que recebeu RU-486 e amitriptilina. O tratamento com RU-486 não produziu efeitos sobre o processo inflamatório, nem foi capaz de reverter o efeito anti-inflamatório da amitriptilina, quando administrados no mesmo animal, conforme observado na figura 9. 


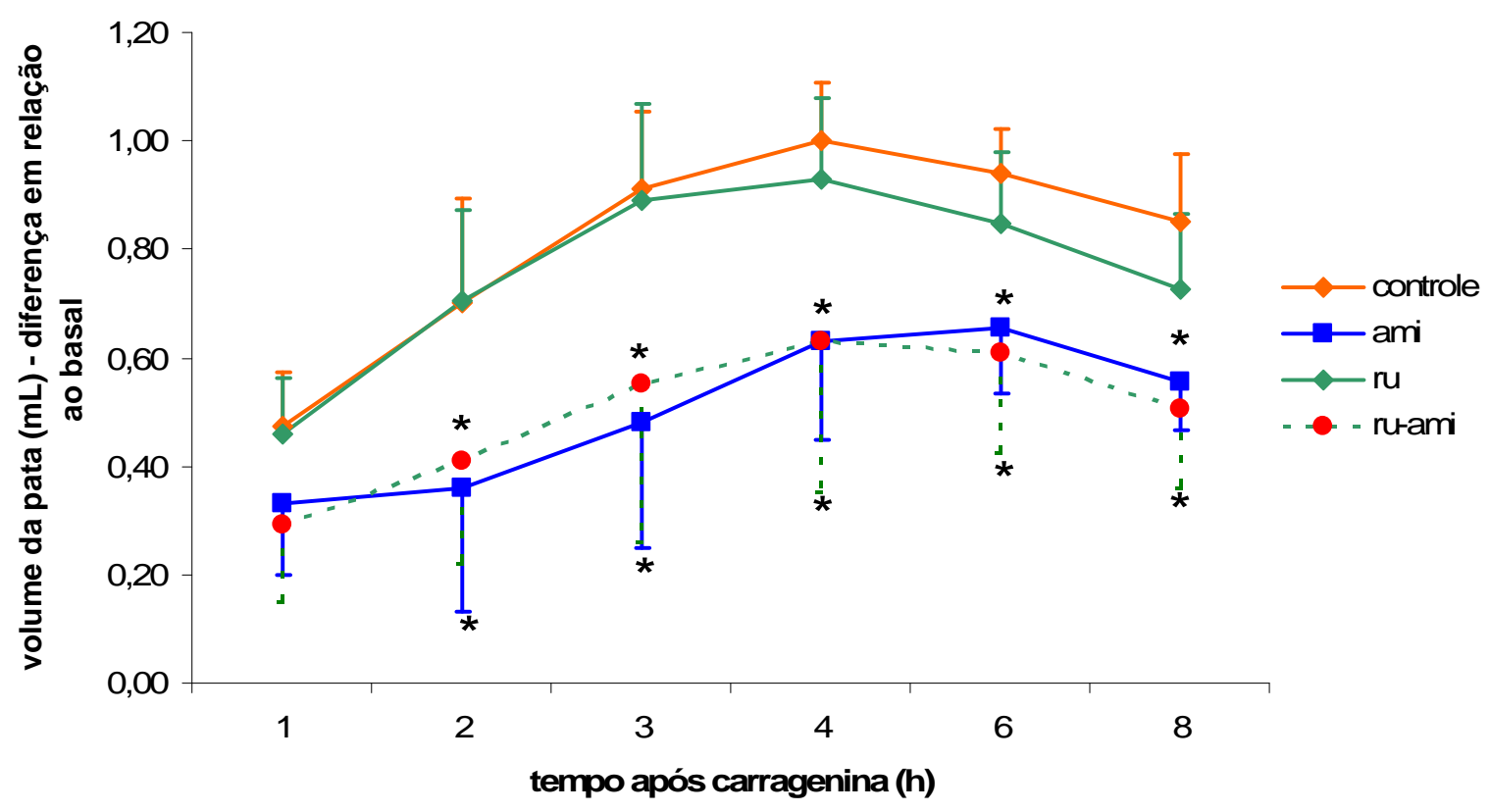

Figura 9 - Efeito do pré-tratamento com um antagonista de receptores de glicocorticoides (RU-486) nas ações da amitriptilina administrada a cada tempo de meia-vida sobre o edema de pata induzido por carragenina $1 \% \mathrm{em}$ ratos. O volume da pata é dado pela diferença de cada medida em relação ao volume basal $(\mathrm{mL})$. Os valores referem-se à média \pm desvio padrão. *: $p<0,05$ em relação ao grupo controle. (ANOVA de duas vias seguida pelo teste de Tukey). controle e ru: $n=9$ por grupo; ami e ru-ami: $n=8$ por grupo

O próximo passo foi avaliar a influência dos receptores alfa-1-adrenérgicos sobre 0 efeito anti-inflamatório da amitriptilina administrada a cada tempo de meia-vida. 


\section{3 - AVALIAÇÃO DA PARTICIPAÇÃO DOS ADRENOCEPTORES ALFA-1}

Experimento 8 - Influência do pré-tratamento com antagonista de adrenoceptores alfa-1 (prazosina) nos efeitos da amitriptilina administrada a cada meia-vida sobre o edema de pata induzido por carragenina $1 \%$.

Quarenta animais foram divididos aleatoriamente em 4 grupos iguais, sendo 1 controle e 3 experimentais. Os animais foram pré-tratados com o veículo de prazosina (PBS, $1 \mathrm{~mL} / \mathrm{kg}$, i.p.), após 30 minutos receberam salina $(1 \mathrm{~mL} / \mathrm{kg}$, i.p.). Os grupos experimentais foram: 1)pré-tratados com veículo de prazosina, após 30 minutos com amitriptilina $10 \mathrm{mg} / \mathrm{kg}$ (grupo amitriptlina); 2) pré-tratados com prazosina (2 mg/kg, i.p.), após 30 minutos com salina (grupo prazosina); 3) pré-tratados com prazosina, após 30 minutos com amitriptilina $10 \mathrm{mg} / \mathrm{kg}$ (grupo prazosina-amitriptilina). Uma hora depois da primeira administração de amitriptilina ou seu veículo - que foram administrados a cada 2,5-3 horas - os animais de todos os grupos foram injetados com carragenina $1 \%$, sendo o volume das patas avaliado conforme experimentos anteriores. $\mathrm{O}$ esquema abaixo ilustra o protocolo experimental:

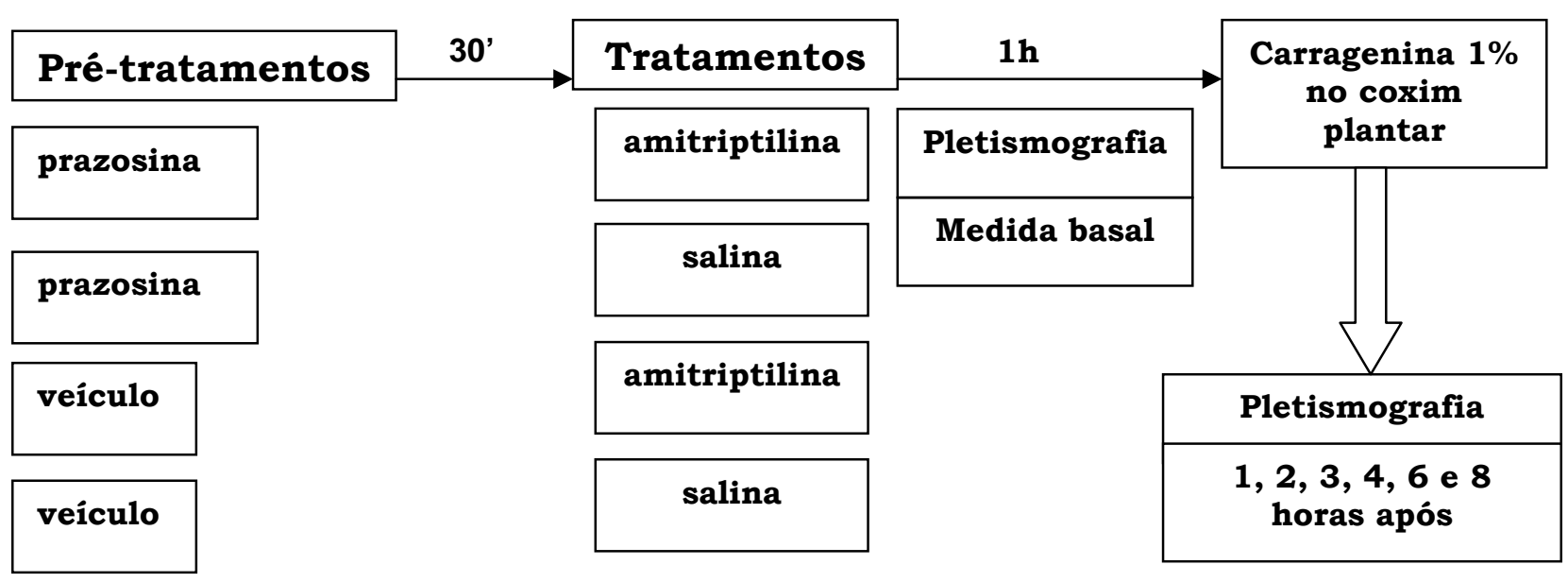


A ANOVA de duas vias mostrou existência de diferenças significantes entre os tratamentos $\left(F_{3,198}=27,426 ; p<0,001\right)$ e entre os tempos $\left(F_{5,198}=29,778, p<0,001\right)$, sem efeito interação entre os fatores $\left(F_{15,198}=1,558 ; p>0,05\right)$. A aplicação do teste pos-hoc de Tukey mostrou que o tratamento com amitriptilina produziu redução significante do edema de pata nos tempos 2 e $3 \mathrm{~h}(\mathrm{p}<0,005)$, quando comparados ao grupo controle. A prazosina per se não produziu efeitos no edema de pata $(p>0,05)$. Os animais que foram pré-tratados com prazosina e que receberam em seguida amitriptilina apresentaram uma redução significante do edema inflamatório nos tempos $1 \mathrm{~h} \quad(\mathrm{p}<0,05), 2$ e $3 \mathrm{~h} \quad(\mathrm{p}<0,001), 4 \mathrm{~h}(\mathrm{p}<0,05)$ e $8 \mathrm{~h} \quad(\mathrm{p}<0,05)$ quando comparados ao grupo controle. Além disso, a redução no edema produzida por este tratamento foi mais intensa que a produzida no grupo tratado com amitriptilina nos tempos 2 e $3 \mathrm{~h}(\mathrm{p}<0,05)$, conforme pode ser observado na Figura 10.

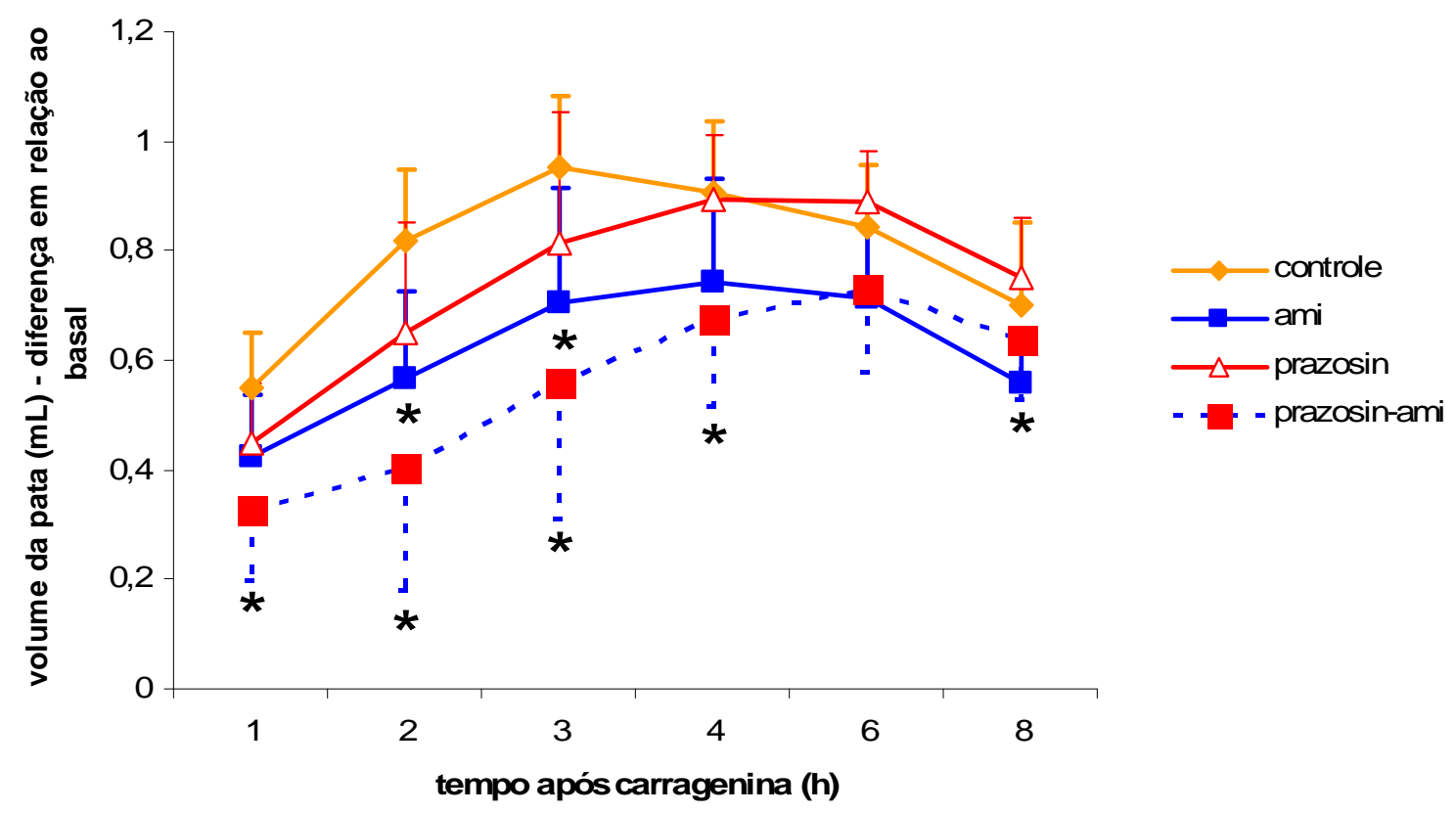

Figura 10 - Efeito do pré-tratamento com um antagonista de adrenoceptores alfa-1 (prazosina) nas ações da amitriptilina administrada a cada tempo de meiavida sobre o edema de pata induzido por carragenina $1 \%$ em ratos. $O$ volume da pata é dado pela diferença de cada medida em relação ao volume basal $(\mathrm{mL})$. Os valores referem-se à média \pm desvio padrão. *: $p<0,05$ em relação ao grupo controle. (ANOVA de duas vias seguida pelo teste de Tukey). Controle: $n=8$; ami: $n=9$; demais grupos: $n=10$

O terceiro mecanismo investigado foi a participação do óxido nítrico (NO) sobre o efeito anti-inflamatório da amitriptilina administrada em dose única. 


\section{4- AVALIAÇÃO DA PARTICIPAÇÃO DO ÓXIDO NÍTRICO NO EFEITO ANTI- INFLAMATÓRIO DA AMITRIPTILINA}

Experimento 9 - Efeito do pré-tratamento com um inibidor da síntese de óxido nítrico nas ações da amitriptilina sobre o edema de pata induzido por carragenina $1 \%$ em ratos

Quarenta animais foram divididos ao acaso em quatro grupos iguais. Vinte deles foram pré-tratados com um inibidor da síntese de óxido nítrico (L-NAME, 50 mg/kg, i.p.) e os outros vinte com o veículo deste (PBS, $1 \mathrm{~mL} / \mathrm{kg}$ ). Uma hora depois, eles receberam amitriptilina (10 mg/kg, i.p.) ou $\mathrm{NaCl} 0,9 \%$ (salina; i.p.). Após $1 \mathrm{~h}$, foram injetados no coxim plantar com carragenina a 1\%, sendo o volume da pata avaliado em diferentes horários, como descrito anteriormente. Segue abaixo o esquema do protocolo experimental usado:

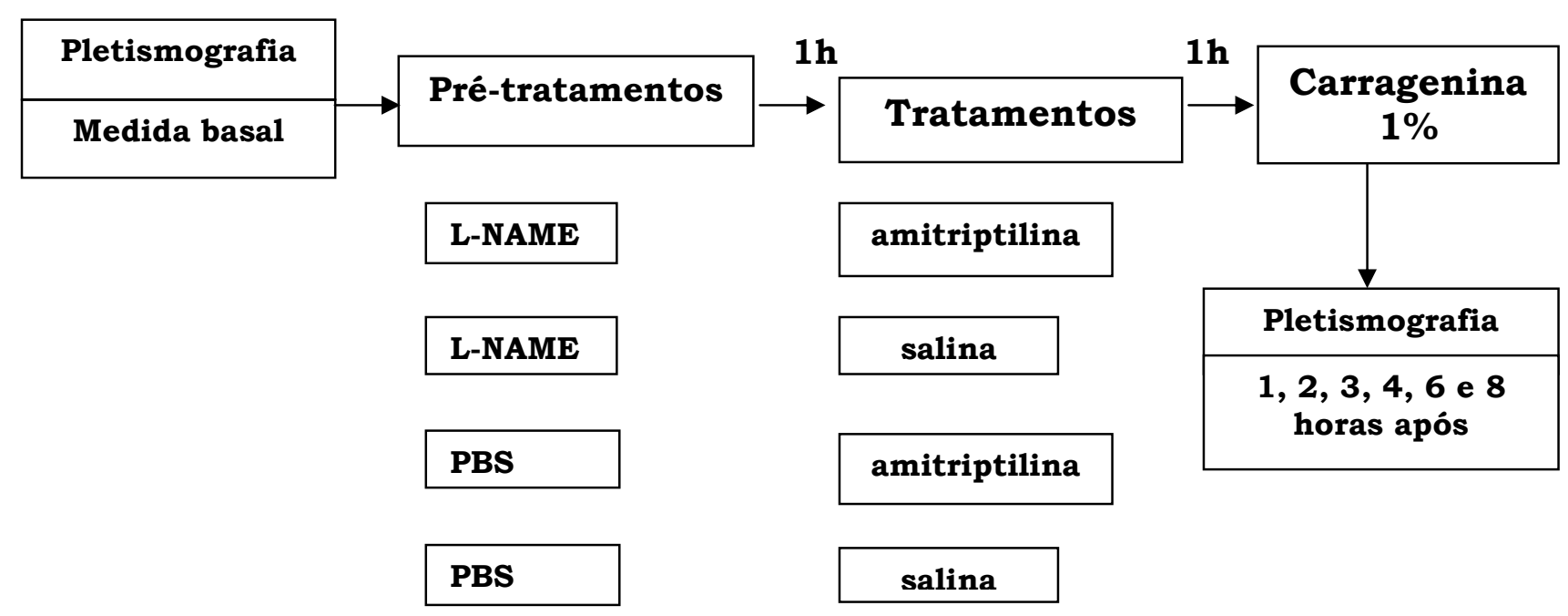


A análise dos dados, ilustrados pela figura 11, mostrou a existência de diferenças significantes entre os tratamentos $\left(F_{3,192}=84,677 ; p<0,001\right)$ e entre os tempos $\left(F_{5,192}=2,954 ; p<0,05\right)$, sem contudo revelar interação significante entre estes fatores $(F=1,581 ; p>0,05)$. O teste pos hoc de Tukey mostrou que o tratamento com amitriptilina produziu uma redução significante do edema de pata quando comparado ao grupo salina apenas no tempo 2 horas $(p<0,05)$. $O$ tratamento com LNAME reduziu o edema nos tempos $2(p<0,01), 3(p<0,005)$ e 4 horas $(p<0,05)$ quando comparado ao grupo controle, enquanto que o grupo que recebeu L-NAME e amitriptilina apresentou uma redução significante do edema de pata durante todo o período de observação, quando comparado aos demais grupos $(p<0,001)$.

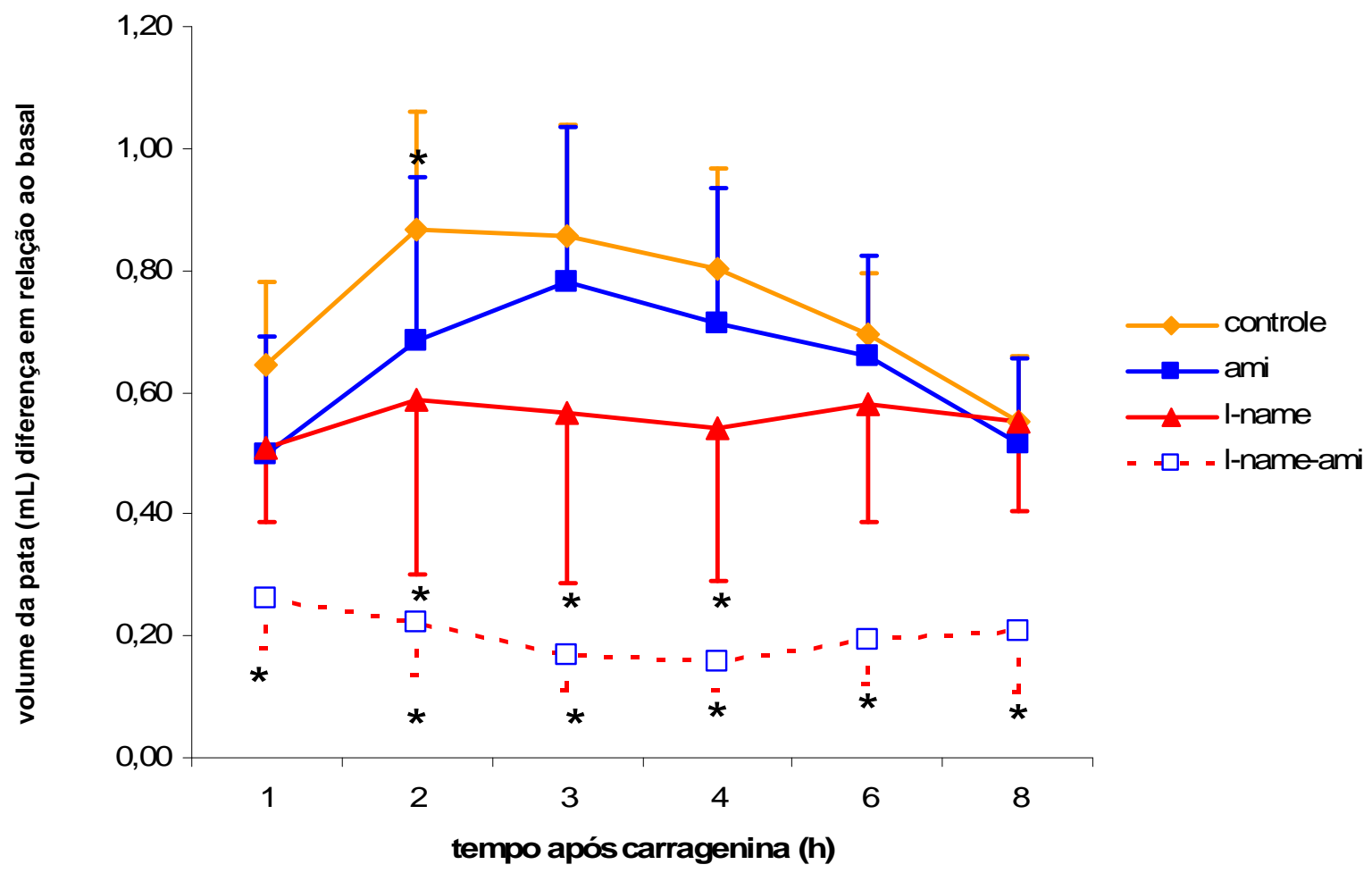

Figura 11 - Efeitos do pré-tratamento com um inibidor da síntese de óxido nítrico (LNAME) nas ações da amitriptilina sobre o edema de pata induzido pela carragenina $1 \%$ em ratos. $O$ volume da pata é dado pela diferença de cada medida em relação ao volume basal $(\mathrm{mL})$. Os valores referem-se à média \pm desvio padrão. *: $p<0,05$ em relação ao grupo controle. (ANOVA de duas vias seguida pelo teste de Tukey). Grupos controle, ami (amitriptilina 10,0mg/kg) e I-name: $n=9$; I-name-ami: $n=8$ 
O cálculo da área sob a curva (ASC) do volume da pata em função do tempo foi realizado com os dados obtidos de cada animal. As médias e desvios-padrões de cada grupo, apresentadas na tabela 3, foram comparadas por meio do teste nãoparamétrico de Kruskal-Wallis, que indicou diferenças significantes entre os grupos $(\mathrm{Kw}=19,920 ; \mathrm{p}<0,001)$. O teste pos hoc de Dunn indicou que apenas o grupo que recebeu L-NAME e amitriptilina diferiu significantemente do grupo controle $(p<0,05)$. Estes animais também diferiram de forma significativa daqueles tratados com amitriptilina ou com L-NAME $(p<0,05)$.

Tabela 3 - Áreas sob a curva (ASC) do volume da pata em função do tempo de animais tratados ou não com L-NAME e amitriptilina. Os valores referem-se à média \pm desvio padrão. * $p<0,01$ em relação ao grupo controle (Teste de Kruskal-Wallis seguido pelo teste de Dunn)

\begin{tabular}{c|cccc}
\hline & controle & $\begin{array}{c}\text { Amitriptilina } \\
10,0 \mathrm{mg} / \mathrm{kg}\end{array}$ & L-NAME & L-NAME-Ami \\
& & & \\
\hline ASC & $5,19 \pm 0,94$ & $4,35 \pm 1,48$ & $3,93 \pm 1,44$ & $1,35 \pm 0,35^{\star}$ \\
\hline
\end{tabular}


Experimento 10 - Efeito do pré-tratamento com um precursor da síntese de óxido nítrico (L-arginina) nas ações da amitriptilina sobre o edema de pata induzido por carragenina $1 \%$ em ratos.

Quarenta animais foram divididos ao acaso em quatro grupos iguais. Vinte deles foram pré-tratados com um precursor da síntese de óxido nítrico (L-arginina, 300 $\mathrm{mg} / \mathrm{kg}$, i.p.) e os outros vinte com o veículo deste (PBS; $1 \mathrm{~mL} / \mathrm{kg}$ ). Uma hora depois, os animais receberam amitriptilina $10 \mathrm{mg} / \mathrm{kg}$ ou salina (i.p.). Após $1 \mathrm{~h}$, eles foram injetados com carragenina a $1 \%$ no coxim plantar, sendo o volume avaliado em diferentes horários, como descrito anteriormente. Segue abaixo o esquema do protocolo experimental usado:

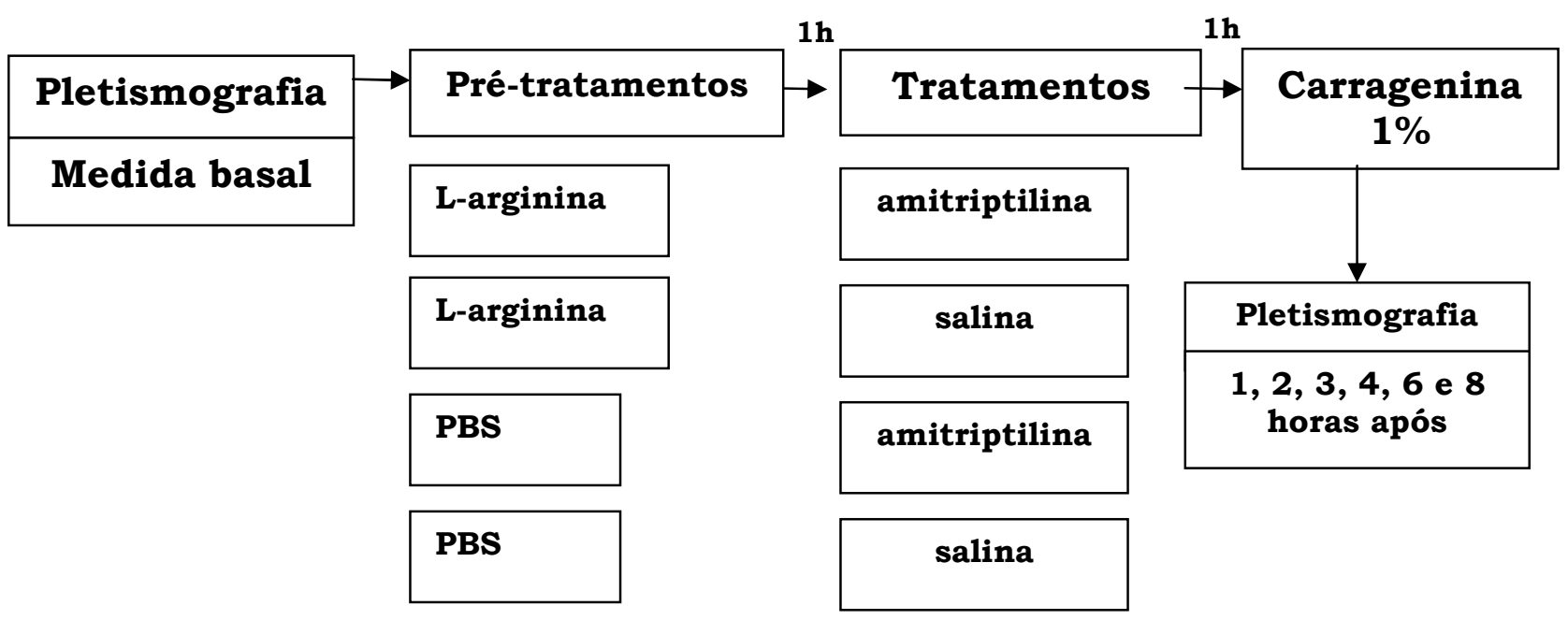

Como se vê na figura 12, o pré-tratamento com L-arginina per se não produziu efeito sobre o edema de pata. A aplicação da ANOVA de duas vias mostrou uma diferença significante entre os tratamentos $\left(F_{3,105}=9,88 ; p<0,001\right)$ e os tempos $\left(F_{5,105}=27,68\right.$; $p<0,001)$, sem contudo haver interação entre os fatores $(F=1,07 ; p>0,05)$. $O$ tratamento com amitriptilina $10 \mathrm{mg} / \mathrm{kg}$ reduziu o edema de pata no tempo $2 \mathrm{~h}$ $(p<0,05)$ quando comparado ao observado nos ratos do grupo controle. O grupo que recebeu pré-tratamento com L-arginina e em seguida amitriptilina (I-arg-ami) apresentou um menor edema de pata nos tempos $1(p<0,01)$ e 2 horas $(p<0,001)$, quando comparado aos animais do grupo controle; a L-arginina não foi capaz de reverter o efeito anti-inflamatório da amitriptilina. 


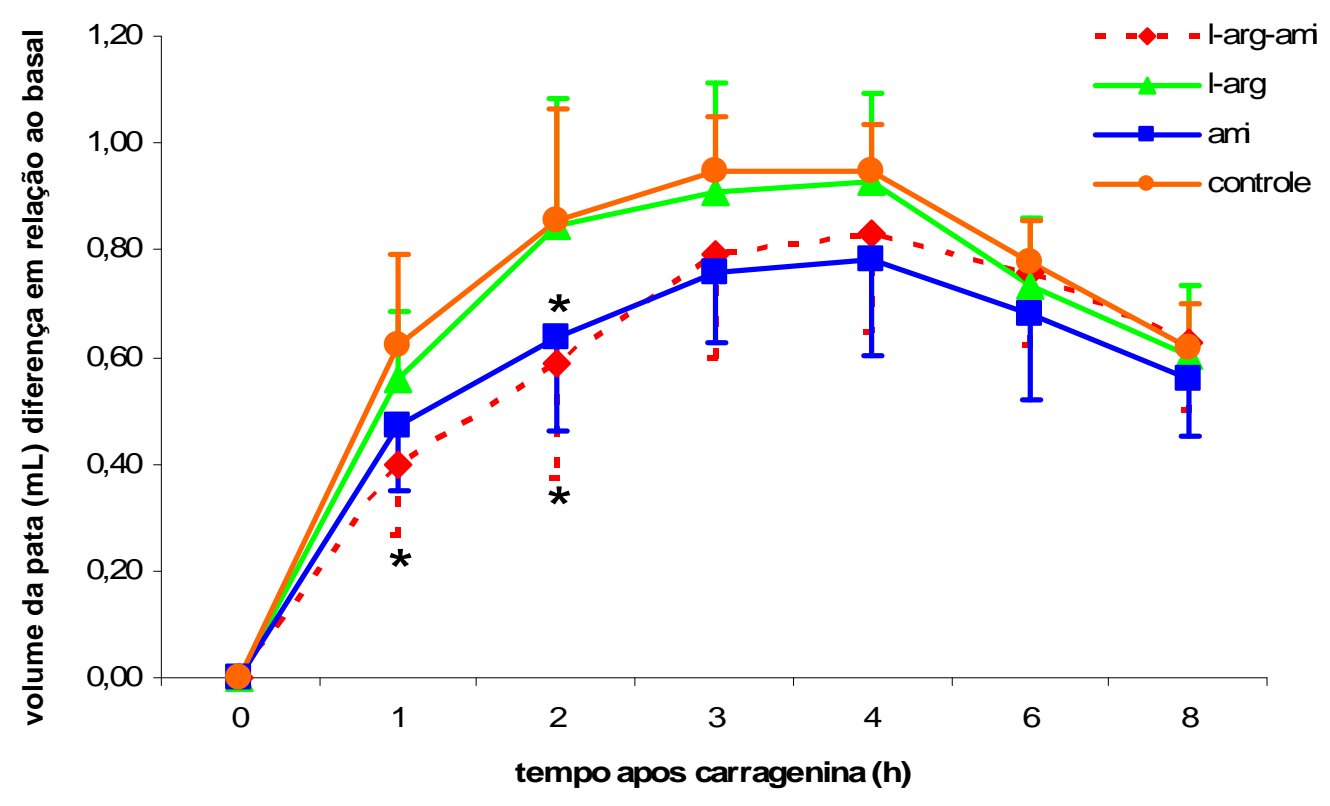

Figura 12 - Efeitos do pré-tratamento com um precursor da síntese de óxido nítrico (L-arginina) nas ações da amitriptilina sobre o edema de pata induzido pela carragenina $1 \%$ em ratos. $O$ volume da pata é dado pela diferença de cada medida em relação ao volume basal $(\mathrm{mL})$. Os valores referem-se à média \pm desvio padrão. ${ }^{*}: p<0,05$ em relação ao grupo controle. (ANOVA de duas vias seguida pelo teste de Tukey). Controle: $n=9$; ami (amitriptilina 10,0mg/kg): n=8; I-arg: $n=10 ;$ I-arg-ami: $n=11$ 
O cálculo da área sob a curva (ASC) do volume da pata em função do tempo foi realizado com os dados obtidos de cada animal. As médias e desvios-padrões de cada grupo, apresentadas na tabela 4, foram comparadas por meio de uma ANOVA de uma via, que não encontrou diferenças significantes entre os grupos $\left(F_{3,34}=1,830\right.$; $p>0,05)$.

Tabela 4 - Áreas sob a curva (ASC) do volume da pata em função do tempo de animais tratados ou não com L-arginina e amitriptilina. Os valores referemse à média \pm desvio padrão. (ANOVA de uma via não encontrou diferenças entre os grupos; $p>0,05$ )

\begin{tabular}{ccccc}
\hline & controle & $\begin{array}{c}\text { Amitriptilina } \\
10,0 \mathrm{mg} / \mathrm{kg}\end{array}$ & L-arginina & L-arginina-Ami \\
& & & \\
\hline ASC & $5,67 \pm 0,59$ & $4,72 \pm 0,93$ & $5,40 \pm 1,05$ & $4,97 \pm 1,04$ \\
\hline
\end{tabular}

A investigação da participação do óxido nítrico no efeito anti-inflamatório também foi feita administrando-se a amitriptilina a cada tempo de meia-vida de eliminação. 
Experimento 11 - Influência do pré-tratamento com um inibidor da síntese de óxido nítrico (L-NAME) nas ações da amitriptilina administrada a cada tempo de meia-vida sobre o edema de pata induzido por carragenina $1 \%$ em ratos.

Foi realizado procedimento idêntico ao anteriormente descrito, no qual ratos foram pré-tratados com um inibidor da síntese de óxido nítrico ou PBS, seguida pela administração intraperitoneal de amitriptilina ou salina e após uma hora pela injeção plantar de carragenina. A única diferença do protocolo anterior está no fato de a amitriptilina ter sido administrada a cada tempo de meia-vida, ou seja, a cada 2,5-3h, conforme esquema abaixo:

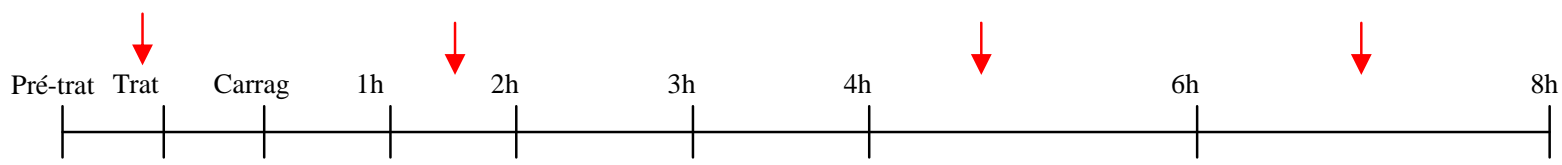

\section{Tratamento com amitriptilina}

A realização de uma ANOVA de duas vias dos dados ilustrados pela figura 13 mostrou uma diferença significante entre os tratamentos $\left(F_{3,174}=27,99 ; p<0,001\right)$ e entre os tempos $\left(F_{5,174}=12,57 ; p<0,001\right)$, sem interação entre os fatores $\left(F_{15,174}=1,12 ; p>0,05\right)$. O tratamento com amitriptilina a cada tempo de meia-vida produziu uma redução significante do edema de pata nos tempos 3, 4, e 6 horas $(\mathrm{p}<0,05)$, quando comparado ao grupo controle. O pré-tratamento com L-NAME reduziu o edema de pata nos tempos 2 e $3 \mathrm{~h}(\mathrm{p}<0,04)$. Os animais que receberam LNAME seguido da amitriptilina apresentaram uma redução no edema nos tempos 2 $(p<0,01), 3(p<0,001), 4(p<0,001), 6(p<0,001)$ e $8(p<0,05)$ horas após a injeção de carragenina. 


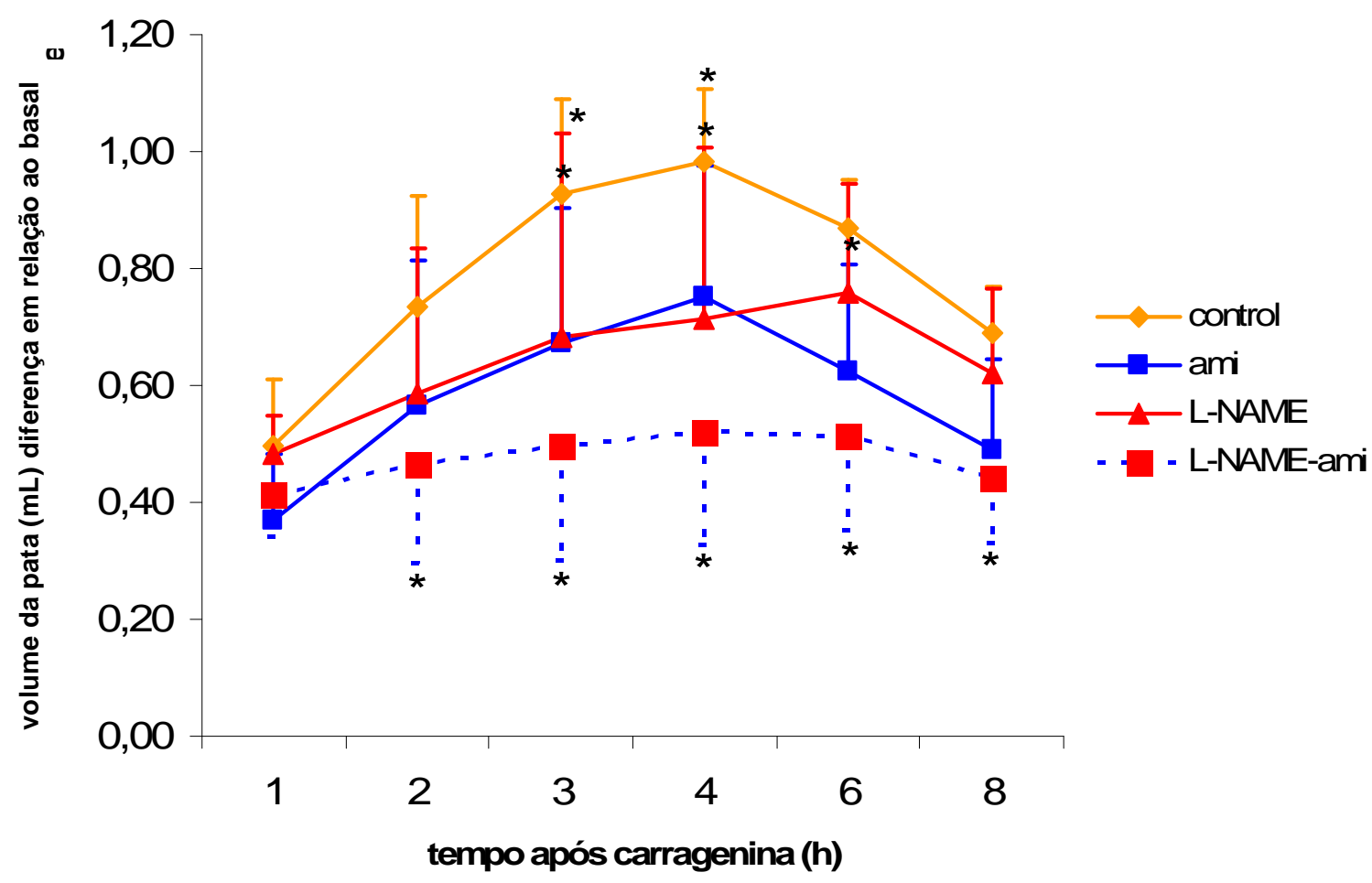

Figura 13 - Efeitos do pré-tratamento com um inibidor da síntese de óxido nítrico (LNAME) nas ações da amitriptilina administrada a cada tempo de meia-vida sobre o edema de pata induzido por carragenina $1 \%$ em ratos. O volume da pata é dado pela diferença de cada medida em relação ao volume basal $(\mathrm{mL})$. Os valores referem-se à média \pm desvio padrão. ${ }^{*}: p<0,05$ em relação ao grupo controle. (ANOVA de duas vias seguida pelo teste de Tukey). Controle: $n=10$, ami $n=8$, I-name: $n=7$; I-name-ami: $n=8$ 
O cálculo da área sob a curva (ASC) do volume da pata em função do tempo foi realizado com os dados obtidos de cada animal. As médias e desvios-padrões de cada grupo, apresentadas na tabela 5, foram comparadas por meio de uma ANOVA de uma via, que indicou diferenças significantes entre os grupos $\left(F_{3,29}=6,895\right.$; $p<0,005)$. O teste pos hoc de Tukey mostrou que os grupos tratados com amitriptilina e L-NAME-amitriptilina diferiram de forma significante dos dados obtidos do grupo controle.

Tabela 5 - Áreas sob a curva (ASC) do volume da pata em função do tempo de animais tratados ou não com L-NAME e amitriptilina (a cada meia-vida). Os valores referem-se à média \pm desvio padrão. * $p<0,01$ em relação ao grupo controle (ANOVA de uma via seguida pelo teste de Tukey)

\begin{tabular}{ccccc}
\hline & controle & $\begin{array}{c}\text { Amitriptilina } \\
10,0 \mathrm{mg} / \mathrm{kg}\end{array}$ & L-NAME & L-NAME-Ami \\
\cline { 3 - 5 } & & $4,29 \pm 1,31^{*}$ & $4,72 \pm 1,51$ & $3,42 \pm 1,03^{*}$ \\
\hline
\end{tabular}


Experimento 12 - Influência do pré-tratamento com um precursor da síntese de óxido nítrico (L-arginina) nas ações da amitriptilina administrada a cada tempo de meia-vida sobre o edema de pata induzido por carragenina $1 \%$ em ratos.

Foi realizado procedimento idêntico ao experimento anterior, no qual ratos foram pré-tratados com L-arginina ou PBS, seguida pela administração intraperitoneal de amitriptilina ou salina e após uma hora pela injeção plantar de carragenina. Novamente a amitriptilina foi administrada a cada tempo de meia-vida, ou seja, a cada 2,5-3h.

A aplicação da ANOVA de duas vias nos dados obtidos neste experimento mostrou uma diferença significante entre os tratamentos $\left(F_{5,216}=42,048, p<0,001\right)$ e entre os tempos $\left(F_{5,216=30,789}, p<0,01\right)$, sem interação entre os fatores $\left(F_{15,216}=1,529\right.$; $p>0,05)$. O teste pos hoc indicou, conforme ilustrado na Figura 14 , que o tratamento com amitriptilina $10 \mathrm{mg} / \mathrm{kg}$ produziu uma redução significante do edema de pata nos tempos $2(p<0,05), 3,4(p<0,001)$ e $6 \quad(p<0,005)$ horas quando comparado ao seu controle. A L-arginina, per se, não produziu efeito sobre o processo inflamatório e também não foi capaz de reverter o efeito anti-inflamatório da amitriptilina até a quarta hora. A partir da sexta hora observou-se reversão do efeito anti-inflamatório da amitriptilina pela L-arginina. 


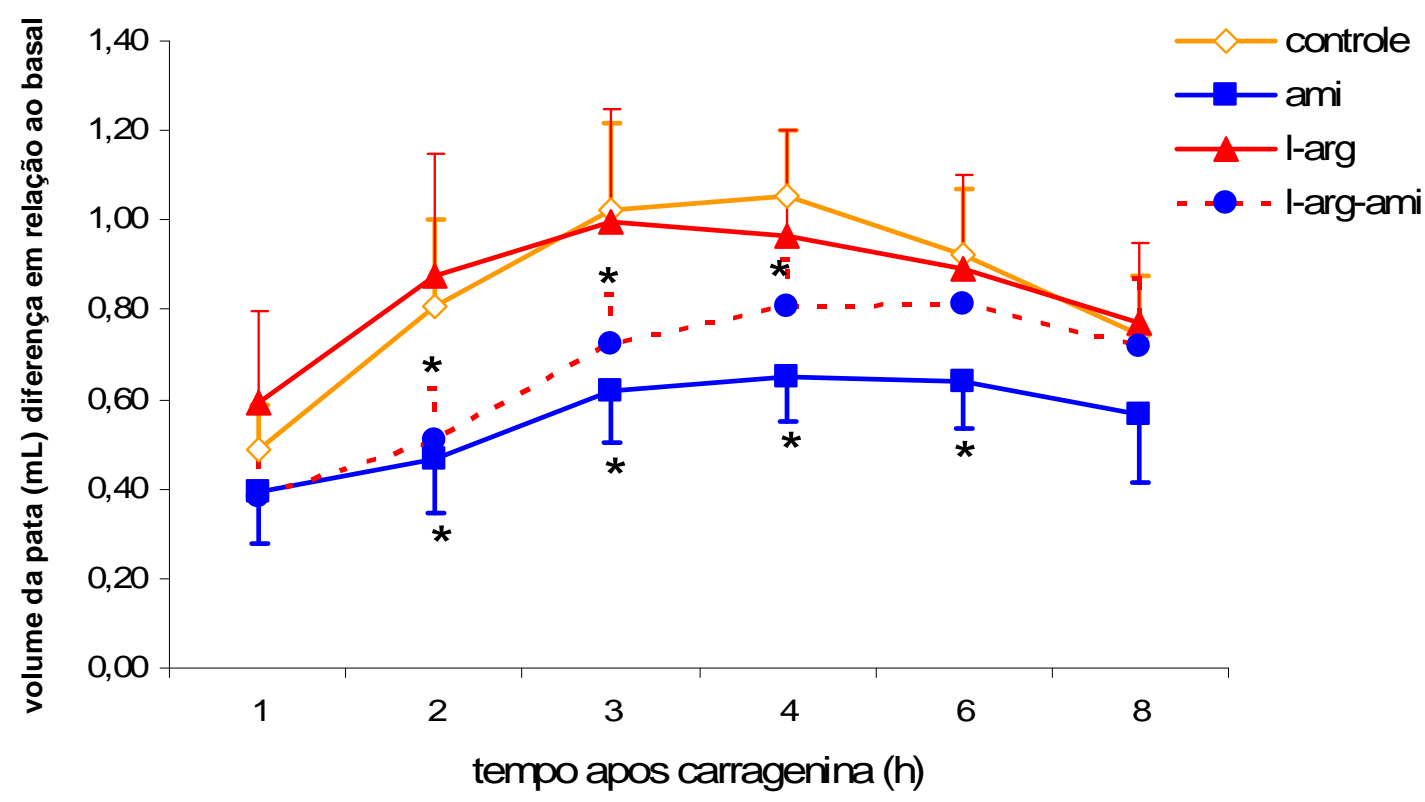

Figura 14 - Efeitos do pré-tratamento com um precursor da síntese de óxido nítrico (L-arginina) nas ações da amitriptilina administrada a cada tempo de meiavida sobre o edema de pata induzido por carragenina $1 \% \mathrm{em}$ ratos. $\mathrm{O}$ volume da pata é dado pela diferença de cada medida em relação ao volume basal $(\mathrm{mL})$. Os valores referem-se à média \pm desvio padrão. *: $p<0,05$ em relação ao grupo controle. (ANOVA de duas vias seguida pelo teste de Tukey). $n=10$ por grupo 
Experimento 13 - Avaliação da influência da administração de amitriptilina e L-NAME sobre a produção de nitratos em ratos.

Vinte e dois ratos foram divididos aleatoriamente em 4 grupos. Todos foram prétratados (1 mL/Kg - i.p.) com PBS ou L-NAME $(50 \mathrm{mg} / \mathrm{Kg}$ ). Após uma hora receberam os respectivos tratamentos: (amitriptilina (10 mg/Kg) ou $\mathrm{NaCl} 0,9 \%$ ); 3 horas após, foi feita a coleta do sangue por punção cardíaca. Cerca de 30 minutos antes da coleta, todos os animais foram adequadamente anestesiados, conforme descrito anteriormente. Segue-se o esquema de tratamento:

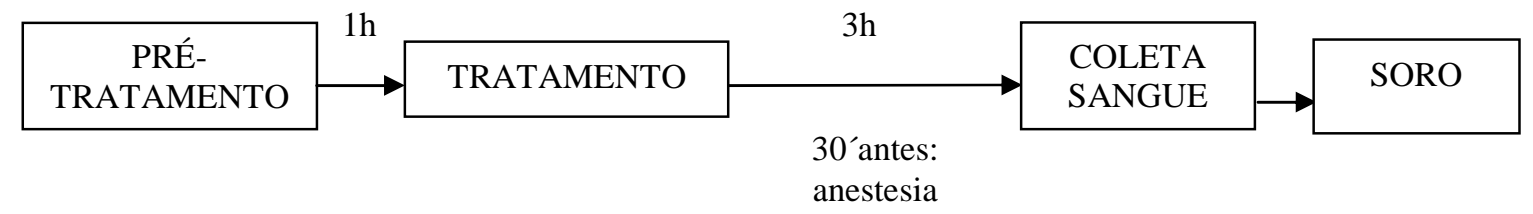

A realização da ANOVA de uma via mostrou existência de diferenças significantes entre os grupos $\left(F_{3,18}=4,99 ; p<0,02\right)$. $O$ teste pos hoc de Tukey mostrou que os animais tratados como L-NAME e amitriptilina apresentaram redução significante do total de nitratos circulantes, quando comparados aos do grupo controle $(p<0,01)$, como demonstrado na figura 15. 


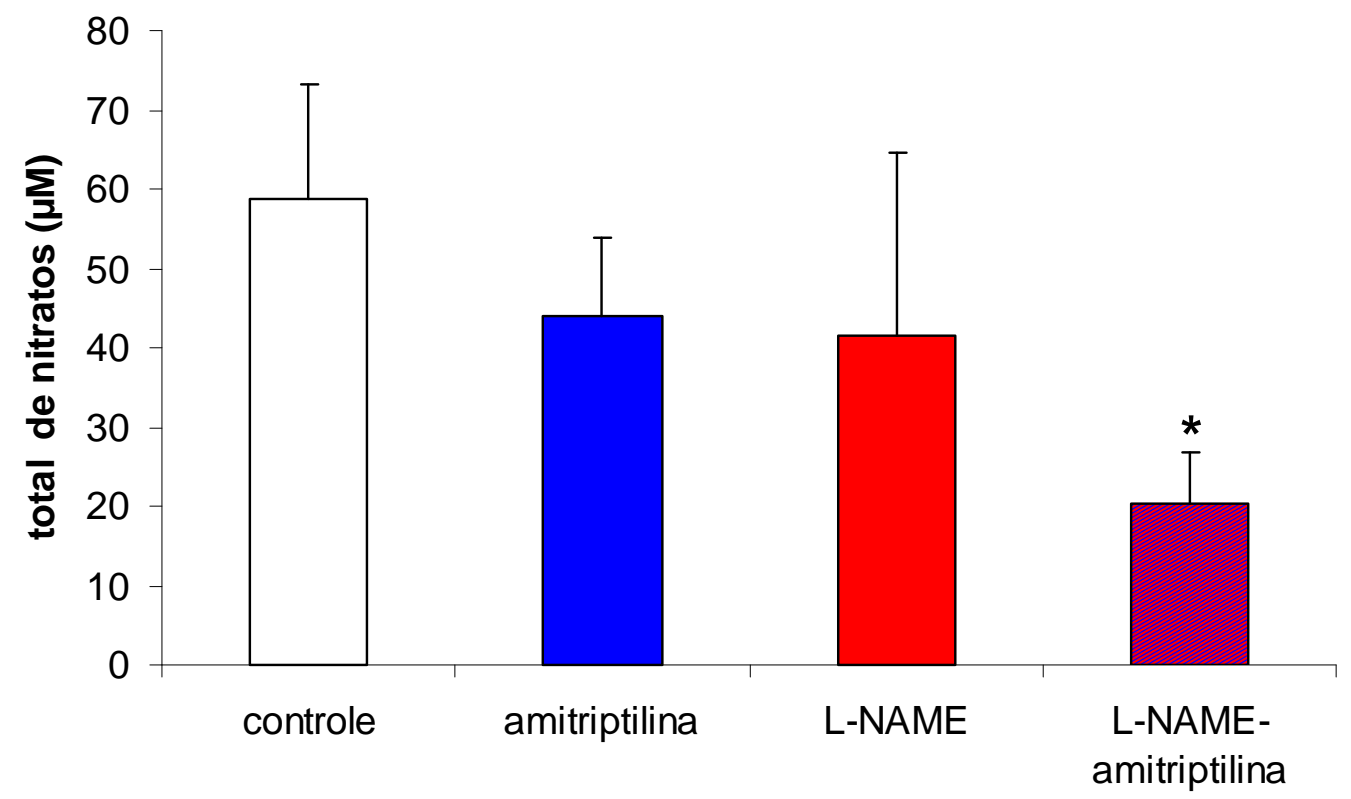

Figura 15 - Efeitos da administração de amitriptilina e L-NAME sobre a produção de nitratos em ratos. Os valores referem-se à média \pm desvio padrão. * : $p<0,05$ em relação ao grupo controle. (ANOVA de uma via seguida pelo teste de Tukey). L-NAME-amitriptilina: $n=4$; demais grupos: $n=6$

- A administração de amitriptilina a cada tempo de meia-vida demonstrou melhor efeito anti-inflamatório;

- Houve um efeito de potencialização/aditivo entre amitriptilina e L-NAME;

- O próximo passo foi avaliar este efeito anti-inflamatório em outro leito vascular, avaliando-se, também, as características do exsudato produzido. 


\section{5- AVALIAÇÃO DOS EFEITOS DA AMITRIPTILINA SOBRE O EXSUDATO INFLAMATÓRIO PERITONEAL INDUZIDO PELA CARRAGENINA}

Experimento 14 - Influência da amitriptilina sobre as características do exsudato inflamatório produzido pela injeção intraperitoneal de carragenina.

30 ratos foram distribuídos ao acaso em três grupos: naive (que receberam injeção de Ringer, $1 \mathrm{~mL} / \mathrm{kg}$ ).), Controle ( $\mathrm{NaCl} 0,9 \% ; 1 \mathrm{~mL} / \mathrm{kg}$ ), amitriptilina (10mg/kg. i.p.). Uma hora após os respectivos tratamentos, os grupos controle e amitriptilina

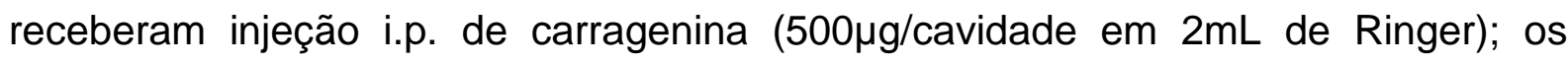
animais do grupo naive receberam neste momento nova injeção de Ringer $(2 \mathrm{~mL})$. Após 2 horas, foram avaliados o volume do exsudato e o número de leucócitos. $\mathrm{O}$ esquema abaixo ilustra o protocolo experimental:

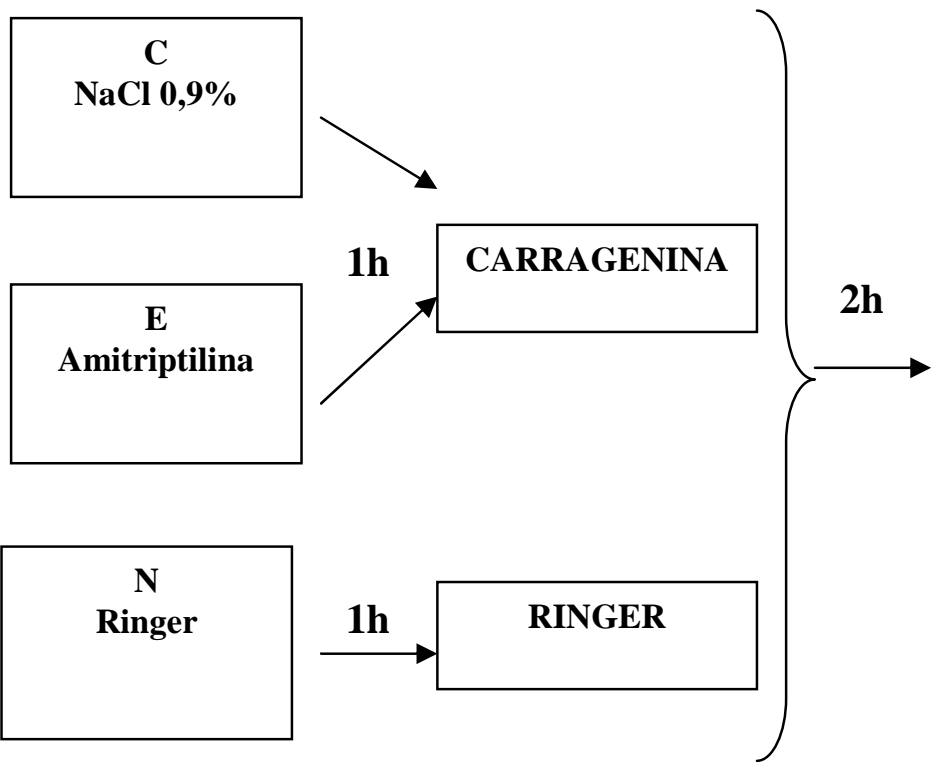

Volume do exsudato: injeção de $5 \mathrm{~mL}$ de PBS $\mathrm{cm}$ heparina 25U/mL, e coleta do líquido peritoneal com uma pipeta de Pasteur . Volume conferido em uma proveta.

Número de leucócitos: contados em câmara de Neubauer e apresentadas como número de leucócitos por $\mathrm{mL}$.

A ANOVA de uma via indicou diferenças significantes entre os grupos em relação ao número de células por $\mathrm{mL}\left(\mathrm{F}_{2,23}=9,664 ; \mathrm{p}<0,001\right)$. $O$ teste de Tukey mostrou que os grupos naive $(p<0,001)$ e amitriptilina $(p<0,05)$ apresentaram uma menor concentração de leucócitos no exsudato peritoneal quando comparados aos do grupo controle, como observado na figura 16A.

Em relação ao total de leucócitos, houve diferença significante apenas entre os grupos controle e naive $(\mathrm{Kw}=8,211 ; \mathrm{p}<0,02)$, como apresentado na figura $16 \mathrm{~B}$. 
Observou-se, ainda, que não houve diferenças significantes entre os grupos quanto ao parâmetro volume de exsudato, apesar de haver uma tendência estatística de aumento do valor no grupo amitriptilina $(\mathrm{Kw}=5,029 ; \mathrm{p}=0,081)$, como representado na figura $16 \mathrm{C}$.

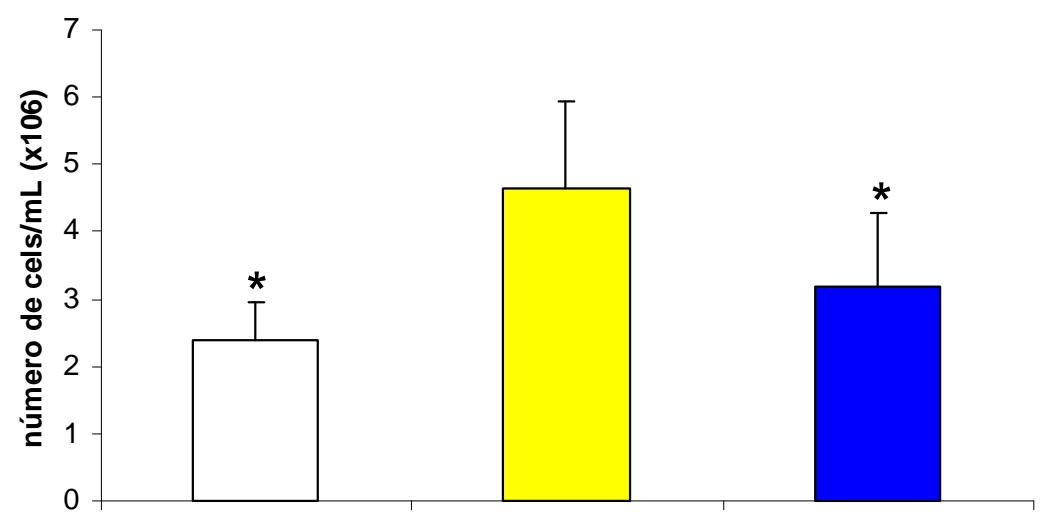

A

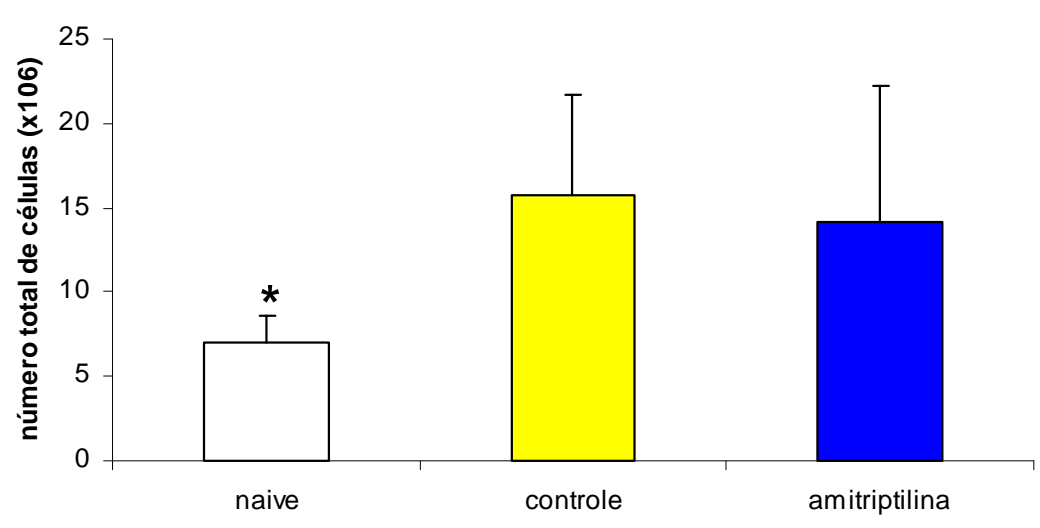

B

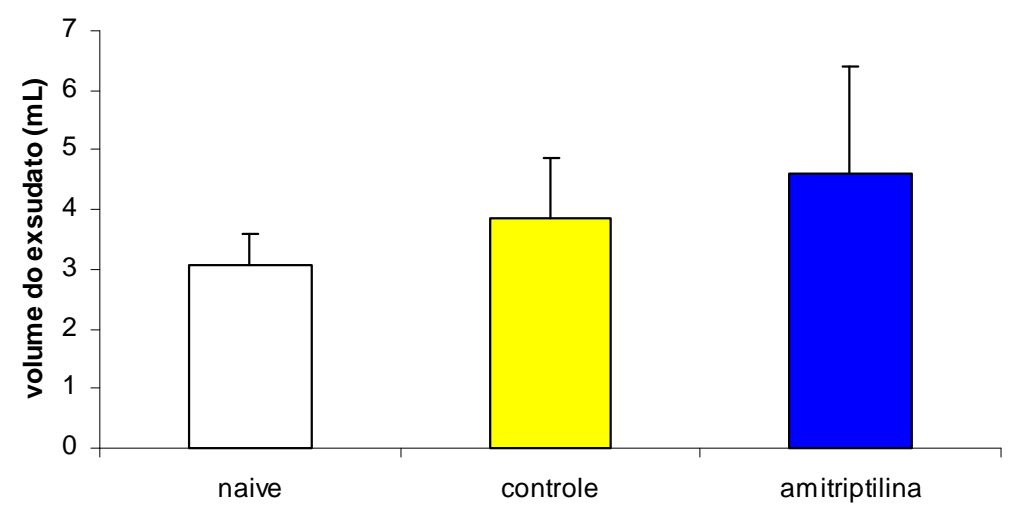

C

Figura 16 - Efeitos da amitriptilina sobre as características do exsudato inflamatório produzido pela injeção intraperitoneal de carragenina. A-número de células por $\mathrm{mL}$ (ANOVA de uma via seguida pelo teste de Tukey; naive: $\mathrm{n}=7$; controle: $n=9$, ami: $n=10$ ); B- número total de células (Teste de Kruskal-Wallis seguido pelo teste de Dunn; naive: $n=7$; controle: $n=8$, ami: $n=9$ ); C- volume do exsudato. Os valores referem-se à média \pm desvio padrão. *: $p<0,05$ em relação ao grupo controle (Teste de Kruskal-Wallis; $n=10$ por grupo) 
Experimento 15 - Influência do pré-tratamento com L-NAME nas ações da amitriptilina sobre as características do exsudato inflamatório produzido pela injeção intraperitoneal de carragenina.

40 ratos foram distribuídos ao acaso em quatro grupos: um controle e três experimentais (denominados como grupos amitriptilina, L-NAME e L-NAMEamitriptilina), como esquematizado abaixo. Os animais do grupo controle foram prétratados com o veículo de L-NAME (PBS, $1 \mathrm{~mL} / \mathrm{kg}$, i.p.) e após 1 hora receberam salina (veículo da amitriptilina, $1 \mathrm{~mL} / \mathrm{kg}$, i.p.). Os grupos experimentais foram: 1)prétratados com PBS e após 1 hora com amitriptilina $10 \mathrm{mg} / \mathrm{kg}$ (grupo amitriptilina; 2) pré-tratados com L-NAME (50 mg/kg, i.p.) e após 1 hora com salina (grupo LNAME); 3) pré-tratados com L-NAME (50 mg/kg, i.p.) e após uma hora com amitriptilina $10 \mathrm{mg} / \mathrm{kg}$ (grupo L-NAME-amitriptilina).

Depois de 1 hora da primeira administração de amitriptilina ou salina, todos os grupos receberam injeção i.p. de carragenina $(500 \mu \mathrm{g} /$ cavidade em $2 \mathrm{~mL}$ de Ringer). Após 2 horas houve nova administração de amitriptilina ou salina (perfazendo o total de 3 h do tempo de meia-vida da amitriptilina). O volume de exsudato e o número de leucócitos foram avaliados três horas após a injeção de carragenina.

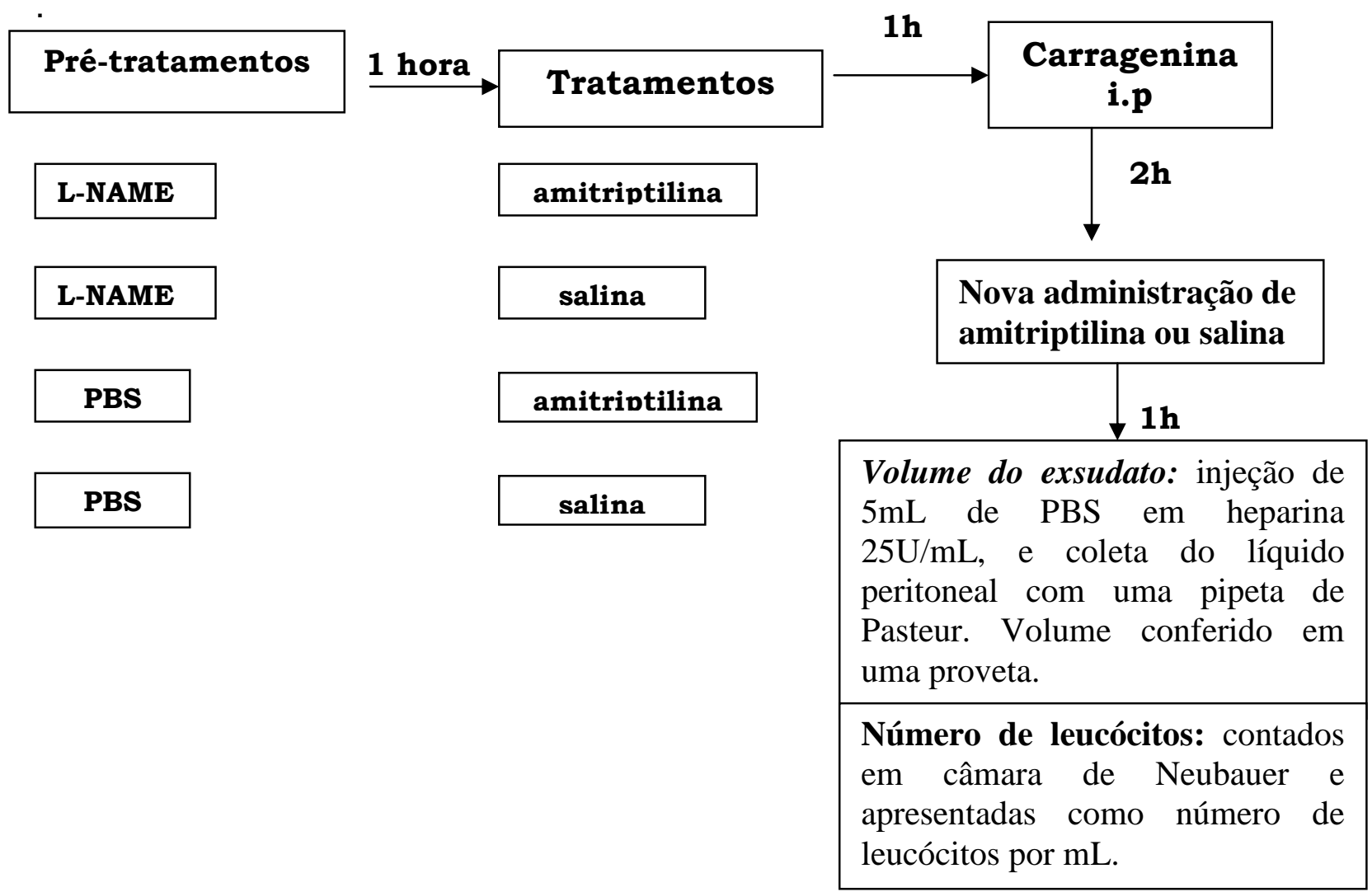


A aplicação de uma ANOVA de uma via indicou diferenças significantes entre os grupos em relação ao número de células por $m L\left(F_{3,24}=16,245 ; p<0,001\right)$. O teste de Tukey mostrou que o tratamento com amitriptilina produziu uma redução significante na concentração de leucócitos, quando comparado aos dados obtidos dos grupos controle e L-NAME $(\mathrm{p}<0,005)$. Além disso, a co-administração de L-NAME e amitriptilina também produziu redução na concentração de leucócitos no exsudato peritoneal em relação aos grupos controle e L-NAME $(p<0,001)$, conforme demonstrado na figura 17A.

Em relação ao número total de leucócitos, representado na figura 17B, a aplicação de ANOVA de uma via mostrou diferenças significantes entre os grupos $\left(F_{3,24}=13,3\right.$; $\mathrm{p}<0,001)$. O teste de Tukey mostrou que o grupo LNAME-ami diferiu significantemente do grupo controle $(p<0,001)$. Além disso, os animais tratados com amitriptilina $(p<0,01)$ ou L-NAME-ami $(p<0,001)$ apresentaram redução no total de leucócitos do exsudato quando comparados ao grupo tratado apenas com L-NAME. Não houve diferença significante entre os grupos no parâmetro volume de exsudato $\left(F_{3,24}=1,301 ; p>0,05\right)$, conforme representado na figura $17 \mathrm{C}$. 

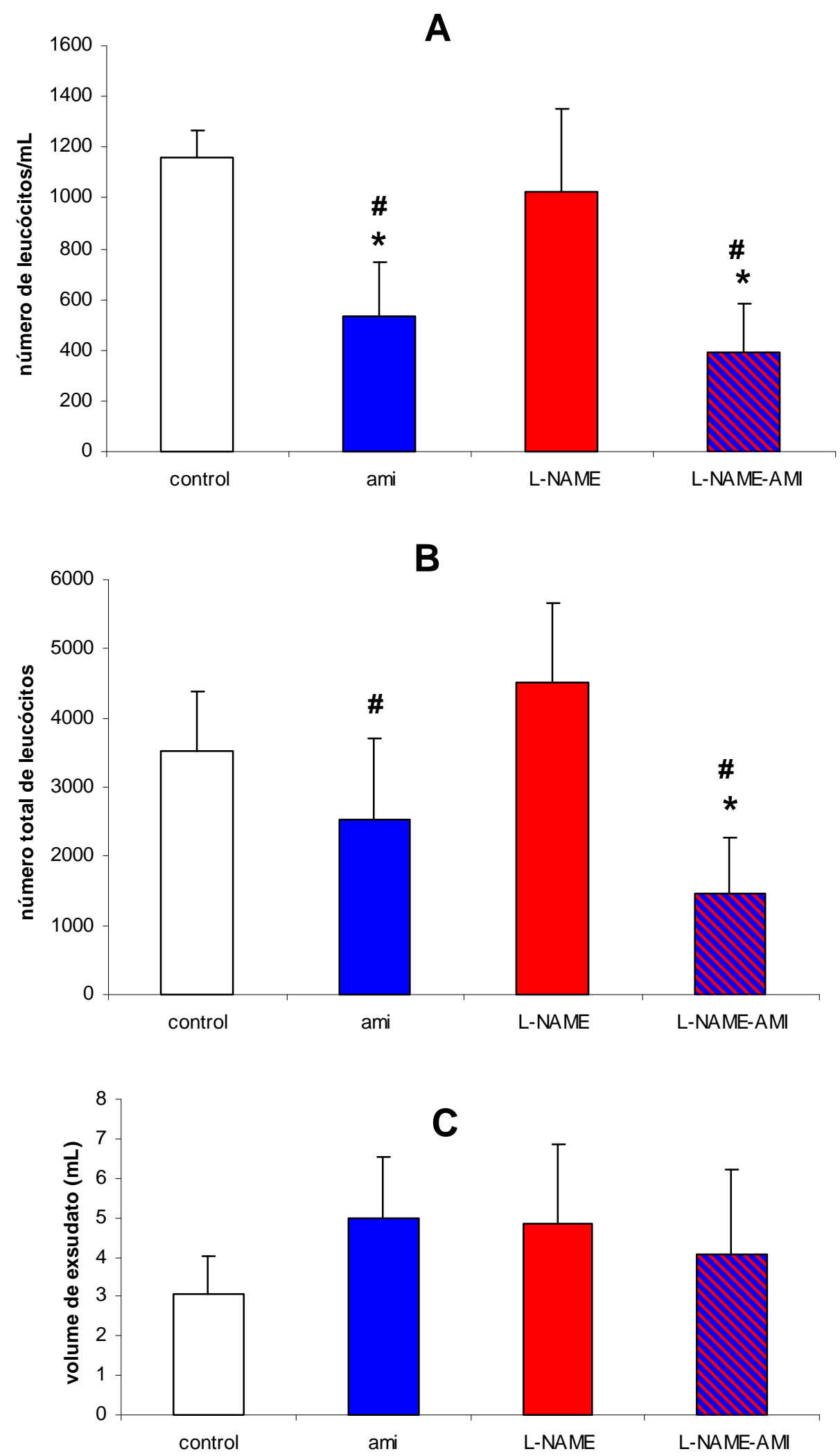

Figura 17 - Efeito do pré-tratamento com L-NAME nas ações da amitriptilina sobre as características do exsudato inflamatório produzido pela injeção intraperitoneal de carragenina. A-número de células por $\mathrm{mL}$; $\mathrm{B}$ - número total de células; C- volume do exsudato. Os valores referem-se à média \pm desvio padrão. *: $p<0,05$ em relação ao grupo controle; \# $p<0,05$ em relação ao grupo L-NAME (ANOVA de uma via seguida pelo teste de Tukey; controle: $\mathrm{n}=5$, ami: $\mathrm{n}=6$, L-NAME: $\mathrm{n}=9$, L-NAME-ami: $\mathrm{n}=8$ ) 


\section{6- EFEITOS DA AMITRIPTILINA SOBRE O COMPORTAMENTO DE LEUCÓCITOS: AVALIAÇÃO POR MICROSCOPIA INTRAVITAL.}

Experimento 16 - Avaliação do rolling, adesão e velocidade de leucócitos em condições não-inflamatórias.

Ratos foram distribuídos ao acaso em três grupos: naive, controle ( $\mathrm{NaCl}$ 0,9\%; $1 \mathrm{~mL} / \mathrm{kg}$ ), amitriptilina (10mg/kg. s.c.). Após 3 horas eles foram preparados para avaliação dos parâmetros de rolling, adesão e velocidade de leucócitos em vênulas pós-capilares de 15 a $30 \mu \mathrm{m}$.

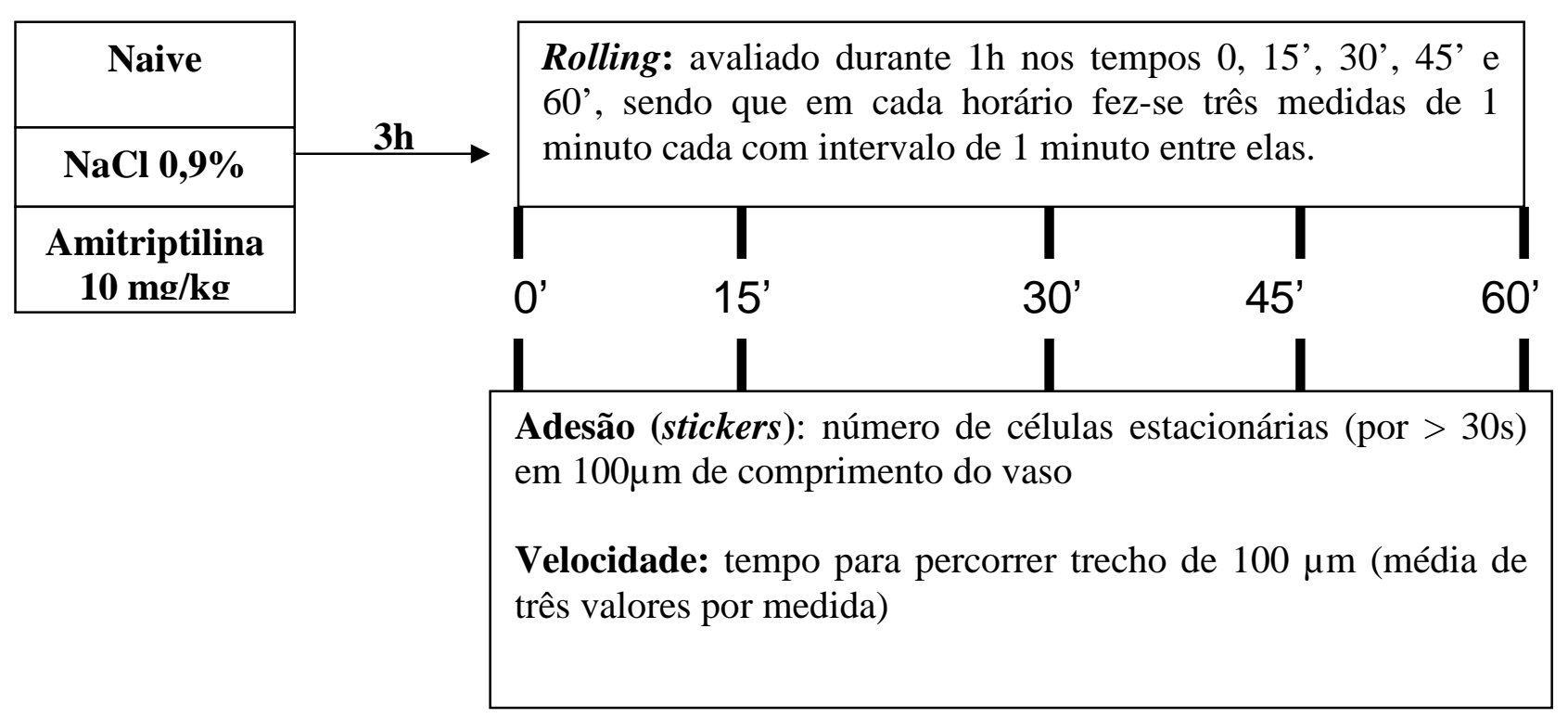


A aplicação de ANOVA de uma via não indicou presença de diferenças significantes entre os grupos em relação ao rolling de leucócitos nos tempos zero $\left(F_{2,16}=1,844\right.$; $p>0,05), 30\left(F_{2,16}=2,45 ; p>0,05\right), 45\left(F_{2,16}=1,029 ; p>0,05\right)$ e 60 minutos $\left(F_{2,16}=1,118\right.$; p >0,05) após o início da avaliação. No tempo 15 minutos, no entanto, o teste de Tukey apontou que o grupo amitriptilina apresentou um maior número de leucócitos em rolling, quando comparado ao grupo naive $\left(F_{2,16}=6,081 ; p<0,01\right)$, como observado na figura $18 \mathrm{~A}$.

Não se observaram diferenças significantes entre os grupos quanto ao parâmetro adesão de leucócitos ( $p>0,05)$ nos tempos zero $\left(F_{2,13}=0,578\right), 15\left(F_{2,13}=0,36\right), 30$ $\left(F_{2,13}=0,662\right), 45(\mathrm{Kw}=0,315)$ e 60 minutos $\left(F_{2,13}=0,0178\right)$ após o início da avaliação, conforme demonstrado na figura 18B.

Como se pode observar na análise da figura 18C, não se encontram diferenças significantes entre os tratamentos com relação ao tempo necessário para os leucócitos percorrerem 100 $\mu \mathrm{m}$ de vênula (tempos zero: $F_{2,17}=1,932 ; 15: K w=0,822$; 30: $K w=1,839 ; 45: F_{2,17}=1,17$ e 60 minutos: $\left.F_{2,17}=0,562 ; p>0,05\right)$. 

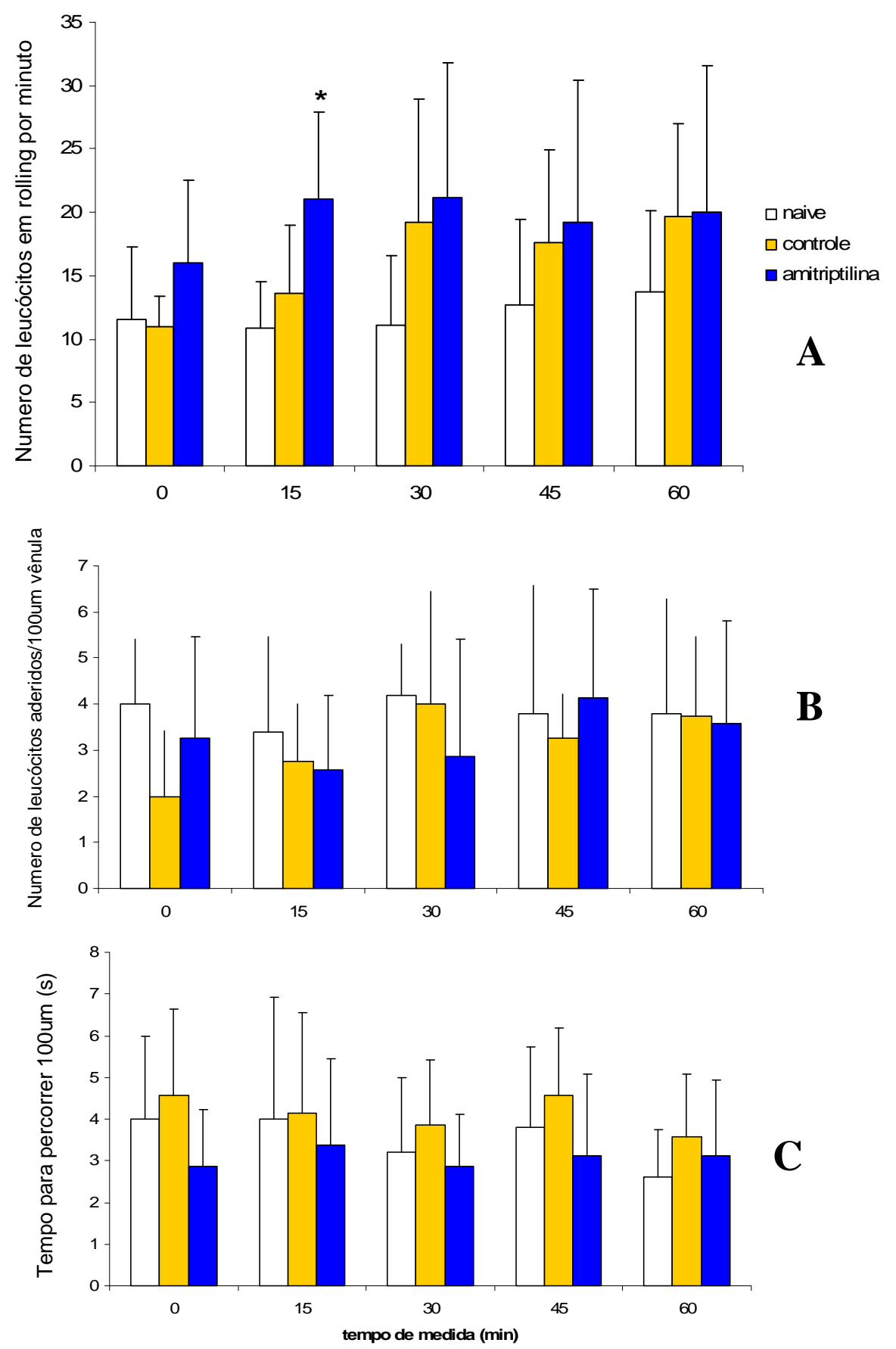

Figura 18 - Efeitos da amitriptilina sobre o comportamento de leucócitos em condição não-inflamatória. A-número de leucócitos em rolling por minuto; B- número de leucócitos aderidos em $100 \mu \mathrm{m}$ de vênula; C- tempo para percorrer 100 $\mu \mathrm{m}$ de vênula por minuto. Os valores referem-se à média \pm desvio padrão. * $p<0,05$ em relação ao grupo naive. (A e B: ANOVA de uma via seguida pelo teste de Tukey; C: Teste de Kruskal-Wallis; naive: $n=7$, controle e amitriptilina: $n=6$ cada) 
Experimento 17 - Avaliação do rolling, adesão, velocidade e transmigração de leucócitos em condições inflamatórias.

Ratos machos foram distribuídos ao acaso em dois grupos: controle $(\mathrm{NaCl} 0,9 \%$; $1 \mathrm{~mL} / \mathrm{kg}$ ) ou amitriptilina (10mg/kg. s.c.). Após 1 hora eles receberam injeção intraperitoneal de carragenina $(500 \mu \mathrm{g} / 2 \mathrm{~mL}$ de Ringer); depois de 2 horas os animais foram preparados para avaliação dos parâmetros de rolling, adesão, velocidade e transmigração de leucócitos em vênulas pós-capilares de 15 a 30 m.

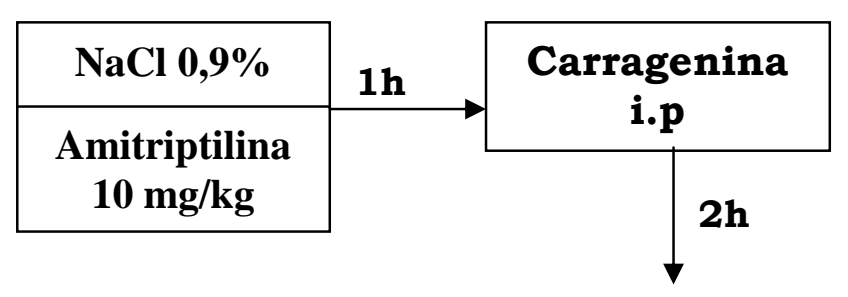

Transmigrados: total de leucócitos localizados em $2000 \mathrm{~m}^{2}$ de área exterior à vênula avaliada, medidos nos tempos zero e 60 minutos.

(

0

15

30

$45^{\prime}$

60

1

Rolling: avaliado durante $1 \mathrm{~h}$ nos tempos $0,15^{\prime}, 30^{\prime}, 45^{\prime}$ e $60^{\prime}$, sendo que em cada horário fez-se três medidas de 1 minuto casa com intervalo de 1 minuto entre elas.

Adesão (stickers): número de células estacionárias (por > 30s) em $100 \mu \mathrm{m}$ de comprimento do vaso

Velocidade: tempo para percorrer trecho de $100 \mu \mathrm{m}$ (média de três valores por medida) 
Em relação ao rolling, os dois grupos diferiram entre si nos tempos zero $(t=2,406$; $p<0,05), 15(t=2,442 ; p<0,05), 30(t=2,751 ; p<0,02), 45(t=3,182 ; p<0,01)$ e 60 minutos $(t=2,567 ; p<0,05)$ de avaliação (controle $n=9$ e amitriptlina $n=8$ ), conforme ilustra a figura 19A. Os animais que receberam amitriptilina também apresentaram diminuição na adesão de leucócitos nos tempos 30 ( $t=1,903$; tendência: $p=0,078)$, $45(t=2,483 ; p<0,05)$ e 60 minutos $(t=2,616 ; p<0,05$; controle $n=9$ e amitriptlina $n=7)$ e também no número de células transmigradas ( $n=9$ por grupo) após 1 hora de avaliação por microscopia intravital $(t=2,864 ; \mathrm{p}<0,02)$ como pode ser visto nas figuras 19B e 19C respectivamente. Não houve alteração significante no tempo necessário para os leucócitos percorrerem $100 \mathrm{~m}$ de vênula, $(p>0,05$; controle $n=11$ e amitriptilina $n=9$ ), conforme representado na figura 19D. No entanto, o grupo tratado com amitriptilina mostrou uma tendência de redução neste tempo, nos intervalos 30 (teste de Mann-Whitney; $T=72,0 ; p=0,09)$ e 60 minutos $(t=2,098$; $p=0,05)$, o que sugere possíveis alterações em parâmetros hemodinâmicos. 


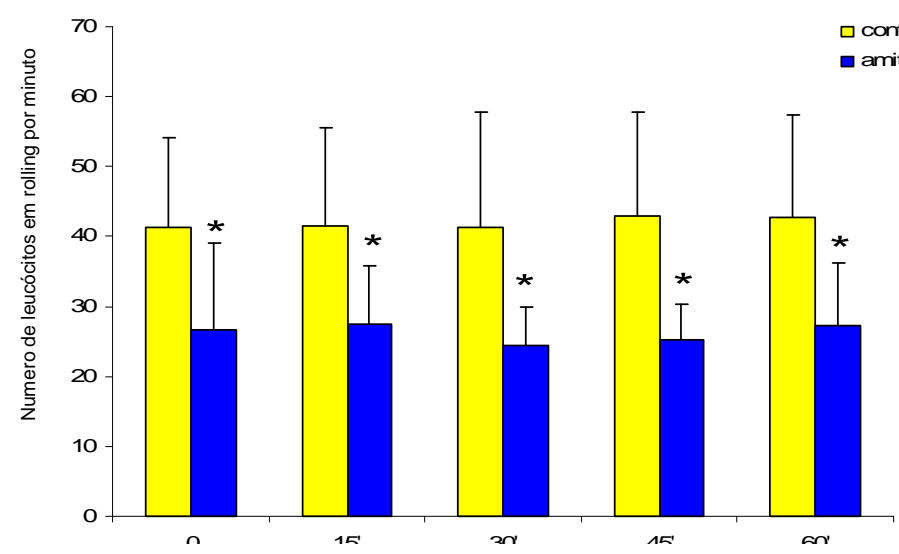

A

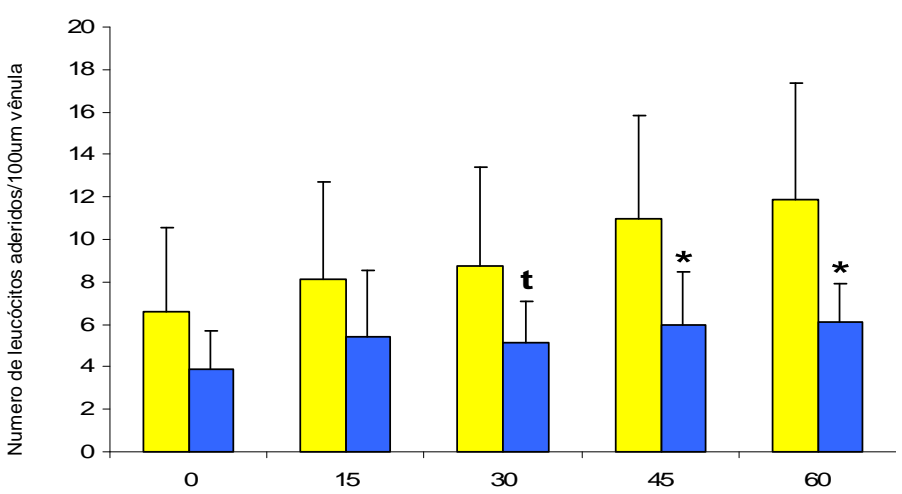

B

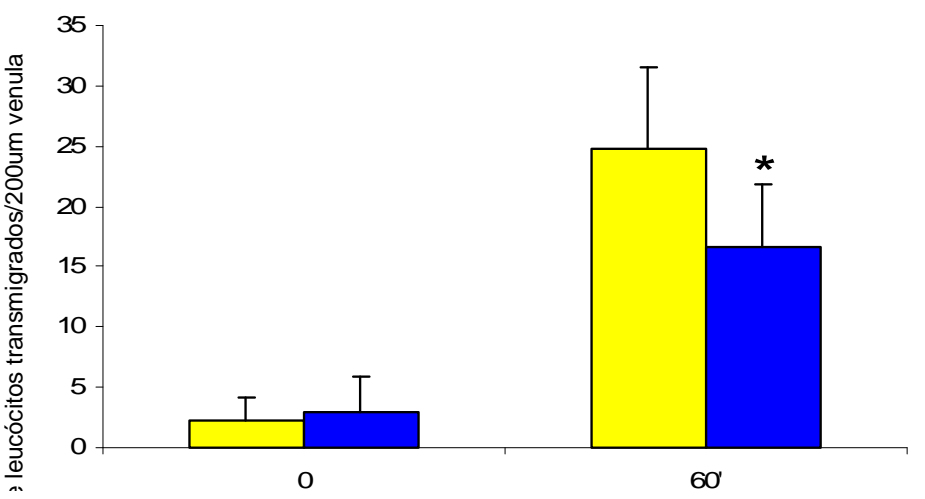

$\mathbf{C}$

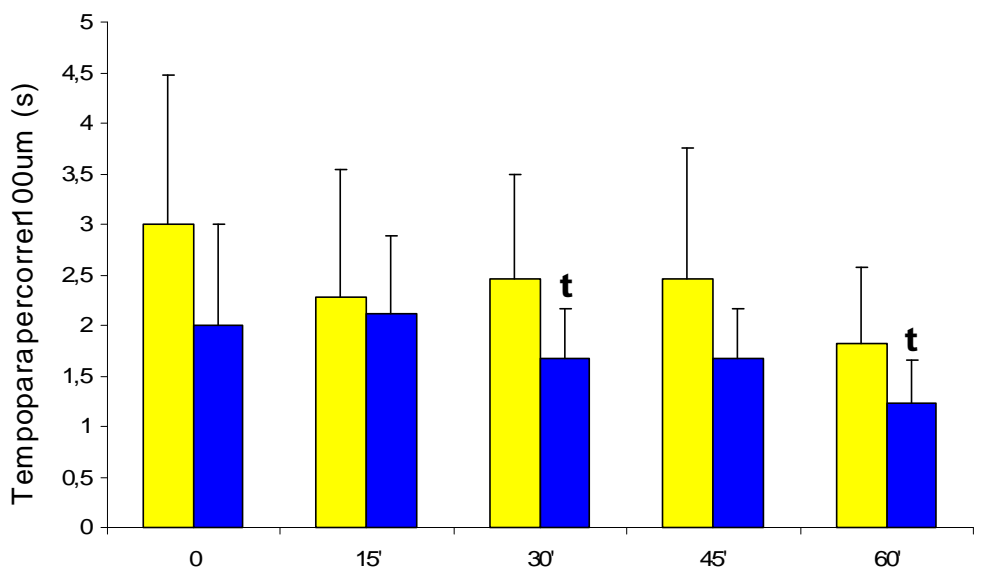

D

Figura 19 - Efeitos da amitriptilina sobre o comportamento de leucócitos em condição inflamatória. A-número de leucócitos em rolling por minuto; B- número de leucócitos aderidos em $100 \mu \mathrm{m}$ de vênula; C-número de leucócitos transmigrados em $200 \mu \mathrm{m}$ de área; D- tempo para percorrer $100 \mu \mathrm{m}$ de vênula por minuto. Os valores referem-se à média \pm desvio padrão. * $p<0,05$ em relação ao grupo controle; $t=$ tendência $(p<0,1)$ comparada ao grupo controle. (teste $t$, exceto em $D$ 30', onde utilizou-se o teste de Mann-Whitney; $A$ : controle: $n=9$, ami: $n=8$; B: controle: $n=9$, ami: $n=7$; C: $n=9$ /grupo; D: controle: $n=11$, ami: $n=9$ ) 
Tendo em vista a capacidade da amitriptilina em alterar o comportamento de leucócitos em uma condição inflamatória, o próximo passo foi avaliar a influência da administração de amitriptilina sobre a expressão de moléculas de adesão.

\section{7- EFEITOS DA AMITRIPTILINA SOBRE A EXPRESSÃO DE MOLÉCULAS DE} ADESÃO: AVALIAÇÃO POR CITOMETRIA DE FLUXO.

Experimento 18 - Influência do tratamento com amitriptilina na expressão de Lselectina, MAC-1, ICAM-1 e PECAM-1 em leucócitos de sangue periférico.

Ratos foram agrupados ao acaso e pré-tratados com L-NAME ou PBS $(50 \mathrm{mg} / \mathrm{kg}$, i.p.); depois de $1 \mathrm{~h}$ os animais receberam tratamento com amitriptilina $10 \mathrm{mg} / \mathrm{kg}$, i.p. ou $\mathrm{NaCl} 0,9 \%$ ( $1 \mathrm{~mL} / \mathrm{kg}$, administrados novamente após $3 \mathrm{~h})$. Depois de $1 \mathrm{~h}$ os ratos receberam carragenina i.p. $(500 \mu \mathrm{g} / 2 \mathrm{~mL} / \mathrm{animal})$. Após três horas os animais foram anestesiados e o sangue coletado por punção cardíaca para análise da expressão de moléculas de adesão por citometria de fluxo, conforme metodologia descrita anteriormente. Segue abaixo o protocolo esquemático:
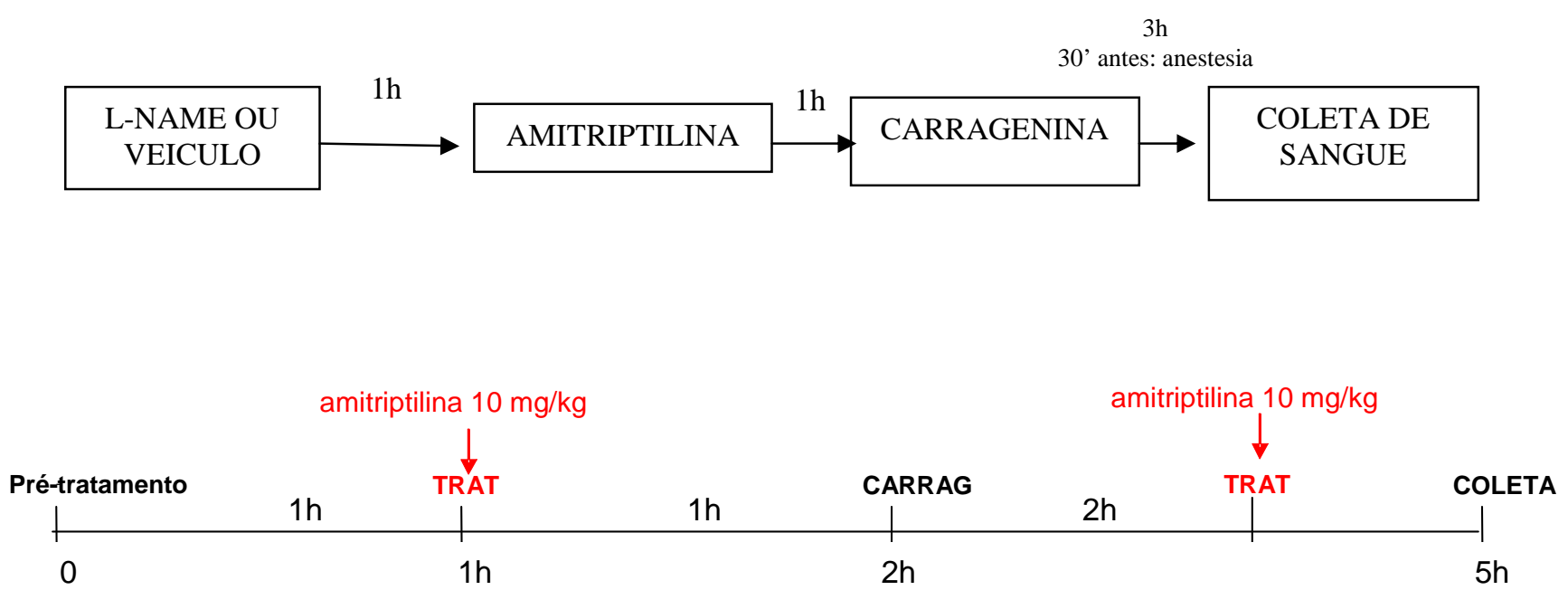
$\mathrm{Na}$ tabela 6 encontram-se representados os valores de intensidade média de fluorescência das moléculas de adesão avaliadas. A aplicação da ANOVA de uma via não mostrou diferenças significativas entre os grupos com relação à expressão de L-selectina em neutrófilos $\left(F_{3,26}=2,017 ; p>0,05\right)$ ou monócitos $\left(F_{3,25}=0,681\right.$; $p>0,05)$, nem na expressão de PECAM-1 por neutrófilos $\left(F_{3,25}=0,6329\right)$ ou monócitos $\left(F_{3,26}=0,3349 ; \quad p>0,05\right)$. Também não se observaram diferenças entre as intensidades médias de fluorescência para expressão de MAC-1 nem de ICAM-1 por leucócitos. 
Tabela 6 - Expressão de moléculas de adesão em leucócitos do sangue periférico. Dados representam intensidade média de fluorescência (média geométrica), obtida pela análise por citometria de fluxo. Os valores referem-se à média \pm desvio padrão. (ANOVA de uma via não encontrou diferenças entre os grupos, $p>0,05$ )

\begin{tabular}{|c|c|c|c|c|c|}
\hline & & CONTROLE & AMITRIPTILINA & L-NAME & $\begin{array}{l}\text { L-NAME- } \\
\text { AMITRIPTILINA }\end{array}$ \\
\hline \multirow[t]{2}{*}{$\begin{array}{l}\text { L- } \\
\text { selectina }\end{array}$} & Neutrófilos & $\begin{array}{c}15,97 \pm 2,68 \\
(n=8)\end{array}$ & $\begin{array}{c}17,43 \pm 3,76 \\
(n=8)\end{array}$ & $\begin{array}{c}14,12 \pm 1,32 \\
(n=7)\end{array}$ & $\begin{array}{c}15,60 \pm 1,79 \\
(n=7)\end{array}$ \\
\hline & Monócitos & $\begin{array}{c}37,68 \pm 7,14 \\
(n=7)\end{array}$ & $\begin{array}{c}44,87 \pm 15,42 \\
(n=8)\end{array}$ & $\begin{array}{c}37,60 \pm 6,72 \\
(n=7)\end{array}$ & $\begin{array}{c}39,76 \pm 13,11 \\
(n=7)\end{array}$ \\
\hline \multirow[t]{2}{*}{ MAC-1 } & Neutrófilos & $\begin{array}{c}132,79 \pm 40,06 \\
(n=5)\end{array}$ & $\begin{array}{c}126,75 \pm 62,19 \\
(n=5)\end{array}$ & $\begin{array}{c}154,32 \pm 31,54 \\
(n=5)\end{array}$ & $\begin{array}{c}164,40 \pm 43,19 \\
(n=5)\end{array}$ \\
\hline & Monócitos & $\begin{array}{c}43,56 \pm 9,80 \\
(n=5)\end{array}$ & $\begin{array}{c}48,73 \pm 5,26 \\
(n=5)\end{array}$ & $\begin{array}{c}45,59 \pm 4,33 \\
(n=5)\end{array}$ & $\begin{array}{c}50,69 \pm 5,12 \\
(n=5)\end{array}$ \\
\hline \multirow[t]{2}{*}{ ICAM-1 } & Neutrófilos & $\begin{array}{c}19,64 \pm 0,97 \\
(n=5)\end{array}$ & $\begin{array}{c}21,71 \pm 4,40 \\
(n=5)\end{array}$ & $\begin{array}{c}21,626 \pm 2,66 \\
(n=5)\end{array}$ & $\begin{array}{c}21,04 \pm 3,17 \\
(n=5)\end{array}$ \\
\hline & Monócitos & $\begin{array}{c}50,42 \pm 7,06 \\
(n=5)\end{array}$ & $\begin{array}{c}48,742 \pm 6,83 \\
(n=5)\end{array}$ & $\begin{array}{c}49,7625 \pm 12,97 \\
(n=4)\end{array}$ & $\begin{array}{c}50,445 \pm 9,08 \\
(n=4)\end{array}$ \\
\hline \multirow[t]{2}{*}{ PECAM-1 } & Neutrófilos & $\begin{array}{c}21,21 \pm 2,16 \\
\quad(n=8)\end{array}$ & $\begin{array}{c}22,10 \pm 2,16 \\
(n=8)\end{array}$ & $\begin{array}{c}20,40 \pm 3,08 \\
(n=7)\end{array}$ & $\begin{array}{c}22,67 \pm 3,39 \\
(n=6)\end{array}$ \\
\hline & Monócitos & $\begin{array}{c}25,17 \pm 8,76 \\
(n=6)\end{array}$ & $\begin{array}{c}34,13 \pm 15,86 \\
(n=8)\end{array}$ & $\begin{array}{c}34,78 \pm 12,27 \\
(n=6)\end{array}$ & $\begin{array}{c}21,46 \pm 3,54 \\
(n=6)\end{array}$ \\
\hline
\end{tabular}




\section{8- EFEITOS DA AMITRIPTILINA SOBRE A CONCENTRAÇÃO DE CITOCINAS PRÓ-INFLAMATÓRIAS NO SORO DE RATOS}

Experimento 19 - Influência do tratamento com amitriptilina na concentração de IL1 beta e TNF-alfa no soro de ratos.

Ratos foram distribuídos ao acaso e pré-tratados com L-NAME ou PBS $(50 \mathrm{mg} / \mathrm{kg}$, i.p.); depois de $1 \mathrm{~h}$ os animais receberam tratamento com amitriptilina $10 \mathrm{mg} / \mathrm{kg}$, i.p. ou $\mathrm{NaCl}$ 0,9\% (1 $\mathrm{mL} / \mathrm{kg}$, administrados novamente após 3h). Após $1 \mathrm{~h}$, os ratos receberam carragenina i.p. (500 $\mathrm{g} / 2 \mathrm{~mL} /$ animal). Três horas após, todos os animais foram anestesiados e o sangue coletado por punção cardíaca para posterior separação do soro por centrifugação (4000 rpm, 5minutos). O soro obtido foi congelado em eppendorfs a $-80^{\circ} \mathrm{C}$, até o momento da análise da concentração das citocinas, por ELISA, conforme descrito anteriormente. Segue abaixo o protocolo esquemático:

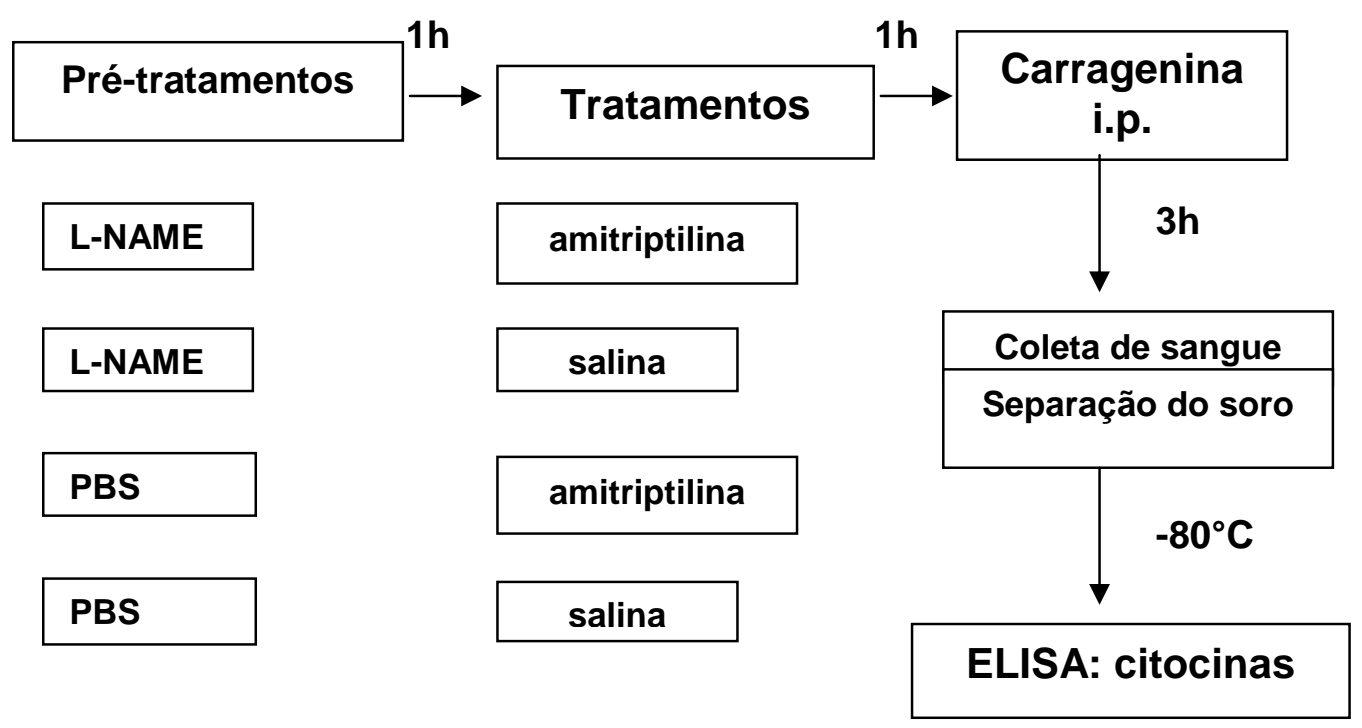


A aplicação da ANOVA de uma via indicou diferenças significantes entre os grupos em relação às concentrações séricas de IL-1beta $\left(F_{3,23}=11,714 ; p<0,001\right)$ e de TNF-alfa $\left(F_{3,23}=6,722 ; p<0,005\right)$, conforme representado nas figuras $20 \mathrm{~A}$ e $20 \mathrm{~B}$, respectivamente. $O$ pós teste de Tukey mostrou que os três grupos experimentais tratados com amitriptilina $(n=7)$, L-NAME $(n=6)$ e L-NAME-amitriptilina $(n=7)$ apresentaram redução estatisticamente significante na concentração de IL-1beta $(p<0,001)$ no soro de ratos em condição inflamatória em comparação ao grupo controle $(n=7)$. O mesmo foi observado em relação aos níveis de TNF-alfa, onde animais tratados com amitriptilina $(p<0,02 ; n=8)$, L-NAME $(p<0,01 ; n=8)$ e L-NAMEamitriptilina $(p<0,005 ; n=7)$ apresentaram uma redução significante quando comparados aos animais do grupo controle $(n=7)$. 

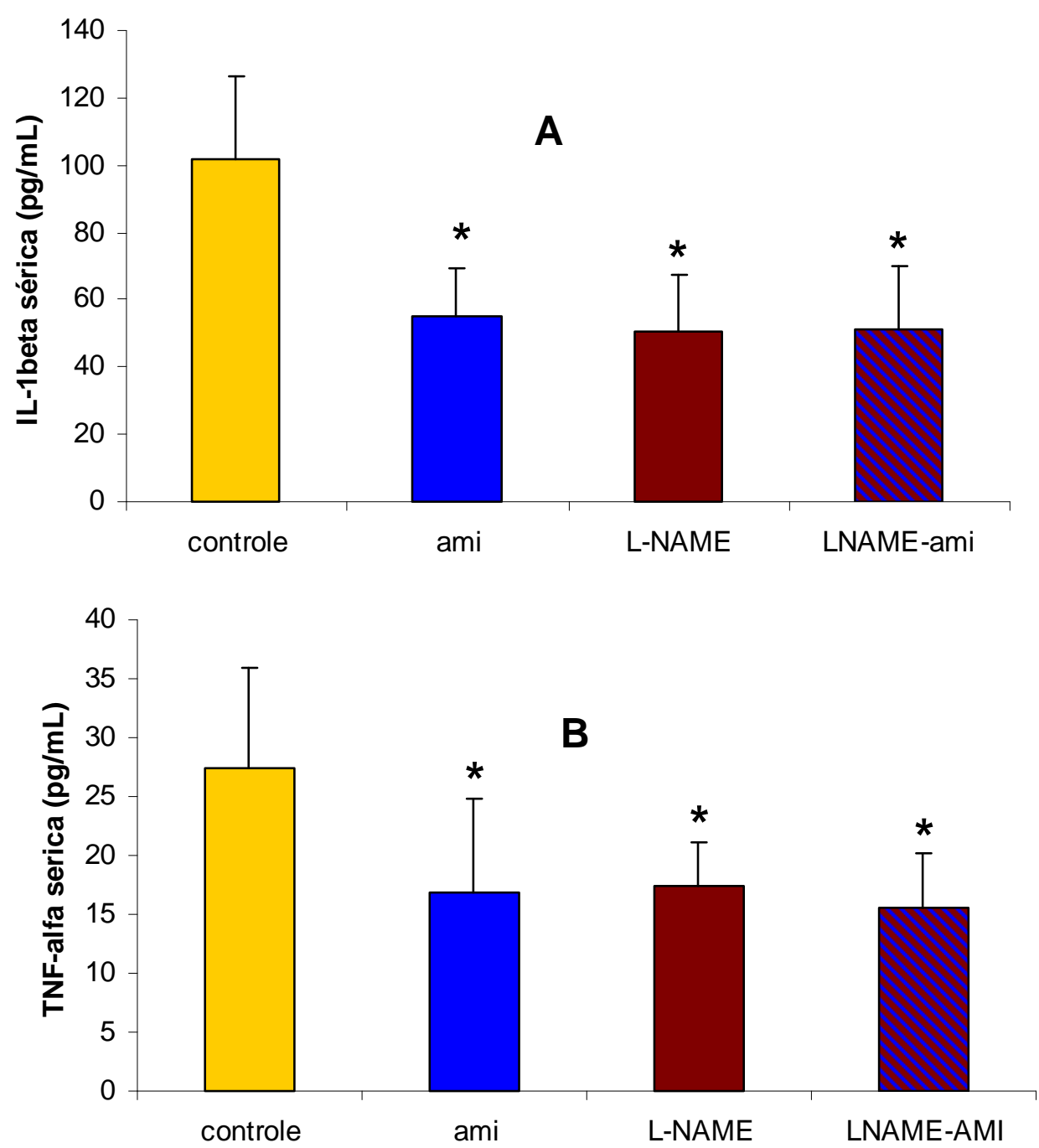

Figura 20 - Efeitos da amitriptilina sobre a concentração de (A) IL-1beta e (B) TNFalfa no soro de ratos em condição inflamatória. Os valores referem-se à média \pm desvio padrão. ${ }^{*} \mathrm{p}<0,05$ em relação ao grupo controle $(\mathrm{pg} / \mathrm{mL})$. (ANOVA de uma via seguida pelo teste de Tukey; A: controle, ami e LNAME-ami: $n=7$, L-NAME: $n=6$; B: controle e L-NAME-ami: $n=7$, ami e LNAME: $n=8$ ) Efeitos da amitriptilina sobre a concentração de (A) IL-1beta e (B) TNF-alfa no soro de ratos em condição inflamatória. Os valores referemse à média \pm desvio padrão. * $p<0,05$ em relação ao grupo controle $(\mathrm{pg} / \mathrm{mL})$. (ANOVA de uma via seguida pelo teste de Tukey; A: controle, ami e LNAME-ami: $n=7$, L-NAME: $n=6$; B: controle e L-NAME-ami: $n=7$, ami e LNAME: $\mathrm{n}=8$ ) 


\section{6- Discussão}

O objetivo primordial deste trabalho foi avaliar os efeitos da amitriptilina sobre a resposta inflamatória aguda e investigar alguns dos possíveis mecanismos envolvidos nestes efeitos. No entanto, para podermos discutir os presentes achados, é fundamental que se compreenda a complexidade dos elementos deste estudo. A amitriptilina é um fármaco com múltiplos mecanismos de ação (MORRISSEY, 2009); além de inibir a recaptação de noradrenalina e serotonina, é um potente antioxidante, promove inibição da liberação de citocinas pró-inflamatórias e de células NK, é antagonista de receptores alfa-1 e H1, além de ser antimuscarínico. Em estudos in vitro e in vivo, a amitriptilina tem demonstrado, além da ação como antidepressivo e analgésico, um importante efeito anti-inflamatório. Os mecanismos envolvidos no efeito anti-inflamatório da amitriptilina agora investigado apóiam o perfil pleiotrópico de ação deste fámaco. Assim, há que ressaltar e já de início, que aos mecanismos investigados no presente trabalho, outros podem vir a se somar, relacionados ou não às suas ações analgésica e antidepressiva ou, ainda, envolver aspectos vasculares.

A inflamação, por outro lado, também é um evento complexo que possui um papel crucial na fisiologia dos mamíferos. Sabe-se que o objetivo primário de uma resposta inflamatória é a remoção do agente agressor, visando restaurar a funcionalidade do tecido. Isto pode ser resolvido de forma aguda ou, de forma mais agressiva para o tecido, em um processo crônico. No entanto, apesar dos mecanismos da inflamação induzida por infecções serem bem conhecidos, os estados inflamatórios crônicos sistêmicos, tais como obesidade, doenças cardiovasculares, diabetes e, por que não dizer, até mesmo e segundo alguns autores, a depressão, são pouco conhecidos. Neste contexto, o fenômeno inflamatório passa a ser discutido não mais do ponto de vista clássico, mas como parte de um amplo espectro. Ou seja, os estímulos que levam à condição inflamatória iriam de um distúrbio leve no funcionamento dos tecidos (estresse tecidual) até a uma injúria de maiores proporções, caracterizada pelos cinco sinais cardinais: rubor, calor, dor, edema e, por fim, perda de função. O estresse tecidual, por sua vez, induziria um fenômeno conhecido como parainflamação, o qual auxiliaria o tecido a se adaptar às condições nocivas, restaurando sua 
funcionalidade. Neste sentido, a perda de controle destas parainflamações poderia ser a responsável pelos estados inflamatórios crônicos associados às muitas doenças modernas humanas, tais como a aterosclerose (MEDZHITOV, 2008).

Sendo assim, diante da complexidade dos elementos do presente estudo amitriptilina e inflamação - devemos analisar os resultados obtidos como fossem elementos de um conjunto maior, ainda não completamente elucidado.

Usando-se o modelo do edema de pata induzido pela carragenina observamos que o tratamento com amitriptilina produziu um efeito anti-inflamatório, corroborando, neste sentido, os dados da literatura (ABDEL-SALAM et al, 2003; KUBERA et al, 2000; SACERDOTE et al, 1994; SACERDOTE et al, 1997). No entanto, quando a amitriptilina foi administrada em dose única ou após tratamento prolongado ( 7,14 ou 28 dias) não se encontrou redução significante no edema de pata além da quarta hora avaliada, para a maioria dos experimentos realizados.

De acordo com artigos de Baumann et al (1984) e Coudore et al (1996), o tempo de meia-vida de eliminação da amitriptilina em ratos varia em torno de 3,25 horas, enquanto que em humanos é referido como variando ao redor de 24 horas. Em um dos experimentos citado por eles, o efeito antinociceptivo da clomipramina só pôde ser observado quando a mesma foi administrada a cada tempo de meia-vida. De fato, quando administramos a amitriptilina a cada 2,5-3h, houve uma redução significativa no edema de pata até a sexta e oitava horas de avaliação, na maioria dos experimentos realizados, o que sugere a importância da manutenção dos níveis plasmáticos deste fármaco, ou de seus metabólitos, para a ocorrência do efeito antiinflamatório.

De posse desta informação, pensamos que o efeito anti-inflamatório observado poderia ter acontecido em decorrência de uma ação da amitriptilina no local da inflamação. Para isto, ela foi administrada diretamente na pata, submetida ou não a um processo inflamatório. Porém, não foi possível a avaliação do efeito desta administração local de amitriptilina, devido à intensa hiperemia acompanhada de edema decorrente de sua injeção no coxim plantar. Barnet, Louis e Kohanet (2005) já haviam verificado que a injeção local de antidepressivos tricíclicos levava a uma injúria tecidual isquêmica com presença de necrose coagulativa muscular e formação de trombos. 
A seguir, considerando-se que os neutrófilos são os primeiros leucócitos sanguíneos a alcançar a área da inflamação aguda, buscou-se avaliar se a administração aguda de amitriptilina alteraria sua atividade. Os resultados mostraram que o tratamento com amitriptilina reduziu significantemente a porcentagem de fagocitose dos neutrófilos, quando comparado àquela medida no grupo controle; resultado semelhante já havia sido observado por Ploppa et al (2008). Amostras de sangue periférico humano foram incubadas com amitriptilina, nortriptilina ou fluoxetina em diferentes concentrações por diferentes intervalos. $\mathrm{Na}$ dose de $10^{-3} \mathrm{M}$, a amitriptilina induziu inibição do burst oxidativo e da fagocitose dos neutrófilos, sendo o único tratamento que preservou a integridade celular dos neutrófilos quando adicionado à cultura de células. Estes efeitos não foram observados quando se usou doses menores que $10^{-4} \mathrm{M}$ de amitriptilina. Sabe-se que a noradrenalina, atuando em adrenoceptores beta, diminui a liberação de citocinas pró-inflamatórias e reduz a atividade de fagócitos (BRASILEIRO-FILHO, 2006). Assim, é possível sugerir que o fato de a amitriptilina promover diminuição da recaptação de noradrenalina e consequente aumento de sua disponibilidade, levaria a uma menor liberação de citocinas pró-inflamatórias, o que teria ocasionado a redução da porcentagem de fagocitose dos neutrófilos observada no presente estudo. De fato, em outro experimento deste trabalho, o tratamento com amitriptilina produziu redução das concentrações séricas de TNF-alfa e IL-1beta, corroborando esta hipótese. As implicações deste achado serão discutidas posteriormente.

Diante dos achados de que a amitriptilina reduziu a resposta inflamatória induzida pela carragenina, além de reduzir a fagocitose de neutrófilos, os próximos passos foram investigar os mecanismos envolvidos nestes efeitos anti-inflamatórios.

Em primeiro lugar, avaliou-se uma possível participação dos glicocorticoides. O pré-tratamento dos animais com RU-486 - um antagonista de receptores do tipo II de glicocorticoides- não foi capaz de reverter o efeito anti-inflamatório da amitriptilina administrada a cada tempo de meia-vida, conforme avaliado pelo modelo do edema de pata induzido pela carragenina. Os hormônios adrenocorticais e a adrenalectomia têm sido implicados na modificação das reações vasculares envolvendo o processo inflamatório. Garcia-Leme e Wilhelm (1975) verificaram que animais adrenalectomizados apresentavam aumento da permeabilidade vascular induzida 
pela injeção de histamina, a qual era revertida pela administração de corticosterona. Adicionalmente, Farsky, et al (1995) demonstraram que animais submetidos à adrenalectomia ou tratados com um antagonista de receptores glicocorticoides apresentavam um número maior leucócitos em rolling. Em trabalho posterior, Cavalcanti et al (2006) mostraram que os glicocorticóides endógenos são capazes de modular a interação leucócito-endotélio graças à modulação da expressão de Lselectina.

Em relação à possível interação com amitriptilina, Weber, Eckert e Muller (2006) avaliaram o efeito de alguns antidepressivos sobre a distribuição plasma/cérebro de corticosterona. Os resultados por eles obtidos mostraram que a amitriptilina $10 \mathrm{mg} / \mathrm{kg}$ (v.o.) não foi capaz de elevar os níveis plasmáticos nem os cerebrais de corticosterona de camundongos, quando administrada em dose única ou durante duas semanas. Esta ausência de interferência da amitriptilina sobre os glicocorticoides poderia ser atribuída ao fato de ser este fármaco um potente antagonista de receptores $5-\mathrm{HT}_{2}$, os quais são responsáveis por mediar a estimulação serotonérgica do eixo HHA. No entanto, Pariante et al (2001) coincubaram células LMCAT com dexametasona e alguns fármacos antidepressivos, entre eles a amitriptilina. Todos, exceto a fluoxetina, aumentaram a transcrição de genes mediada por receptores de glicocorticoides. Ou seja, a amitriptilina foi capaz de aumentar a função dos receptores de glicocorticoides in vitro. Este dado sugere que uma possível participação dos glicocorticóides não pode ser completamente descartada dos mecanismos ligados ao efeito anti-inflamatório da amitriptilina.

A seguir foi investigado o papel dos adrenoceptores alfa-1 sobre a resposta inflamatória. O pré-tratamento com prazosina - um antagonista de adrenoceptores alfa-1 - produziu uma potencialização do efeito anti-inflamatório da amitriptilina, sem apresentar, contudo, um efeito anti-inflamatório per se. Este resultado difere do esperado, tendo em vista que o antagonismo de adrenoceptores alfa-1 induz vasodilatação - um evento importante no processo inflamatório. Este efeito, inclusive, serve de base para seu uso na clínica como anti-hipertensivo. Sendo assim, esta potencialização do efeito anti-inflamatório da amitriptilina após o uso de um antagonista de adrenoceptores alfa-1 deve ser interpretada como sendo independente de seus efeitos vasculares. O efeito da prazosina no processo inflamatório foi recentemente avaliado por Sugino et al (2009). Neste trabalho, os 
autores verificaram que a administração de prazosina (1 a $3 \mathrm{mg} / \mathrm{kg}$, v.o.) a camundongos tratados com LPS produziu uma diminuição nos níveis séricos das citocinas pró-inflamatórias TNF-alfa e IL-6, com um leve incremento da citocina antiinflamatória IL-10, indicando com isto a participação do adrenoceptores alfa-1 no processo inflamatório.

Buyuksekerci e Gultekin (2005) avaliaram a interação entre amitriptilina e prazosina em camundongos submetidos ao modelo da placa quente. Conforme esperado, a amitriptilina $10 \mathrm{mg} / \mathrm{kg}$ produziu um efeito analgésico; a prazosina $(0,1$; 0,2; 0,5 e 1,0 mg/kg), no entanto, não promoveu per se analgesia, mas quando associada à amitriptilina, a prazosina em doses menores potencializou seu efeito analgésico. Este resultado sugere que a potencialização de efeitos entre estes dois fármacos não se restringe ao processo inflamatório; mostra, ainda, a importância da dose de prazosina utilizada nesses estudos. Sugere, também, que possa haver uma via comum entre os mecanismos anti-inflamatório e analgésico da amitriptilina.

Considerando-se a importância do óxido nítrico (NO) no processo inflamatório, o próximo passo foi investigar o seu possível papel no efeito antiinflamatório da amitriptilina. No presente estudo, a administração de amitriptilina juntamente a um inibidor inespecífico de síntese de óxido nítrico (L-NAME) potencializou o efeito anti-inflamatório avaliado pelo modelo do edema de pata. Esta associação produziu, ainda, uma redução significante do total de nitratos circulantes, e uma redução significante no exsudato peritoneal da concentração de leucócitos e do número total de leucócitos induzidos pela carragenina. Neste contexto, este efeito anti-inflamatório avaliado pelo edema de pata não foi revertido pela administração de um precursor da síntese de NO, o que sugere que a ação da amitriptilina possa ter sido decorrente da inibição da NO sintase, ou seja, não adiantaria aumentar o substrato se a enzima estivesse inibida.

A ação de diversos fármacos antidepressivos sobre a expressão de NOS tem sido investigada (FINKEL et al, 1996; JOCA et al, 2007); os resultados obtidos nestes estudos sugerem que a inibição da atividade da NOS é um dos mecanismos envolvidos com a ação destes fármacos. Por outro lado, a utilização de um inibidor de iNOS e nNOS mostrou produzir efeito antidepressivo em estudo conduzido em camundongos submetidos ao modelo do estresse crônico imprevisível (MUTLU et al, 2009). 
Finkel et al (1996) verificaram que a paroxetina, mas não a nortriptilina, produziu redução significante dos níveis plasmáticos de nitratos e nitritos de pacientes com cardiopatia isquêmica em tratamento de depressão. Além disso, a paroxetina, e em menor proporção a nortriptilina, diminuíram a atividade da NOS in vitro. Vale lembrar que a nortriptilina é um dos principais metabólitos da amitriptilina, sugerindo, então este achado, um efeito indireto da amitriptilina sobre a atividade desta enzima.

Hwang et al (2008) mostraram que os antidepressivos clomipramina e imipramina reduziram de forma significante a produção de nitritos em diferentes culturas de microglia estimuladas com LPS, fato este não observado em culturas não-estimuladas. Estes dados concordam com os resultados do presente trabalho; em condições não-estimuladas, isto é, não-inflamatórias, a amitriptilina per se não reduziu de forma significante os níveis circulantes de nitrato. A co-administração de L-NAME e amitriptilina, por outro lado, produziu uma redução estatisticamente significante deste parâmetro avaliado.

Salvemini et al (1996) verificaram que a administração endovenosa do inibidor inespecífico da síntese de NO (L-NAME) produziu uma redução significante no edema de pata induzido pela carragenina durante as 10 horas avaliadas, fato não observado quando os animais receberam inibidores específicos de iNOS (Niminoetil-L-lisina (L-NIL) ou aminoguanidina), os quais inibiram o edema apenas após a quarta hora. Além disso, a inibição do edema de pata pela utilização de inibidores de NOS foi acompanhada por uma redução na produção de PGE2 e de nitratos e nitritos e por uma diminuição no infiltrado de leucócitos no exsudato plantar. Os resultados sugeriram que o óxido nítrico que participa da fase inicial (4h) do edema agudo induzido pela injeção plantar de carragenina seja produzido pela ativação de eNOS; sugerem, ainda, que após este período ocorra uma ativação da iNOS. Este mesmo artigo propôs um mecanismo importante para a inflamação induzida pela carragenina. Segundo SALVEMINI et al (1996), a injeção de carragenina produz inicialmente a liberação de mediadores como histamina, serotonina e bradicinina, os quais ativariam uma NOS constitutiva (endotelial ou neuronal) e consequentemente a produção de NO. Posteriormente, ocorreria a indução de iNOS, a qual seria a responsável pela produção do NO que manteria o edema no restante do período. A regulação da iNOS envolveria a participação, dentre outros, das citocinas TNF-alfa e interferon-gama. O mecanismo proposto 
também envolveria a participação da ciclooxigenase. Logo, o efeito anti-inflamatório de inibidores da NOS seria decorrente da inibição tanto de NO como de prostaglandinas.

Em trabalho posterior, Handy e Moore (1998) utilizaram o mesmo inibidor específico de iNOS e verificaram, de forma semelhante, uma redução no edema de pata apenas após a terceira hora de administração de carragenina, enquanto que o pré-tratamento com um inibidor de nNOS reduziu o edema de pata em ambas as fases, sendo a segunda fase (após a quarta hora) consequência provavelmente da inibição também da iNOS. Seus resultados sugerem que a nNOS, provavelmente localizada em nervos sensoriais, desempenhe um importante papel na fase inicial da inflamação induzida pela carragenina.

No presente trabalho, a co-administração de amitriptilina e L-NAME produziu redução significante do total de nitratos circulantes, quando comparados aos valores obtidos dos animais do grupo controle. Considerando-se que: 1) tal avaliação se deu em condição não-inflamatória; 2) em outro experimento a dose única de amitriptilina não foi capaz de reduzir o edema de pata induzido pela carragenina além da quarta hora de avaliação; 3) a fase inicial da inflamação induzida pela carragenina envolve a participação de nNOS; pode-se sugerir um efeito da amitriptilina sobre a NOS constitutiva (provavelmente neuronal), sendo este fármaco capaz de inibir a iNOS apenas após a utilização de doses repetidas (a cada 2,5-3h). Esta possível inibição da NOS pela amitriptilina somada à inibição desta enzima pelo L-NAME seriam responsáveis por potencializar a redução da disponibilidade de NO e de suas ações pró-inflamatórias, ou seja, vasodilatação e produção de prostaglandinas. Isto foi observado nos resultados do presente trabalho, onde a co-administração de LNAME e amitriptilina potencializou o efeito anti-inflamatório nos diversos modelos utilizados.

A administração de amitriptilina produziu uma menor concentração de leucócitos no exsudato peritoneal, duas horas após a injeção de carragenina; tal efeito pode ser devido à tendência observada de aumento no volume do exsudato, que resultou em uma diluição do número de células por $\mathrm{mL}$. $\mathrm{O}$ fato de não ter havido alteração no número total de células corrobora esta hipótese.

A avaliação deste exsudato três horas após a indução da inflamação mostrou que o pré-tratamento com L-NAME também potencializou o efeito anti-inflamatório 
da amitriptilina, pois produziu uma redução significante na concentração de leucócitos e no número total de leucócitos, sem alterar o volume de exsudato.

Apesar de parecer contraditório o fato de termos observado que a administração isolada de amitriptilina ou L-NAME foi capaz de produzir redução no edema de pata sem diminuir o número de leucócitos e o volume do exsudato, um resultado semelhante já havia sido observado no trabalho de Medeiros et al (1995). Neste trabalho, o tratamento com L-NAME produziu uma redução no edema de pata sem, contudo, interferir com a permeabilidade vascular e sem alterar a migração de leucócitos e a formação de exsudato na pleurisia. Estes resultados poderiam refletir uma diminuição no fluxo sanguíneo local (já que o L-NAME é vasoconstritor) ou, até mesmo, uma diferença de responsividade ao NO variando de acordo com o leito vascular estudado.

Em relação a este último aspecto, o trabalho de Fukatsu et al (1997) trouxe resultados bastante esclarecedores. Neste estudo, foram avaliados os efeitos da administração intraperitoneal de uma dose aguda de L-NAME (10 e 100 mg/kg) sobre a adesão de neutrófilos no peritôneo, pulmões, fígado e rins, empregando-se um modelo de peritonite; um microscópio de fluorescência foi usado para detectar os neutrófilos marcados que foram injetados em animais pré-tratados ou não com LNAME e que sofreram indução de peritonite. O pré-tratamento com L-NAME produziu uma redução significante na adesão de neutrófilos no peritôneo e um aumento naquela medida nos pulmões e no fígado; não houve alteração aparente de adesão nos rins. Os dados sugeriram que os efeitos da inibição de NO sobre a adesão de neutrófilos difere de acordo com o leito vascular avaliado e, ainda, que a produção de NO seja essencial para a preservação da adesão de leucócitos, tão necessária para a sobrevivência à infecção.

Extrapolando esta discussão para a amitriptilina, sabe-se que na clínica um dos efeitos colaterais relacionados ao uso de antidepressivos tricíclicos é a hipotensão, relacionada ao antagonismo alfa-1-adrenérgico e que desaparece com o seu uso continuado (HARDMAN; LIMBIRD 2003). Por outro lado, a amitriptilina também é antagonista $\mathrm{H} 1$ e antimuscarínico, que, em menor proporção, levariam a vasoconstrição. De fato, Svens e Ryrfeldt (2001) verificaram que a amitriptilina, in vitro, induz broncoconstrição e vasoconstrição, com redução da perfusão sanguínea. No entanto, apesar destes achados, não é possível afirmar que seus efeitos sobre o edema de pata agora relatados tenham sido meros eventos vasculares. Dados do 
presente trabalho demonstraram a habilidade da amitriptilina em reduzir 0 comportamento de leucócitos em vênulas pós-capilares em condições inflamatórias avaliadas por microscopia intravital. Isto sugere um papel para a amitriptilina na migração de leucócitos, o que está de acordo com Sacerdote et al (1994), que verificaram ser a nortriptilina - o principal metabólito da amitriptilina - capaz de bloquear tanto a migração espontânea como aquela induzida por FMLP de polimorfonucleares humanos in vitro.

Neste sentido, a avaliação do papel da amitriptilina sobre o comportamento de leucócitos mostrou que a administração de dose única deste fármaco não foi capaz de alterar o comportamento de leucócitos em condições não-inflamatórias, avaliados por microscopia intravital. Em condição inflamatória induzida por carragenina, no entanto, o tratamento com amitriptilina induziu uma redução significante no rolling, na adesão e na transmigração de leucócitos. Não houve, contudo, alteração significante na velocidade do rolamento, apesar da tendência observada em diminuir o tempo necessário para percorrer o trecho de vênula avaliado. Este fato sugere que o fenômeno observado independa dos efeitos vasculares do fármaco.

Sendo assim, diante dos resultados obtidos, avaliamos o papel da amitriptilina sobre a expressão de moléculas de adesão por leucócitos e a influência do NO neste processo. O tratamento com amitriptilina não produziu alterações significantes na expressão das moléculas de adesão ICAM-1, PECAM-1, L-selectina e MAC-1 por leucócitos do sangue periférico. De igual forma, a administração de L-NAME sozinho ou em conjunto com amitriptilina também não alterou a expressão destas moléculas pelos leucócitos.

A literatura apresenta várias controvérsias à respeito do papel do L-NAME no comportamento de leucócitos e expressão de moléculas de adesão. Já foi verificado que o bloqueio da produção de NO promove aumento do rolling e adesão de leucócitos, enquanto que sua suplementação reduz o recrutamento de leucócitos em um processo inflamatório agudo. Kubes; Suzuki; Granger (1991) avaliaram o mesentério de gatos após superfusão com inibidores da NOS (L-NAME e L-NMMA) e verificaram aumento da adesão de polimorfonucleares; a incubação de neutrófilos isolados de gatos com L-NMMA, mas não com L-NAME (ambos inibidores da NOS), resultou em upregulation de CD11/CD18, conforme avaliado por citometria de fluxo. Segundo os autores, a inibição de NO causa vasoconstrição e consequente 
diminuição das forças de cisalhamento (shear forces) que impelem os leucócitos ao longo do vaso, produzindo em decorrência, um aumento da sua adesão. TRIPATHI et al (2007) mostraram, em um artigo de revisão, que o NO promove uma downregulation da expressão de selectinas ( $\mathrm{P}$ and E), VCAM-1 e ICAM-1 por células endoteliais. Isto resultaria em inibição do rolamento e migração de leucócitos pelo vaso. Por outro lado, Farsky et al (2004), tratando ratos durante 14 dias com LNAME misturado à água de bebida (20 mg/ $\mathrm{kg} / \mathrm{dia})$ e submetendo-os ao modelo de inflamação da bolsa de ar (air pouch model), mostraram que a inibição inespecífica da síntese de NO produziu uma redução significante no infiltrado de polimorfonucleares, na produção de nitratos e nitritos e no comportamento de rolling e adesão dos leucócitos e na sua expressão de L-selectina. Hebeda et al (2008), utilizando um protocolo de administração prolongada de L-NAME semelhante ao de Farsky et al (2004), verificaram uma menor expressão de L-selectina e PECAM-1 em leucócitos e de PECAM-1 no endotélio de ratos com inibição de NOS constitutiva; apenas L-selectina apresentou diminuição na transcrição de RNAm, não havendo alteração na expressão endotelial de E-selectina, ICAM-1 e VCAM-1. Esses dados sugerem que o NO produzido constitutivamente module a expressão de moléculas de adesão de diferentes formas: L-selectina no nível transcricional e PECAM-1 em sua expressão. $O$ estresse de cisalhamento, neste sentido, seria um dos fatores que ativariam PECAM, o que levaria à ativação de eNOS via fosforilação e consequentemente à produção de NO, já que PECAM-1 e eNOS co-localizam-se em células endoteliais. A modulação de NO sobre PECAM, no entanto, não dependeria de parâmetros hemodinâmicos, o que sugere outras vias de modulação. Finalmente, e entre outros relatos interessantes, Zilberberg e Harris (2001) não encontraram aumento da adesão de leucócitos após o uso de L-NAME.

A discrepância entre estes resultados e os do presente estudo em relação ao papel do L-NAME na expressão de moléculas de adesão talvez se deva ao protocolo de administração; no presente trabalho foi agudo, uma hora antes dos tratamentos e, em outros artigos, foi realizado em doses múltiplas por via oral (FARSKY et al, 2004, HEBEDA et al, 2008) ou por aplicação local (KUBES et al, 1991) em diferentes doses. A dose, por sinal, é um fator bastante importante, tendo em vista que a concentração de NO pode ser protetora ou lesiva dependendo da quantidade disponível. 
A este respeito, um trabalho recente trouxe uma discussão bastante interessante. Células endoteliais foram incubadas com TNF-alfa e doadores de NO; verificou-se uma diminuição na adesão de linfócitos, um fato não relacionado a redução na expressão de moléculas de adesão. Os autores sugeriram que teria ocorrido uma alteração conformacional ou de afinidade das moléculas de adesão, e não em sua expressão, o que justificaria os achados (NORMAN et al, 2008). Ou seja, a não observância de alterações na expressão de moléculas de adesão por leucócitos de animais tratados com amitriptilina no presente trabalho poderia ter sido decorrência de uma alteração na conformação ou afinidade dessas moléculas. Pelo exposto, depreende-se que outros estudos sejam necessários para uma melhor avaliação da influência da amitriptilina na expressão de moléculas de adesão pelo endotélio vascular.

A expressão de moléculas de adesão por leucócitos ou endotélio é influenciada por inúmeros mediadores, entre eles LPS e citocinas, como IL-1 e TNFalfa, além dos produtos secretados por mastócitos, principalmente histamina, a qual está associada à indução do rolling (KUBES e GRANGER, 1996). Diversos estudos têm apontado a diminuição de citocinas pró-inflamatórias como uma das ações dos antidepressivos (CASTANON, 2002; LEONARD, 2001; SCHIEPPERS et al, 2005). Obuchowicz et al (2006) demonstraram que a amitriptilina foi capaz de reduzir a produção das citocinas pró-inflamatórias IL-1ß e TNF- $\alpha$ em cultura de células gliais de ratos. Por outro lado, outro estudo já havia mostrado que a administração de amitriptilina por quatro semanas em camundongos da linhagem C57BL/6 estimulava a atividade proliferativa de esplenócitos e aumentava a secreção de IL-10, uma citocina com propriedades antiinflamatórias e imunossupressoras (KUBERA et al, 2000). Além disso, diante do fato de ter a amitriptilina ação inibitória sobre a liberação de histamina por mastócitos (THEOHARIDES et al, 1985), e lembrando-se ser ela um antagonista de receptores $\mathrm{H1}$, não se pode descartar o envolvimento desta via na regulação do rolling de leucócitos. No entanto, Achar et al (2009) sugeriram que o efeito anti-inflamatório da amitriptilina no modelo murino da obstrução ureteral unilateral independeria do antagonismo de receptores histaminérgicos, o que nos reforça a idéia - agora formulada - do envolvimento das citocinas nos efeitos observados. 
De fato, o presente trabalho observou que o tratamento com amitriptilina produziu redução significante nas concentrações de TNF-alfa e IL-1beta no soro de ratos, corroborando os dados da literatura neste sentido. Tendo em vista a importância destas citocinas no processo inflamatório, este poderia ser um dos importantes mecanismos influenciados pelos antidepressivos no sentido de alterarem o comportamento dos leucócitos durante um evento inflamatório. Além disso, o fato de a amitriptilina ter reduzido a concentração destas citocinas contextualiza a presente discussão de um ponto de vista neuroimunomodulatório. Isto porque as citocinas participam da comunicação não apenas entre células do sistema imunológico, como se pensava inicialmente, mas também de outras localizadas nos sistemas nervoso e endócrino. A principal produção de citocinas se faz por células do sistema imune periférico, e elas podem adentrar o cérebro através de regiões onde a barreira hematoencefálica está ausente (ex: órgãos circunventriculares), menos restritiva (como na eminência mediana) ou em situações onde ela esteja comprometida (ex. esclerose múltipla). Existem, também, sistemas transportadores para citocinas, além de liberação de citocinas pró-inflamatórias por neurônios e células da glia dentro do próprio SNC, como, por exemplo, no hipotálamo, hipocampo, núcleos da base e outros, com a presença de receptores funcionalmente ativos para citocinas em neurônios dessas regiões (MÜLLER; ACKENHEIL, 1998; KULMATYCKI; JAMALII, 2006; SZELENYI; VIZI, 2007). Está se tornando cada vez mais claro que os compartimentos centrais e periféricos atuam de forma integrada, e também que a produção de citocinas passa pelo controle tônico do sistema nervoso central e periférico, já que as células imunes apresentam receptores para diversos neurotransmissores, sendo que a ativação destes modula a produção de citocinas (SZELENYI; VIZI, 2007).

Uma ativação do sistema de estresse e, consequentemente do sistema nervoso simpático, está ligada à liberação de citocinas pró-inflamatórias, como a de IL-6. Por sua vez, uma desregulação no balanço citocinérgico poderia induzir sintomas depressivos, já que parecem mediar a síndrome do comportamento doentio em humanos e animais, caracterizada por alterações no sono, apetite, atividade, humor, energia e sociabilização.

Tendo em vista esta participação neuroimunomodulatória das citocinas e a influência regulatória dos antidepressivos, faz-se necessária neste momento uma 
reflexão à respeito da relevância dos resultados agora obtidos do ponto de vista farmacológico e fisiopatológico.

Historicamente, a depressão foi proposta como decorrente da diminuição na disponibilidade de monoaminas em 1965, com a Teoria Monoaminérgica da depressão. Isto decorreu do fato, e foi reforçado posteriormente, pela constatação de que antidepressivos aumentariam a disponibilidade destes neurotransmissores na fenda sináptica. Hoje, mais de 40 anos depois, esta teoria não é capaz de explicar, dentre outras questões, o porquê da latência de até um mês para a ação antidepressiva, e a taxa de refratariedade ao redor de $30 \%$ dos pacientes aos antidepressivos (LANNI et al, 2009). Isto abriu margem para o surgimento de diversas teorias, dentre elas a que implica a depressão como um fenômeno inflamatório. 


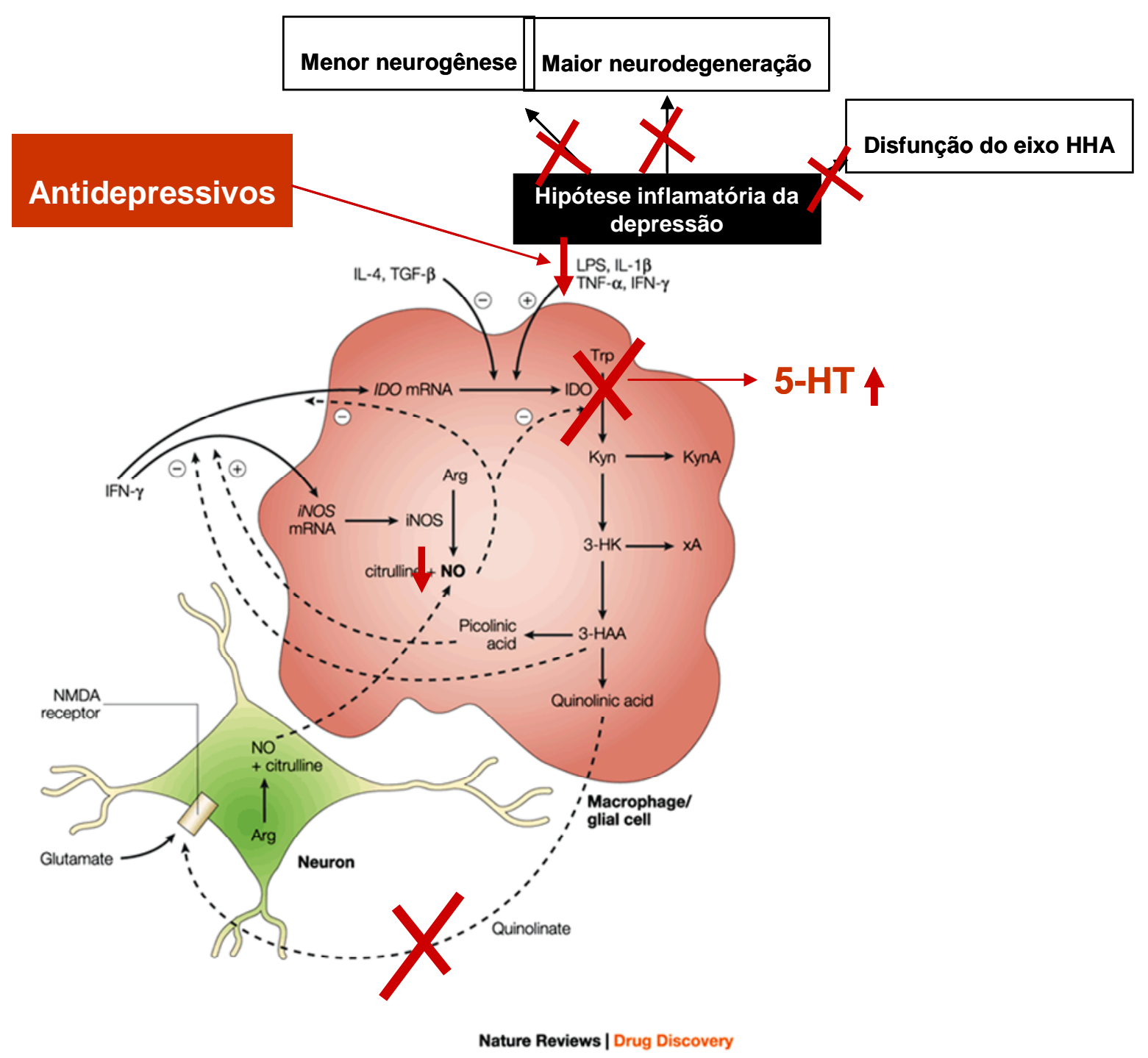

Figura 21 - Interrelações entre hipótese inflamatória da depressão, IDO, NO, receptores NMDA e o uso de antidepressivos (ATD). Adaptado de STONE; DARLINGTON (2002) e MAES (2009)

De acordo com a Hipótese Inflamatória da Depressão, esquematizada na figura 21, citocinas pró-inflamatórias seriam responsáveis por ativar a enzima indolamina-2,3-dioxigenase (IDO), reduzindo a disponibilidade de triptofano para a síntese de serotonina e aumentando os compostos da via da quinurenina. Dentre estes compostos, o ácido quinolínico, um agonista NMDA, com consequente aumento da liberação de NO e dos efeitos deletérios a ele associados. A utilização de antidepressivos, por sua vez, levaria a uma diminuição das citocinas próinflamatórias e da atividade da NOS, com conseqüente redução da disfunção do eixo HHA, da neurodegeneração e de todos os aspectos inflamatórios e neurodegenerativos da depressão (STONE; DARLINGTON, 2002; MAES, 2009; MÜLLER, 2010). 
Estabelece-se, neste contexto, a relevância dos presentes achados experimentais. Acreditamos, data venia, que nossos resultados, por mostrarem a participação do NO e das citocinas no efeito anti-inflamatório dos antidepressivos, contribua não apenas com os estudos que buscam uma melhor compreensão da farmacologia dos antidepressivos, mas, e de forma mais ampla, com aqueles que investigam a fisiopatologia do próprio transtorno depressivo. 


\section{7- CONCLUSÕES}

O presente trabalho fundamentou-se em oito objetivos específicos, cujas conclusões encontram-se abaixo descritas:

1- A avaliação dos efeitos anti-inflamatórios da amitriptilina mostrou que:

- este fármaco administrado em dose única ou durante 7,14 ou 28 dias produziu redução significante do edema de pata induzido pela carragenina em ratos, no geral até a quarta hora avaliada;

- quando a administração de amitriptilina ocorreu a cada tempo de meia-vida de eliminação (2,5-3h), o efeito anti-inflamatório permaneceu além da quarta hora de avaliação do volume da pata;

- o tratamento com amitriptilina durante 16 dias produziu uma redução significante na porcentagem de fagocitose por neutrófilos, avaliados por citometria de fluxo;

- a aplicação local de amitriptilina produziu injúria tecidual;

2- O efeito anti-inflamatório da amitriptilina não se deve, aparentemente, à participação glicocorticoides, já que não houve reversão do efeito anti-inflamatório da amitriptilina quando os animais foram pré-tratados com um antagonista de receptores de glicocorticoides (RU-486);

3- O uso de um antagonista de receptores alfa-1-adrenérgicos (prazosina) produziu uma potencialização do efeito anti-inflamatório da amitriptilina;

4- A administração de amitriptilina juntamente a um inibidor inespecífico de síntese de óxido nítrico (L-NAME) levou a uma potencialização no efeito anti-inflamatório avaliado pelo modelo do edema de pata; este efeito anti-inflamatório não foi revertido pela administração de um precursor da síntese de NO;

5- Quando se avaliou o efeito do pré-tratamento com L-NAME sobre o efeito antiinflamatório da amitriptilina em um outro leito vascular, verificou-se uma redução significante na concentração de leucócitos e no número total de leucócitos do exsudato peritoneal induzido por carragenina, quando comparados aos animais controle. 
6- O tratamento com amitriptilina induziu uma redução significante no rolling, adesão e transmigração de leucócitos, em condição inflamatória induzida pela carragenina intraperitoneal, avaliados por microscopia intravital;

7- Os tratamentos com amitriptilina e L-NAME, isoladamente ou em conjunto, não produziram alterações significantes na expressão das moléculas de adesão ICAM-1, PECAM-1, L-selectina e MAC-1 por leucócitos do sangue periférico.

8- Os tratamentos com amitriptilina e L-NAME, isoladamente ou em conjunto, reduziram de forma estatisticamente significante as concentrações de IL-1beta e TNF-alfa no soro de ratos.

Podemos assim concluir que amitriptilina apresentou um efeito antiinflamatório na maioria dos modelos avaliados. Os mecanismos parecem envolver a participação dos receptores alfa-1-adrenérgicos, do óxido nítrico - provavelmente pela inibição da cNOS e iNOS, com consequente redução na síntese de NO e das ações pró-inflamatórias a ele associadas - e a diminuição de citocinas de padrão pró-inflamatório, particularmente, IL-1beta e TNF-alfa.

A importância de se estudar o efeito anti-inflamatório da amitriptilina não reside na possibilidade de um provável novo uso para este antigo fármaco. A relevância deste achado centra-se na possibilidade de correlacioná-lo às novas teorias que buscam entender a depressão como um fenômeno inflamatório. Assim, os presentes achados experimentais somam-se a estas investigações e também sugerem que seja este um provável mecanismo para os transtornos depressivos. 


\section{REFERÊNCIAS BIBLIOGRÁFICAS ${ }^{2}$}

ABDEL-SALAM, O.M.; BAIUOMY, A.R.; ARBID, M.S. Studies on the antiinflammatory effect of fluoxetine in the rat. Pharmacol Res.,v.49, n.2, p.119-31, 2004.

ABDEL-SALAM, OM; NOFAL, SM; EL-SHENAWY, S.M. Evaluation of the anti-inflammatory and anti-nociceptive effects of different antidepressants in the rat. Pharmacol Res., v.48, n.2, p.157-65, 2003.

ACHAR, E.; ACHAR, R. A., et al. Amitriptyline eliminates calculi through urinary tract smooth muscle relaxation. Kidney Int, v.64, n.4, p.1356-64, 2003.

ACHAR, E.; MACIEL, T. T., et al. Amitriptyline attenuates interstitial inflammation and ameliorates the progression of renal fibrosis. Kidney Int, v.75, n.6, p.596-604, 2009.

ADER, R.; COHEN, N. Behaviorally conditioned immunosuppression. Psychosom Med, v.37, n.4, p.333-40, 1975.

ALVES, GJ ; VISMARI, L, PALERMO-NETO, J. Cohabitation with a sick cage mate: effects on ascitic form of Ehrlich tumor growth and macrophage activity. Neuroimmunomodulation, v.14, n.6, p.297-303, 2007.

ALVES, G.J. ; PALERMO-NETO, J. Neuroimunomodulação: sobre o diálogo entre os sistemas nervoso e imune. Rev. Bras. Psiquiatr, v. 34, p. 6-12, 2007.

BARNET, C. S.; LOUIS, D. N., et al. Tissue injury from tricyclic antidepressants used as local anesthetics. Anesth Analg, v.101, n.6, p.1838-43, 2005.

BARTROP, R. W.; LUCKHURST, E., et al. Depressed lymphocyte function after bereavement. Lancet, v.1, n.8016, p.834-6, 1977.

BAUMANN, P.; GAILLARD, J. M., et al. Evaluation of the levels of free and total amitriptyline and metabolites in the plasma and brain of the rat after long-term administration of doses used in receptor studies. Psychopharmacology (Berl), v.84, n.4, p.489-95, 1984.

BESEDOVSKY, H.; DEL REY, A., et al. Immunoregulatory feedback between interleukin-1 and glucocorticoid hormones. Science, v.233, n.4764, p.652-4, 1986.

BESEDOVSKY, H.; SORKIN, E., et al. Hypothalamic changes during the immune response. Eur J Immunol, v.7, n.5, p.323-5, 1977.

${ }^{2}$ De acordo com:

Diretrizes para apresentação de dissertações e teses da USP : documento eletrônico e impresso Parte I (ABNT) / Sistema Integrado de Bibliotecas da USP ; Vânia Martins Bueno de Oliveira Funaro, coordenadora ... [et al.] . - 2. ed. - São Paulo : Sistema Integrado de Bibliotecas da USP, 2009. 
BESEDOVSKY, H. O.; REY, A. D. Physiology of psychoneuroimmunology: a personal view. Brain Behav Immun, v.21, n.1, p.34-44, 2007.

BIANCHI, M.; ROSSONI, G., et al. Effects of chlomipramine and fluoxetine on subcutaneous carrageenin-induced inflammation in the rat. Inflamm Res, v.44, n.11, p.466-9, 1995.

BIANCHI, M.; SACERDOTE, P., et al. Fluoxetine reduces inflammatory edema in the rat: involvement of the pituitary-adrenal axis. Eur J Pharmacol, v.263, n.1-2, p.81-4, 1994.

BLALOCK, J. E. The immune system as a sensory organ. J Immunol, v.132, n.3, p.1067-70, 1984.

BLALOCK, J.E. The syntax of immune-neuroendocrine communication. Immunology Today, v.15, n.11, p. 504-511, 1994.

BLALOCK, J. E.; SMITH, E. M. Conceptual development of the immune system as a sixth sense. Brain Behav Immun, v.21, n.1, p.23-33, 2007.

BRASILEIRO FILHO. Bogliolo, Patologia. 7a. Ed. Rio de Janeiro. Guanabara Koogan, 2006. 1472p

BUYUKSEKERCI, M.; GULTEKIN, H. [Low doses of prazosin potantiates the antinociceptive/analgesic effect of amitriptyline]. Agri, v.17, n.1, p.54-6, 2005.

CASTANON, N.; LEONARD, B.E.; NEVEU, P.J.; YIRMIYA, R. Effects of antidepressants on cytokine production and actions. Brain Behav Immun, v.16, n.5, p. 569-74, 2002.

CASTELLS, E.T.; DELGADO, E.V.; ESCODA, C.G. Use of amitriptyline for the treatment of chronic tension-type headache. Review of the literature Med Oral Patol Oral Cir Bucal, V.13, n.9, p.E567-72, 2008.

CASTRÉN, E.; VOIKAR, V.; RANTAMAKI, T. Role of neurotrophic factors in depression. Curr Opin Pharmacol, v.7, n.1, p.18-21, 2007.

CAVALCANTI, D.M.H.; LOTUFO, C.M.C.; et al. Adrenal deficiency alters mechanisms of neutrophil mobilization. Molecular and Cellular Endocrinology, v.249, n.1-2, p.32-9, 2006.

CHEN, L.W.; JAN, C.R. Mechanisms and modulation of formyl-methionyl-leucylphenylalaninežfMLP/-induced $\mathrm{Ca}^{2+}$ mobilization in human neutrophils. International Immunopharmacology, v.1, p.1341-1349, 2001.

COHN, D.W.; DE SÁ-ROCHA, L.C. Differential effects of lipopolysaccharide in the social behavior of dominant and submissive mice. Physiol Behav, v.87, n.5, p.932-7, 2006. 
COSTA-PINTO, F. A.; COHN, D. W., et al. Behavior: a relevant tool for brain-immune system interaction studies. Ann N Y Acad Sci, v.1153, p.107-19, 2009.

COTRAN, R. S.; KUMAR, V.; COLLINS, T. Robbins: Patologia Estrutural e Funcional. 6ำ ed. Rio de Janeiro. Guanabara Koogan. 2000.

COUDORE, F.; BESSON, A., et al. Plasma and brain pharmacokinetics of amitriptyline and its demethylated and hydroxylated metabolites after one and six half-life repeated administrations to rats. Gen Pharmacol, v.27, n.2, p.215-9, 1996.

COUSSENS, L. M.; WERB, Z. Inflammation and cancer. Nature, v.420, n.6917, p.860-7, 2002.

CROSS, R.J.; JACKSON, J.C.; BROOKS, W.H.; SPARKS, S.L.; MARKESBERY, W.R.; ROSZMAN, T.L. Neuroimmunomodulation: impairment of humoral immune responsiveness by 6-hydroxydopamine treatment. Immunology. v.57, p.145-152, 1986.

CZURA, C.J.; TRACEY, K.J. Autonomic neural regulation of immunity. J Intern Med, v.257, n.2, p.156-66, 2005.

DA SILVA, F.R.; LAZZARINI, R,; DE SÁ-ROCHA, L.C.; MORGULIS, M.S.; DE OLIVEIRA MASSOCO, C.; PALERMO-NETO, J. Effects of acute and long-term diazepam administrations on neutrophil activity: a flow cytometric study. Eur $\mathbf{J}$ Pharmacol., v.478, n.2-3, p.97-104, 2003.

DANTZER, R.; KELLEY, K. W. Stress and immunity: an integrated view of relationships between the brain and the immune system. Life Sciences., v.44, n.26, p.1995-2008, 1989.

DAWSON, T.M.; DAWSON, V.L. Nitric Oxide: actions and pathological roles. The Neuroscientist. v.1, n.1, p.7-18, 1995.

DE PAULA, VF; RIBEIRO, A; PINHEIRO, ML; SAKAI, M; LACAVA, MC; LAPACHINSKE, SF; MOREAU, RL; PALERMO-NETO, J. Methylenedioxymethamphetamine (Ecstasy) decreases neutrophil activity and alters leukocyte distribution in bone marrow, spleen and blood. Neuroimmunomodulation., v.16, n.3, p.191-200, 2009.

DOMINGUES-JUNIOR M, PINHEIRO SR, GUERRA JL, PALERMO-NETO J. Effects of treatment with amphetamine and diazepam on Mycobacterium bovis-induced infection in hamsters. Immunopharmacol Immunotoxicol, v.22, n.3, p.555-574, 2000.

DUNN, A.J. Interactions between the nervous system and the immune system: implications for psychopharmacology. In: BLOOM, F.E. E KUPFER, D.J. Psychopharmacology: the fourth generation of progress. New York: Raven press, 1995. 719-731. 
FARSKY, S.P; SANNOMIYA, P; GARCIA-LEME, J. Secreted glucocorticoids regulate leukocyte-endothelial interactions in inflammation. A direct vital microscopic study. $\mathbf{J}$ Leukoc Biol. v.57, n.3, p.379-86, 1995.

FARSKY, S. H.; BORELLI, P., et al. Chronic blockade of nitric oxide biosynthesis in rats: effect on leukocyte endothelial interaction and on leukocyte recruitment. Inflamm Res, v.53, n.9, p.442-52, 2004.

FINKEL, M.S.; LAGHRISSI-THODE, F.; POLLOCK, B.G.; RONG, J. Paroxetine is a novel nitric oxide synthase inhibitor. Psychopharmacol Bull., v.32, n.4, p.653-8. 1996.

FISCHLER, B. Psychoneuroimmunology and neuroimmunomodulation: an outline of some recent developments presented at de Second International Workshop on Neuroimmunomodulation. Acta Psychiat. Belg., v.87, p.617-619, 1987.

FONSECA, C.S.; VILORIA, M.IV.; REPETTI, L. Alterações fetais induzidas pelo uso de antiinflamatórios durante a gestação. Ciência Rural, v.32, n.4, p.529-534, 2002.

FORTES, Z.B.; FARSKY, S.P.; OLIVEIRA, M.A.; GARCIA-LEME, J. Direct vital microscopic study of defective leukocyte-endothelial interaction in diabetes mellitus. Diabetes., v.40, n.10, p.1267-73, 1991.

FUKATSU, K.; SAITO, H., et al. Nitric oxide inhibition decreases neutrophil adhesion at the inflammatory site, while increasing adhesion in remote organs in peritonitis. $\mathbf{J}$ Surg Res, v.68, n.1, p.79-86, 1997.

GARCIA, X.; STEIN, F. Nitric oxide. Semin Pediatr Infect Dis. v.17, n.2, p.55-7, 2006.

GARCIA-LEME, J.; WILHELM, D.L. The effects of adrenalectomy and corticosterone on vascular permeability responses in the skin of the rat. Br. J. Exp. Path, v.56, p.402-7, 1975.

GOSHEN, I; YIRMIYA, R. Interleukin-1 (IL-1): a central regulator of stress responses. Front Neuroendocrinol., v.30, n.1, p.30-45, 2009.

HAJJAR, L.A.; PINHEIRO, A.M.C. Ação do furoato de mometasona sobre as citocinas inflamatórias. Ass. Bras. Dermat., v.74, n.1, p.1-22, Supplement 1, 1999.

HANDY, R.L.C.; MOORE, P.K. A comparison of the effects of L-NAME, 7-NI and LNIL on carrageenan-induced hindpaw oedema and NOS activity. Br.J. Pharmacol., v.123, p.1119-26, 1998.

HARDMAN, J.G.; LIMBIRD, L.E.. Goodman e Gilman: As Bases Farmacologicas da Terapêutica. 10르. Ed., Rio de Janeiro:McGrawHill, 2003.

HASUI, M.,;HIRABAYASHI, Y., et al. Simultaneous measurement by flow cytometry of phagocytosis and hydrogen peroxide production of neutrophils in whole blood. $\mathbf{J}$ Immunol Methods, v.117, n.1, p.53-8, 1989. 
HEBEDA, C. B.; TEIXEIRA, S. A., et al. In vivo blockade of $\mathrm{Ca}(+2)$-dependent nitric oxide synthases impairs expressions of L-selectin and PECAM-1. Biochem Biophys Res Commun, v.377, n.2, p.694-8, 2008.

HWANG J.; ZHENG LT; et al. Inhibition of glial inflammatory activation and neurotoxicity by tricyclic antidepressants. Neuropharmacology, v.55, p.826-834, 2008.

IRWIN, M.R.; MILLER, A.H. Depressive disorders and immunity: 20 years of progress and discovery. Brain Behav Immun., v.21, n.4, p.374-83, 2007.

JANEWAY, C. A. Imunobiologia: o sistema imunológico na saúde e na doença. 4⿳ạ. Ed. Porto Alegre: Artes Médicas, 2000.634p.

JOCA, S.R.L.; FERREIRA, F.R.; GUIMARÃES, F.S. Modulation of stress consequences by hippocampal monoaminergic, glutamatergic and nitrergic neurotransmitter systems. Stress, v.10, n.3, p.227-49, 2007.

KLEEB, S.R.; RIZZO, M.; DAGLI, M.L.; FRUSSA-FILHO, R. Haloperidol increases spreading and nitric oxide production in macrophages from tumor-bearing mice: a possible mechanism for its antitumoral effect. Int $\mathbf{J}$ Immunopharmacol., v.21, n.9, p.575-80, 1999.

KLEEB, S.R.; XAVIER, J.G.; FRUSSA-FILHO, R; DAGLI ML. Effect of haloperidol on the development of the solid Ehrlich tumor in mice. Life Sci., v.60, n.4-5, p.PL69-74, 1997.

KONSMAN, J. P.; PARNET, P., et al. Cytokine-induced sickness behaviour: mechanisms and implications. Trends Neurosci, v.25, n.3, p.154-9. 2002.

KUBERA, M.; HOLAN, V.; MATHISON, R.; MAES, M. The effect of repeated amitriptyline and desipramine administration on cytokine release in C57BL/6 mice. Psychoneuroendocrinology, v.25, n.8, p.785-97, 2000.

KUBES, P.; GRANGER, D.N. Leukocyte-endothelial cell interactions evoked by mast cells. Cardiovasc Res., v.32, p.699-708, 1996.

KUBES, P; SUZUKI, M.; GRANGER, D.N. Nitric oxide: An endogenous modulator of leukocyte adhesion. Proc. Natl. Acad. Sci. v.88, p.4651-4655, 1991.

KULMATYCKI, K. M.; JAMALI, F. Drug disease interactions: role of inflammatory mediators in depression and variability in antidepressant drug response. J Pharm Pharm Sci, v.9, n.3, p.292-306, 2006.

KUMMER, C.L.; COELHO, T.C.R.B. Antiinflamatório não-esteróides inibidores da ciclooxigenase-2 (cox-2): aspectos atuais. Revista Brasileira. Anest., v.52, n.4, p.498-512, 2002.

LANNI C, GOVONI S, LUCCHELLI A, BOSELLI C. Depression and antidepressants: molecular and cellular aspects. Cell Mol Life Sci., v.66, n.18, p.2985-3008, 2009. 
LAZZARINI, R.; MALUCELLI, B.E.; MUSCARA, M.N.; DE NUCCI, G.; PALERMONETO, J. Reduction of inflammation in rats by diazepam: tolerance development. Life Sci., v.72, n.21, p.2361-8, 2003.

LAZZARINI, R.; PAULINO, C.A.; MALUCELLI, B.E.; PALERMO-NETO, J. Effects of high doses of diazepam on carrageenin-induced paw edema in rats. Braz $\mathbf{J}$ Med Biol Res., v.29, n.11, p.525-9, 1996.

LEONARD, B.E. The immune system, depression and the action of antidepressants. Prog Neuropsychopharmacol Biol Psychiatry. v.25, n.4, p.767-80, 2001

LEONARD, B. E. Psychopathology of depression. Drugs Today (Barc), v.43, n.10, p.705-16, 2007.

LEONARD, B.E; MYINT, A. The psychoneuroimmunology of depression. Hum Psychopharmacol., v.24, n.3. p.165-75, 2009.

LOURENCO, G.A.; DORCE, V.A.; PALERMO-NETO, J. Haloperidol treatments increased macrophage activity in male and female rats: influence of corticosterone and prolactin serum levels. Eur Neuropsychopharmacol., v.15, n.3, p.271-7, 2005.

MAES M.; YIRMYIA, R.; et al. The inflammatory \& neurodegenerative (I\&ND) hypothesis of depression: leads for future research and new drug developments in depression. Metab Brain Dis., v.24, p.27-53, 2009.

MAK, O. T.; CHEN, S. H., et al. Effects of arsenate and ergot alkaloid compounds on prostacyclin synthesis in human umbilical endothelium. Cell Biol Int Rep, v.10, n.4, p.287-93, 1986.

MARQUES-DEAK, A.H.; NETO, F.L,; DOMINGUEZ, W.V.; SOLIS, A.C.; KURCGANT, D.; SATO, F, et al. Cytokine profiles in women with different subtypes of major depressive disorder. J Psychiatr Res., v.41, n.1-2, p.152-9, 2007.

MARTINEZ, L.L.; OLIVEIRA, M.A.; MIGUEL, A.S.; RASTELLI, V.M.; WALBER, J; CRUZ, M.C.; TOSTES, R.C.; CARVALHO, M.H.; NIGRO, D.; FORTES, Z.B. Enalapril interferes with the effect of diclofenac on leucocyte-endothelium interaction in hypertensive rats. J Cardiovasc Pharmacol., v.43, n.2, p.258-65, 2004

MASSOCO, C.O.; PALERMO-NETO, J. Diazepam effects on peritoneal macrophage activity and corticosterone serum levels in balb/c mice. Life Sci., v.65, n.20, p.215765, 1999.

MEDEIROS, M.V.; BINHARA, I.M.; MORENO-JUNIOR, H.; ZATZ, R.; DE NUCCI, G.; ANTUNES, E. Effect of chronic nitric oxide synthesis inhibition on the inflammatory responses induced by carrageenin in rats. Eur J Pharmacol., v.285, n.2, p.109-14, 1995.

MEDZHITOV, R. Origin and physiological roles of inflammation. Nature, v. 454, n.24, p.428-435, 2008. 
MELLO, S.B.V.; LAURINDO, I.M.M. A resposta inflamatória. In: YOSHINARI, N.H.; BONFA, E.S.D.O. Reumatologia para o clínico. São Paulo:Roca, 2000.

MICHELSON, D.; MISIEWICZ-POLTORAK, B; RAYBOURNE, R.B.; GOLD, P.W.; STERNBERG, E.M. Imipramine reduces the local inflammatory response to carrageenin. Agents Actions.,v.42, n.1-2, p.25-8, 1994.

MILLER, A.M. Neuroendocrine and immune system interactions in stress and depression. Psychoneuroendocrinology, v.21, n.2, p.443-463, 1998.

MONCADA, S.; HIGGS, E.A. Endogenous nitric oxide: physiology, pathology and clinical relevance. Eur J Clin Invest., v.21, n.4, p.361-74, 1991.

MORRISSEY, J.J. Pleiotropic effects of amitriptyline ameliorate renal fibrosis. Kidney Int., v.75, n.6 p.583-4, 2009.

MÜLLER, N.; ACKENHEIL, M. Psychoneuroimmunology and the cytokine action in the CNS: implications for psychiatric disorders. Prog. Neuro-Psychopharmacol \& Biol. Psychiat., v.22, p.1-33, 1998.

MÜLLER, N; SCHWARZ, N.J. The immune-mediated alteration of serotonin and glutamate: towards an integrated view of depression. Mol. Psychiatry., v.12, n.11, p.988-1000, 2007.

MÜLLER N. COX-2 inhibitors as antidepressants and antipsychotics: clinical evidence. Curr Opin Investig Drugs. v.11, n.1, p.31-42, 2010.

MUSCARA, M. N.; DE NUCCI, G. Simultaneous determination of nitrite and nitrate anions in plasma, urine and cell culture supernatants by high-performance liquid chromatography with post-column reactions. J Chromatogr B Biomed Appl, v.686, n.2, p.157-64. 1996.

MUTLU, O.; ULAK, G.; LAUGERAY, A.; BELZUNG, C. Effects of neuronal and inducible NOS inhibitor 1-[2-(trifluoromethyl) phenyl] imidazole (TRIM) in unpredictable chronic mild stress procedure in mice. Pharmacol Biochem Behav., v.92, n.1, p.82-7, 2009.

NISHIDA, A; HISAOKA, K.; ZENSHO, H.; UCHITOMI, Y.; MORINOBU, S.; YAMAWAKI, S. Antidepressant drugs and cytokines in mood disorders. Int Immunopharmacol., v. 2, n.12, p.1619-26, 2002.

NORMAN, MU.; ZBYTNUIK, L.; KUBES, P. Interferon-c limits Th1 lymphocyte adhesion to inflamed endothelium: A nitric oxide regulatory feedback mechanism. Eur. J. Immunol. v.38, p.1368-1380, 2008.

O'BRIEN, S.M.; SCULLY, P.; FITZGERALD, P.; SCOTT, L.V.; DINAN, T.G. Plasma cytokine profiles in depressed patients who fail to respond to selective serotonin reuptake inhibitor therapy. J Psychiatr Res., V.41, n.3-4, p.326-31, 2007. 
OBUCHOWICZ, E.; KOWALSKI, J.; LABUZEK, K.; KRYSIAK, R.; PENDZICH, J.; HERMAN, Z.S. Amitriptyline and nortriptyline inhibit interleukin-1 release by rat mixed glial and microglial cell cultures. Int J Neuropsychopharmacol., v.9, n.1, p.27-35, 2006.

OLIVEIRA, R.M.W.; GUIMARÃES, F.S.; DEAKIN, J.F.W.. Expression of neuronal nitric oxide synthase in the hippocampal formation in affective disorders. Brazilian Journal of Medical and Biological Research, v.41, p.333-341, 2008.

PALERMO-NETO, J.; FONSECA, E. S., et al. Effects of individual housing on behavior and resistance to Ehrlich tumor growth in mice. Physiol Behav, v.95, n.3, p.435-40. 2008.

PALERMO-NETO, J.;GUIMARÃES, R.K. Pavlovian conditioning of lung anaphylactic response in rats. Life Sci., v.68, p.611-23, 2000.

PARIANTE, C.M.; MAKOFF, A.; LOVESTONE, S.; FEROLI, S.; HEYDEN, A.; MILLER, A.H.; KERWIN, R.W. Antidepressants enhance glucocorticoid receptor function in vitro by modulating the membrane steroid transporters. Br J Pharmacol.,. v.134, n.6, p.1335-43, 2001.

PETRI,B.; PHILLIPSON, M.;KUBES, P. The Physiology of Leukocyte Recruitment: An In Vivo Perspective. The Journal of Immunology, v.180, p.6439-6446, 2008.

PLOPPA, A.; AYERS, D. M., et al.The inhibition of human neutrophil phagocytosis and oxidative burst by tricyclic antidepressants. J. Anesth Analg., v.107, n.4, p. 1229-35, 2008.

RANG, H.P.; DALE, M.M., RITTER, J.M. Farmacologia. 4o ed, Rio de Janeiro:Guanabara Koogan, 2001.

RETTORI, V.; SOLARI, J.F., et al. Nitric Oxide at the Crossroad of Immunoneuroendocrine Interactions. Neuroimmunomodulation: Ann. N.Y. Acad. Sci. v.1153, p.35-47, 2009.

RIGHI, D.A.; PINHEIRO, S.R.; GUERRA, J.L.; PALERMO-NETO, J. Effects of diazepam on Mycobacterium bovis-induced infection in hamsters. Braz.J. Med. Biol. Res., v.32, p.1145-53, 1999.

SACERDOTE, P.; BIANCHI, M.; PANERAI, A.E. In vivo and in vitro clomipramine treatment decreases the migration of macrophages in the rat. European Journal of Pharmacology, v.319, p.287-90, 1997.

SACERDOTE, P., BIANCHI, M.; PANERAI, A.E. Chlorimipramine and nortriptyline but not fluoxetine and fluvoxamine inhibit human polymorphonuclear cell chemotaxis in vitro. Gen Pharmacol, v.25, n.3, p.409-12. 1994.

SAKAI, M.; FONSECA, E.S.; DAGLI, M.L.; PALERMO-NETO, J. Diazepam effects on Ehrlich tumor growth and macrophage activity in mice. Life Sci., v.78, n.16, p.177783, 2006. 
SALVEMINI, D.; WANG, Z.Q.; WYATT, P.S.; BOURDON, D.M.; MARINO, M.H.; MANNING, P.T.; CURRIE, M.G. Nitric oxide: a key mediator in the early and late phase of carrageenan-induced rat paw inflammation. Br $\mathbf{J}$ Pharmacol., v.118, n.4, p.829-38,1996.

SANZ, M.J.; ALVAREZ, A.; et al. Rolipram inhibits leukocyte-endothelial cell interactions in vivo through $\mathrm{P}$ - and E-selectin downregulation. British Journal of Pharmacology, v.135, p.1872-81, 2002

SAUTEBIN, L.; IALENTI, A.; IANARO, A.; DI ROSA, M. Relationship between nitric oxide and prostaglandins in carrageenin pleurisy. Biochem Pharmacol., v.55, n.7, p.1113-7, 1998.

SCHIEPERS, O.J.; WICHERS, M.C.; MAES, M. Cytokines and major depression. Prog Neuropsychopharmacol Biol Psychiatry., v.29, n.2, p.201-17, 2005.

SELMECZY, Z.; SZELÉNYI, J.; VIZI, E.S. Intact noradrenaline transporter is needed for the sympathetic fine-tuning of cytokine balance. Eur J Pharmacol., v.469, n.1-3, p.175-81, 2003.

SELVATICI, R.;FALZARANO, S.;MOLLICA, A.; SPISANI, S. Signal transduction pathways triggered by selective formylpeptide analogues in human neutrophils. European Journal of Pharmacology, v. 534, p.1-11, 2006.

SELYE, H. A syndrome produced by diverse inocuous agents. Nature, p.32, 1936.

SELYE, H. A syndrome produced by diverse inocuous agents. Journal of Neuropsychiatry, v.10, n.2, p.230-1, 1998.

SMITH, R.S. The macrophage theory of depression. Med. Hypotheses, v.35, n.4, p.298-306, 1991.

STAHL, S.M. Psychopharmacology of antidepressants. London:Martin Dunitz, 1998, 114p.

STEVENS, A.; LOWE, J. Patologia. 2ª.ed. São Paulo:Manole, 2002, 671p.

STITES, D.P.; TERR, A; PARSLOW, T.G. Basic and Clinical Immunology. $8^{\mathrm{a}}$ ed. New Jersey:Prentice Hall, 1994.

STONE, T.W.; DARLINGTON, L.G. Endogenous kynurenines as targets for drug discovery and development. Nature Reviews, v.1, p.609-20, 2002

SUGINO, H.; FUTAMURA, T.; MITSUMOTO, Y.; MAEDA, K.; MARUNAKA, Y. Atypical antipsychotics suppress production of proinflammatory cytokines and upregulate interleukin-10 in lipopolysaccharide-treated mice. Prog, Neuropsychopharmacol. Biol. Psychiatry, v.33, v.2, p.303-7, 2009. 
SVENS, K.; RYRFELDT, A.A study of mechanisms underlying amitriptyline-induced acute lung function impairment. Toxicol Appl Pharmacol., v.177, n.3, p.179-87, 2001.

SZELÉNYI, J.; VIZI, E.S.The catecholamine-cytokine balance: Interaction between the brain and the immune system. Ann N Y Acad Sci., v.1113, p.311-24, 2007.

SZUSTER-CIESIELSKA, A.; TUSTANOWSKA-STACHURA, A.; SLOTWINSKA, M.; MARMUROWSKA-MICHALOWSKA, H.; KANDEFER-SZERSZEN, M. In vitro immunoregulatory effects of antidepressants in healthy volunteers. Pol $\mathbf{J}$ Pharmacol., v.55, n.3, p.353-62, 2003.

TANAKA, S.; ICHIKAWA, A. Recent advances in molecular pharmacology of the histamine systems: immune regulatory roles of histamine produced by leukocytes. $\mathbf{J}$. Pharmacol. Sci. v.101, p.19-23, 2006.

TAKESHITA, K.; SAKAI, K.; BACON, K.B.; GANTNER, F.J. Critical role of histamine $\mathrm{H} 4$ receptor in leukotriene B4 production and mast cell-dependent neutrophil recruitment induced by zymosan in vivo. Pharmacol Exp Ther., v. 307, n.3, p.10728, 2003.

THEOHARIDES, T.C.; KOPS, S.K.; BONDY, P.K.; ASKENASE, P.W. Differential release of serotonin without comparable histamine under diverse conditions in the rat mast cell. Biochem Pharmacol., v.34, n.9, p.1389-98,1985.

TOMIYOSHI, M.Y.; SAKAI, M.; BALEEIRO, R.B.; STANKEVICIUS, D.; MASSOCO, C.O.; PALERMO-NETO, J; BARBUTO, J.A. Cohabitation with a B16F10 melanomabearer cage mate influences behavior and dendritic cell phenotype in mice. Brain Behav Immun., v.23, n.4, p.558-67, 2009.

THOMAS, A.J.; DAVIS, S.; MORRIS, C.; JACKSON, E.; HARRISON, R.; O'BRIEN, J.T. Increase in interleukin-1beta in late-life depression. Am J Psychiatry., v.162, n.1, p.175-7, 2005.

TRACEY KJ. The inflammatory reflex. Nature, v.420, n.6917, p.853-9, 2002.

TRIPATHI, P.; TRIPATHI, P.; KASHYAP, L.; SINGH, V. The role of nitric oxide in inflammatory reactions. Immunol Med Microbiol., v.51, n.3, p.443-52, 2007.

UGAZ EM, PINHEIRO SR, GUERRA JL, PALERMO-NETO J. Effects of prenatal diazepam treatment on Mycobacterium bovis-induced infection in hamsters. Immunopharmacology., v.41, n.3, p.209-17, 1999.

VASSALLE C, DOMENICI C, LUBRANO V, L'ABBATE A. Interaction between nitric oxide and cyclooxygenase pathways in endothelial cells. J Vasc Res. v.40, n.5, p.491-9, 2003.

VISMARI, L.; ALVES, G.J.; PALERMO NETO, J. Depressão, antidepressivos e sistema imune: um novo olhar sobre um velho problema. Revista de Psiquiatria Clínica, v. 35, p. 196-204, 2008. 
WEBER, C.C.; ECKERT, G.P.; MÜLLER, W.E. Effects of antidepressants on the brain/plasma distribution of corticosterone. Neuropsychopharmacology, v.31, n.11, p.2443-8, 2006.

YARON, I.; SHIRAZI, I.; JUDOVICH, R.; LEVARTOVSKY, D.; CASPI, D.; YARON, M. Fluoxetine and amitriptyline inhibit nitric oxide, prostaglandin $\mathrm{E} 2$, and hyaluronic acid production in human synovial cells and synovial tissue cultures. Arthritis Rheum., v.42, n.12, p.2561-8, 1999.

YIRMIYA, R.; POLLAK, Y.; MORAG, M.; REICHENBERG, A.; BARAK, O.; AVITSUR, R.; OVADIA, H.; WEIDENFELD, J.; MORAG, A.; NEWMAN, M.E.; POLLMÄCHER, T. Illness, cytokines, and depresión. Ann N Y Acad Sci., v.917, p.478-87, 2000.

ZILBERBERG, J.; HARRIS, N.R. Synergism between leukocyte adherence and shear determines venular permeability in the presence of nitric oxide. Microvasc Res., v. 62, n.3, p.410-20, 2001. 